\title{
ANALYZING THE PARAMETERS OF MEMBRANE CATALYTIC SYSTEMS FOR EXTRACTION OF HIGHLY PURE HYDROGEN FROM HYDROCARBON FEEDSTOCK WITH THE APPLICATION OF MATHEMATICAL MODELING
}

\author{
A. B. Vandyshev* \\ Institute of Engineering Science, Ural Branch of the Russian Academy of Sciences, 34 Komsomolskaya st., 620049, \\ Ekaterinburg, Russian Federation \\ *Corresponding author. E-mail address: vandyshev@imach.uran.ru; address for correspondence: 620049, \\ ul. Komsomolskaya 34, Ekaterinburg, Russian Federation. Tel.: +7 343 375 3562; fax: +7 3433745330.
}

This paper presents the results of using a mathematical model of membrane extraction of highly pure hydrogen from the products of steam conversion of hydrocarbons. The model is intended for estimating the basic parameters of a number of membrane catalytic systems different in efficiency and design. It is shown that the mathematical model accurately describes the experimental data available in the literature, as well as the results of calculating the parameters of a membrane catalytic reformer by a "kinetic" mathematical model.

Keywords: mathematical modeling; technological and design parameters; membrane catalytic systems; highly pure hydrogen; methane; natural gas.

DOI: $10.17804 / 2410-9908.2016 .4 .006-045$

\section{References}

1. Uemiya S. Brief review of steam reforming using a metal membrane reactor. Topics in Catalysis, 2004, vol. 29, iss. 1, pp. 79-84. DOI: 10.1023/B:TOCA.0000024930.45680.c7.

2. Shirasaki Y., Tsuneki T., Ota Y., Yasuda I., Tachibana S., Nakajima H., Kobayashi K. Development of membrane reformer system for highly efficient hydrogen production from natural gas. International Journal of Hydrogen Energy, 2009, vol. 34, iss. 10, pp. 4482-4487. DOI: 10.1016/j.ijhydene.2008.08.056.

3. Tereshchenko G.F., Orekhova N.V., Ermilova M.M. Metal-containing membrane reactors. Kriticheskie tekhnologii. Membrany, 2007, no. 1, pp. 4-20. (In Russian).

4. Vandyshev A.B., Kulikov V.A. Preparation of specially pure hydrogen at $500-700{ }^{\circ} \mathrm{C}$ from methane in high-temperature converter-membrane equipment, combined with a $\mathrm{CH}_{4}$ conversion catalyst. Chemical and Petroleum Engineering, 2011, vol. 47, nos. 5-6, pp. 327-333. DOI: $10.1007 / \mathrm{s} 10556-011-9469-\mathrm{z}$.

5. Vandyshev A.B., Kulikov V.A. Determination of efficiency of special-purity hydrogen production from products of methane conversion with oxygen in membrane apparatus in combination with catalytic methane or carbon monoxide conversion. Chemical and Petroleum Engineering, 2011, vol. 47, nos. 7-8, pp. 468-474. DOI: 10.1007/s10556-011-9494-y.

6. Vandyshev A.B., Kulikov V.A. Extraction of extra pure hydrogen from methane steam conversion products in membrane equipment, combined simultaneously with two $\mathrm{CO}$ and $\mathrm{CH}_{4}$ conversion catalysts. Chemical and Petroleum Engineering, 2012, vol. 47, nos. 11-12, pp. 831-836. DOI: $10.1007 / \mathrm{s} 10556-012-9558-7$.

7. Vandyshev A.B., Kulikov V.A. Evaluation of efficiency of special-purity hydrogen production from products of steam conversion of methane and its close homologs in high-temperature converter-membrane equipment system using methane or carbon monoxide conversion catalyst. Chemical and Petroleum Engineering, 2013, vol. 48, iss. 9-10, pp. 566-575. DOI: $10.1007 / \mathrm{s} 10556-013-9659-\mathrm{y}$.

8. Compact membrane reformer for hydrogen production. Available at: http://www.lindeusengineering.com. 
9. Murav'ev L.L., Vandyshev A.B., Makarov V.M. Modeling of membrane extraction of hydrogen from the products of steam conversion of hydrocarbons. Theoretical Foundations of Chemical Engineering, 1999, vol. 33, iss. 3, pp. 258-263.

10. Gallucci F., Fernandez E., Corengia P., Annaland M. Recent advances on membranes and membrane reactors for hydrogen production (Review). Chemical Engineering Science, 2013, vol. 92, pp. 40-66. DOI: 10.1016/j.ces.2013.01.008.

11. Gallucci F., Basile A., Iulianelli A., Kuipers H. A Review on Patents for Hydrogen Production Using Membrane Reactors. Recent Patents on Chemical Engineering, 2009, vol. 2, iss. 3, pp. 207-222. DOI: 10.2174/1874478810902030207.

12. Kataoka A., Ishikawa H., Yasuda I., Nishikawa K., Mukai T., Asakura T., Azuma T., Tsuneki T., Takahashi T., Shirasaki Y., Inoue K., Miyaki M., Shinkai H. New concept hydrogen production system based on membrane reformer. In: Fuel Cell Seminar, Palm Springs, California, USA, November 18-November 21, 2002: Abstracts. Palm Springs, California, USA, 2002, pp. 733-736.

13. Kurokawa H., Shirasaki Y., Tsuneki T., Yasuda I., Tachibana S., Nakajima H., Kobayashi $\mathrm{K}$. Development of highly efficient membrane reformer system for hydrogen production from natural gas. In: Proc. of the 17th World Hydrogen Energy Conference (WHEC 2008), Queensland, Australia, 15-19 June, 2008, pp. 41-45.

14. Lukyanov B.N. Obtaining Ultra-Pure Hydrogen for Fuel Cells in the Reactors with Membrane. Chemistry for Sustainable Development, 2012, no. 20, pp. 251-263. Available at: http://sibran.ru/upload/iblock/fb6/fb61628e4d8dae3d9f6ee28e7e53d223.pdf.

15. Burkhanov G.S., Gorina N.B., Kolchugina N.B., Roshan N.R. Palladium alloys for hydrogen energy. Rossiyskiy khimicheskiy zhurnal, 2006, vol. 50, no. 4, pp. 36-40. (In Russian).

16. Lukyanov B.N., Andreev D.V., Parmon V.N. Catalytic reactors with hydrogen membrane separation. Chemical Engineering Journal, 2009. vol. 154, iss. 1-3. pp. 258-266. DOI: 10.1016/j.cej.2009.04.023.

17. Sakamoto Y., Chen F.L., Furukawa M., Noguchi M. Permeability and diffusivity of hydrogen in palladium-rich Pd-Y(Gd)-Ag ternary alloys. J. Alloys Compounds, 1992, vol. 185, iss. 2, pp. 191-205. DOI: 10.1016/0925-8388(92)90468-O.

18. Murav'ev L.L., Vandyshev A.B., Makarov V.M. The modeling of membrane extraction of hydrogen from multicomponent gas mixtures. Theoretical Foundations of Chemical Engineering, 1999, vol. 33, iss. 2, pp. 169-171.

19. Yakabe H., Iseki T., Kurokawa H., Hikosaka H., Takagi Y., Ito M. Development of hydrogen production systems with Pd-based alloy membrane. In: Proc. of the 19th World Hydrogen Energy Conference, Toronto, Canada, 3-7 June, 2012.

20. Chen Y., Wang Y., Xu H., Xiong G. Hydrogen production capacity of membrane reformer for methane steam reforming near practical working conditions. Journal of Membrane Science, 2008, vol. 322, iss. 2, pp. 453-459. DOI: 10.1016/j.memsci.2008.05.051.

21. Chen Y., Wang Y., Xu H., Xiong G. Efficient production of hydrogen from natural gas steam reforming in palladium membrane reactor. Appl. Catal. B, 2008, vol. 80, pp. 283-294.

22. Goltsov V.A. Hydrogen in metals. In: Voprosy atomnoy nauki i tekhniki. Seriya: Atomnovodorodnaya energetika. [Problems of Nuclear Science and Technology. Series: Atomic-Hydrogen Energy, iss. 1 (2)]. M., IAE Publ., 1978, pp. 65-100. (In Russian).

23. Shigarov A.B., Kirillov V.A. Modeling of membrane reactor for steam methane reforming: From granular to structured catalysts. Theoretical Foundations of Chemical Engineering, 2012, vol. 46, no. 2, pp. 97-107. DOI: 10.1134/S004057951202011X24.

24. Gallucci F., Paturzo L., Basile A. A simulation study of the steam reforming of methane in a dense tubular membrane reactor. Int. J. Hydrogen Energy, 2004, vol. 29, iss. 6, pp. 611-617. DOI: 10.1016/j.ijhydene.2003.08.003.

25. Fernandes F.A.N., Soares A.B. Modeling of methane reforming in a palladium membrane reactor. Latin American Applied Research, 2006, vol. 36, no. 3, pp. 155-161. 
26. Kirillov V.A., Meshcheryakov V.D., Brizitskii O.F., Terent'ev V.Ya. Analysis of a power system based on low-temperature fuel cells and a fuel processor with a membrane hydrogen separator. Theoretical Foundations of Chemical Engineering, 2010, vol. 44, no. 3, pp. 227-235. DOI: $10.1134 / \mathrm{S} 0040579510030012$.

27. Vandyshev A.B., Kulikov V.A. Hydrogen permeability of palladium membranes made of alloy V-1 in laboratory investigations and membrane devices. Chemical and Petroleum Engineering, 2015, vol. 51, iss. 5-6, pp. 396-401. DOI: 10.1007/s10556-015-0058-4. 
Подана в журнал: 29.06 .2016

УДК 543.544:621.593

DOI: $10.17804 / 2410-9908.2016 .4 .006-045$

\title{
АНАЛИЗ ПАРАМЕТРОВ МЕМБРАННО-КАТАЛИТИЧЕСКИХ СИСТЕМ ПОЛУЧЕНИЯ ВЫСОКОЧИСТОГО ВОДОРОДА ИЗ УГЛЕВОДОРОДНОГО СЫРЬЯ МЕТОДОМ МАТЕМАТИЧЕСКОГО МОДЕЛИРОВАНИЯ
}

\author{
А. Б. Вандышев* \\ Федеральное государственное бюджетное учреждение науки Институт машиноведения Уральского \\ отделения Российской академии наук, ул. Комсомольская, 34, Екатеринбург, Российская Федерация \\ *Ответственный автор. Электронная почта: vandyshev@imach.uran.ru, адрес для переписки: 620049, \\ ул. Комсомольская 34, Екатеринбург, Россия. Тел.: +7 (343) 375-35-62; Факс: +7 (343) 374-53-30
}

Приведены результаты использования математической модели мембранного извлечения особо чистого водорода из продуктов паровой конверсии углеводородов для оценки основных параметров ряда различных по производительности и конструкции мембраннокаталитических (МК) систем. Показано, что математическая модель адекватно описывает имеющиеся в литературе экспериментальные данные, а также результаты расчетов параметров мембранно-каталитического реформера по “кинетической” математической модели.

Ключевые слова: математическое моделирование, технологические и конструктивные параметры, мембранно-каталитические системы, высокочистый водород, метан, природный газ.

\section{1. Введение}

В создании демонстрационных и опытно-промышленных образцов МК-устройств и установок получения газообразного водорода высокой чистоты $(99,999$ \%) из природного газа и других углеводородов в последнее время наметился существенный прогресс [1-3]. Принцип действия МК-систем основан на совмещении мембранного извлечения высокочистого водорода с каталитической конверсией метана и позволяет повысить эффективность и экономичность производства водорода, существенно уменьшить габариты устройства, а также снизить рабочую температуру до 550-500 ${ }^{\circ} \mathrm{C}$ [4-7]. В последнее время один из известных производителей промышленного водородного оборудования (Linde engineering) приступил к разработке установок производства высокочистого водорода до $1000 \mathrm{~m}^{3} \mathrm{H}_{2} /$ ч из углеводородного сырья на базе мембранных реформеров с использованием композитных мембран из палладия и его сплавов толщиной в несколько микрон на пористой металлической подложке [8].

В сложившихся условиях представляется актуальным дальнейшее развитие и совершенствование математических моделей, а также проверка их на адекватность при описании имеющихся в литературе результатов испытаний мембранно-каталитических систем для получения высокочистого водорода из различных видов углеводородного сырья. Не менее интересным представляется и сравнение разных математических моделей.

\section{2. Основные принципы мембранно-каталитического извлечения высокочистого водорода из углеводородного сырья}

Структурная схема и принцип работы МК-устройства для получения высокочистого водорода из углеводородного сырья [1-3] практически не отличались от использованной нами при разработке математической модели для системы высокотемпературный конвертор - высокотемпературный мембранный аппарат [9], схематично изображенной на рис. 1. 


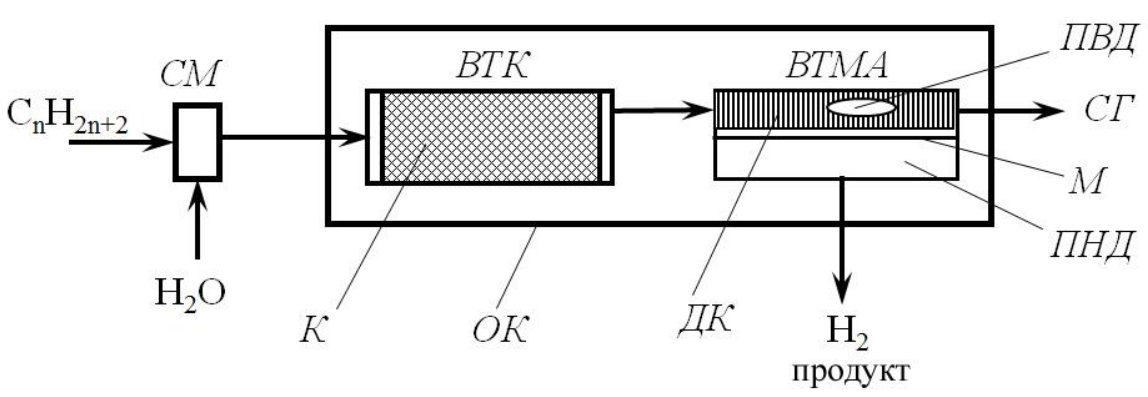

Рис.1. Упрощенная схема системы BTK-BTMA: $\mathrm{C}_{\mathrm{n}} \mathrm{H}_{2 \mathrm{n}+2}$ - углеводородное сырье;

$C M$ - смеситель; BTK - высокотемпературный конвертор метана;

BTMA - высокотемпературный мембранный аппарат; ПВД - полость высокого давления;

ПНД - полость низкого давления; $C \Gamma$ - сбросной газ; $K$ - катализатор конверсии метана;

$Д K$ - дополнительный катализатор конверсии метана; $M$ - мембрана; $O K$ - общий корпус

Исходная смесь углеводорода (в простейшем случае метана) и водяного пара под избыточным давлением подается в смеситель $C M$ и далее последовательно поступает в высокотемпературный конвертор (BTK) и полость высокого давления (ПВД) высокотемпературного мембранного аппарата $(B T M A)$ с палладиевой мембраной, находящиеся в общем корпусе $(O K)$ и нагретые до одинаковой рабочей температуры. В высокотемпературном конверторе исходная смесь природного газа и водяного пара на никелевом катализаторе превращается в водородосодержащую многокомпонентную газовую смесь $\left(\mathrm{H}_{2}, \mathrm{H}_{2} \mathrm{O}, \mathrm{CO}_{2}, \mathrm{CO}, \mathrm{CH}_{4}\right)$, которая подается в ПВД мембранного аппарата, где под действием перепада давлений из нее происходит селективное извлечение водорода. Водород под действием перепада давлений из ПВД диффундирует через мембрану в полость низкого давления (ПНД) мембранного аппарата и в виде высокочистого водорода $(99,999$ \%) поступает потребителю, а обедненная по водороду газовая смесь удаляется из ПВД мембранного аппарата в виде сбросного газа $(C \Gamma)$ (рис. 1).

По мере прохождения продуктов паровой конверсии над поверхностью мембраны происходит извлечение молекулярного водорода из продуктов паровой конверсии. При этом в присутствии катализатора конверсии метана в надмембранном пространстве нарушается термодинамическое равновесие в газовой фазе и за счет смещения химических равновесий

$$
\begin{gathered}
\mathrm{CH}_{4}+2 \mathrm{H}_{2} \mathrm{O}=4 \mathrm{H}_{2}+\mathrm{CO}_{2}, \\
\mathrm{CO}+\mathrm{H}_{2} \mathrm{O}=\mathrm{H}_{2}+\mathrm{CO}_{2}
\end{gathered}
$$

вправо, а также опосредованного вовлечения в процесс извлечения водорода, главным образом метана, по реакции (1), общее количество извлекаемого водорода увеличивается.

\section{3. Математическая модель мембранного извлечения высокочистого водорода из продуктов паровой конверсии углеводородов}

Математическая модель [9], используемая в данной работе, предназначена для оценки влияния основных параметров технологического процесса (давлений в обеих полостях $B T M A$, температуры, расхода и состава исходной смеси), а также параметров водородоселективных мембран (площади, толщины, удельной проницаемости) на производительность и полноту извлечения высокочистого водорода из продуктов паровой конверсии углеводородов.

Для обеспечения быстрого установления термодинамического равновесия в объеме над каждым участком поверхности мембраны по сравнению со скоростью диффузии водорода через мембрану в ПВД мембранного аппарата размещен дополнительный катализатор (ДК) конверсии метана (рис. 1).

Vandyshev A. B. / Analyzing the parameters of membrane catalytic systems for extraction of highly pure 
В рассматриваемой математической модели системы $B T K-B T M A$ не учитывались изменения давлений и температур в обеих полостях мембранного аппарата (рис. 1). Полагалось, что изменение концентраций продуктов конверсии вдоль поверхности мембраны обусловлено не только стоком водорода через мембрану, но и обратимыми химическими реакциями (1) и (2), а газовая смесь подчиняется законам идеального газа. Предполагалось также, что состав исходной смеси и технологические условия системы $B T K-B T M A$ выбраны таким образом, чтобы исключить термодинамическую вероятность углеродоотложения в газовой фазе.

Расчетную схему системы $B T K$ - BTMA представили в виде ряда последовательно соединенных ячеек, показанных на рис. 2.

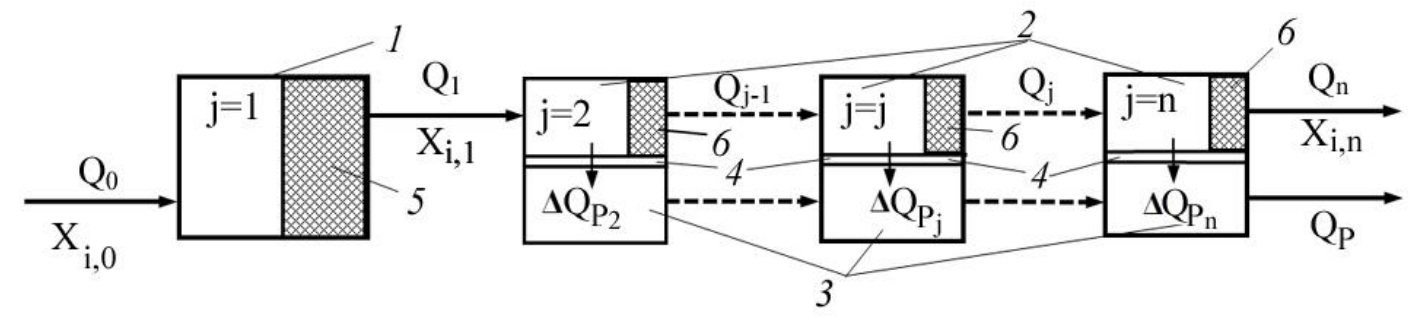

Рис.2. Принципиальная расчетная схема $B T K-B T M A: 1$ - высокотемпературный конвертор;

2 - полость высокого давления мембранного аппарата; 3 - полость низкого давления мембранного аппарата; 4 - Pd-мембрана; 5 - катализатор конверсии $\mathrm{CH}_{4}$;

6 - дополнительный катализатор конверсии метана

На расчетной схеме для $\mathrm{j}$-й ячейки газовая смесь из ПВД предыдущей $(\mathrm{j}-1)$-ячейки потоком $\mathrm{Q}_{\mathrm{j}-1}$ и концентрациями компонентов $\mathrm{X}_{\mathrm{i}, \mathrm{j}-1}$ поступает на вход в ПВД $\mathrm{j}$-й ячейки и, проходя над мембраной, обедняется по водороду и выходит из ячейки потоком $\mathrm{Q}_{\mathrm{j}} \mathrm{c}$ концентрациями компонент $\mathrm{X}_{\mathrm{i}, \mathrm{j}}$ (рис. 2). Высокочистый водород проходит через мембрану в j-й ячейке потоком $\Delta \mathrm{Q}_{\mathrm{p}_{\mathrm{j}}}=\Delta \mathrm{Q}_{\mathrm{p}} /(\mathrm{n}-1)$.

Введены следующие обозначения: $\gamma$ - коэффициент удельной водородопроницаемости мембраны, м ${ }^{3} \mathrm{H}_{2} \mathrm{M} /\left(\mathrm{м}^{2} ч \sqrt{\mathrm{MПа}}\right) ; \delta$ - толщина мембраны, м; $\mathrm{P}_{\mathrm{B}}$ - абсолютное давление в ПВД, МПа; $\mathrm{P}_{\mathrm{H}}$ - абсолютное давление в ПНД, МПа; $\Delta \mathrm{F}_{\mathrm{j}}$ - площадь участка мембраны в ј-й ячейке, $\mathrm{m}^{2} ; \mathrm{X}_{\mathrm{i}, \mathrm{j}-1}$ - объемная доля i-й компоненты на входе в j-ю ячейку; $\mathrm{X}_{\mathrm{i}, \mathrm{j}}$ - объемная доля i-й компоненты на выходе из ј-й ячейки, $Q_{j}-$ поток смеси на выходе из ПВД j-й ячейки. Индексы $\mathrm{i}=1,2,3,4,5$ соответствуют $\mathrm{H}_{2}, \mathrm{H}_{2} \mathrm{O}, \mathrm{CO}_{2}, \mathrm{CO}, \mathrm{CH}_{4}$.

Связь между входными и выходными параметрами потоков и составов газовой фазы j-й ячейки определяется уравнениями материального баланса (3)-(5) соответственно по атомам водорода, кислорода и углерода; уравнением закона Дальтона (6); законом действующих масс (7) и (8) соответственно для обратимых химических реакций $\mathrm{H}_{2}+\mathrm{CO}_{2}=\mathrm{CO}+\mathrm{H}_{2} \mathrm{O}$ и $4 \mathrm{H}_{2}+\mathrm{CO}_{2}=\mathrm{CH}_{4}+2 \mathrm{H}_{2} \mathrm{O}$; уравнением (9), вытекающим из закона Сивертса-Фика для участка площади мембраны $\Delta \mathrm{F}$.

$$
\begin{gathered}
Q_{j}\left(X_{1, j}+X_{2, j}+2 X_{5, j}\right)=Q_{j-1}\left(X_{1, j-1}+X_{2, j-1}+2 X_{5, j-1}\right)-\Delta Q_{j} \\
Q_{j}\left(X_{2, j}+2 X_{3, j}+X_{4, j}\right)=Q_{j-1}\left(X_{2, j-1}+2 X_{3, j-1}+X_{4, j-1}\right) \\
Q_{j}\left(X_{3, j}+X_{4, j}+X_{5, j}\right)=Q_{j-1}\left(X_{3, j-1}+X_{4, j-1}+X_{5, j-1}\right) \\
X_{1, j}+X_{2, j}+X_{3, j}+X_{4, j}+X_{5, j}=1 ;
\end{gathered}
$$




$$
\begin{gathered}
\mathrm{K}_{1}=\frac{\mathrm{X}_{2, \mathrm{j}} \mathrm{X}_{4, \mathrm{j}}}{\mathrm{X}_{1, \mathrm{j}} \mathrm{X}_{3, \mathrm{j}}} \\
\mathrm{K}_{2}=\frac{\mathrm{X}_{2, \mathrm{j}}^{2} \mathrm{X}_{5, \mathrm{j}}}{\mathrm{X}_{1, \mathrm{j}}^{4} \mathrm{X}_{3, \mathrm{j}}} ; \\
\Delta \mathrm{Q}_{\mathrm{p}_{\mathrm{j}}}=\frac{\gamma}{\delta} \sqrt{\mathrm{P}_{\mathrm{B}}} \cdot \Delta \mathrm{F} \cdot\left(\sqrt{\frac{\mathrm{X}_{1, \mathrm{j}}+\mathrm{X}_{1, \mathrm{j}-1}}{2}}-\sqrt{\frac{\mathrm{P}_{\mathrm{H}}}{\mathrm{P}_{\mathrm{B}}}}\right) .
\end{gathered}
$$

В системе уравнений (3)-(9) заданными являются параметры с индексами j-1, а искомыми - параметры с индексами ј. Далее путем преобразований систему уравнений (3)-(9) свели к одному уравнению (10), которое решается численным методом:

$$
\lambda(1+\lambda)\left(a_{1}+\lambda\right)^{2}=a_{1}^{2} a_{2} a_{3} a_{4}^{2}
$$

где:

$$
\begin{gathered}
a_{1}=1 / \mathrm{K}_{1} ; \\
a_{2}=\frac{\mathrm{K}_{2}}{\mathrm{~K}_{1}^{2}} \cdot \frac{2}{\mathrm{r}_{1, \mathrm{j}}+\mathrm{r}_{2, \mathrm{j}}-1} ; \\
a_{3}=\frac{1-\mathrm{r}_{1, \mathrm{j}}+\mathrm{r}_{2, \mathrm{j}}}{2} ; \\
a_{4}=1-\mathrm{r}_{2, \mathrm{j}} ; \\
\mathrm{r}_{1, \mathrm{j}}=\frac{\mathrm{Q}_{\mathrm{j}-1}}{\mathrm{Q}_{\mathrm{j}}}\left(\mathrm{X}_{1, \mathrm{j}-1}+\mathrm{X}_{2, \mathrm{j}-1}+2 \mathrm{X}_{5, \mathrm{j}-1}\right)-\frac{\Delta \mathrm{Q}_{\mathrm{j}}}{\mathrm{Q}_{\mathrm{j}}} ; \\
\mathrm{r}_{2, \mathrm{j}}=\frac{\mathrm{Q}_{\mathrm{j}-1}}{\mathrm{Q}_{\mathrm{j}}}\left(\mathrm{X}_{3, \mathrm{j}-1}+\mathrm{X}_{4, \mathrm{j}-1}+\mathrm{X}_{5, \mathrm{j}-1}\right) ; \\
\mathrm{r}_{3, \mathrm{j}}=\frac{\mathrm{Q}_{\mathrm{j}-1}}{\mathrm{Q}_{\mathrm{j}}}\left(\mathrm{X}_{2, \mathrm{j}-1}+2 \mathrm{X}_{3, \mathrm{j}-1}+\mathrm{X}_{4, \mathrm{j}-1}\right) ; \\
\lambda=-\mathrm{W}_{2}+\sqrt{\mathrm{W}_{2}^{2}-\mathrm{W}_{3}} ; \\
\mathrm{W}_{1}=a_{4}+2 a_{3}-\mathrm{r}_{3, \mathrm{j}} ; \\
\mathrm{W}_{2}=\left[a_{4, \mathrm{j}}=a_{4} \frac{\lambda}{a_{1}+\lambda} ;\right. \\
\mathrm{X}_{1, \mathrm{j}}=\frac{a_{1} a_{4}}{a_{1}+\lambda} ; \\
\left.\mathrm{W}_{3}=a_{3}+a_{3}-\mathrm{r}_{3, \mathrm{j}}\left(1+a_{1}\right)\right] / 2 \mathrm{~W}_{1} ; \\
\left.\mathrm{r}_{3, \mathrm{j}}\right) / \mathrm{W}_{1} ;
\end{gathered}
$$




$$
\begin{gathered}
\mathrm{X}_{3, \mathrm{j}}=a_{3} \frac{\lambda}{1+\lambda} ; \\
\mathrm{X}_{4, \mathrm{j}}=\frac{a_{3}}{1+\lambda} ; \\
\mathrm{X}_{5, \mathrm{j}}=\frac{\mathrm{r}_{1, \mathrm{j}}+\mathrm{r}_{2, \mathrm{j}}-1}{2} .
\end{gathered}
$$

Неизвестная величина $\mathrm{Q}_{\mathrm{j}}$ находится на интервале $\mathrm{Q}_{\mathrm{j}, \min }<\mathrm{Q}_{\mathrm{j}}<\mathrm{Q}_{\mathrm{j}, \mathrm{max}}$, где

$$
\begin{gathered}
\mathrm{Q}_{\mathrm{j}, \min }=\frac{\mathrm{Q}_{\mathrm{j}-1}\left(1+\mathrm{X}_{2, \mathrm{j}-1}+\mathrm{X}_{3, \mathrm{j}-1}+\mathrm{X}_{5, \mathrm{j}-1}\right)-\Delta \mathrm{Q}_{\mathrm{p}, \mathrm{j}-1}}{2} ; \\
\mathrm{Q}_{\mathrm{j}, \max }=\mathrm{Q}_{\mathrm{j}-1}\left(1+2 \mathrm{X}_{5, \mathrm{j}-1}\right)-\Delta \mathrm{Q}_{\mathrm{p}, \mathrm{j}-1}
\end{gathered}
$$

Задавая величину $\Delta \mathrm{Q}_{\mathrm{p}, \mathrm{j}}=\mathrm{Q}_{\mathrm{p}} /(\mathrm{n}-1)$, учитывая, что при $\mathrm{j}=1 \mathrm{Q}_{\mathrm{j}-1}=\mathrm{Q}_{0}, \mathrm{X}_{\mathrm{i}, \mathrm{j}-1}=\mathrm{X}_{\mathrm{i}, 0}$, последовательно для ячеек от $\mathrm{j}=1$ до $\mathrm{j}=\mathrm{n}$, численным методом решали уравнение (10) путем подбора $\mathrm{Q}_{\mathrm{j}}$ в диапазоне от $\mathrm{Q}_{\mathrm{j}, \min }$ до $\mathrm{Q}_{\mathrm{j}, \max }$ таким образом, чтобы небаланс уравнения (10) $\varepsilon=\lambda(1+\lambda)\left(a_{1}+\lambda\right)^{2}-a_{1}^{2} a_{2} a_{3} a_{4}^{2}$ не превышал требуемую точность расчета $\varepsilon_{0}$. После определения неизвестной величины $\mathrm{Q}_{\mathrm{j}}$ по уравнениям (22)-(26) вычисляли $\mathrm{X}_{\mathrm{i}, \mathrm{j}}$ ·

Далее по формуле

$$
\Delta \mathrm{F}_{\mathrm{j}}=\frac{\Delta \mathrm{Q}_{\mathrm{p}}}{\frac{\gamma}{\delta} \sqrt{\mathrm{P}_{\mathrm{B}}} \cdot\left(\sqrt{\frac{\mathrm{X}_{1, \mathrm{j}}+\mathrm{X}_{1, \mathrm{j}-1}}{2}}-\sqrt{\frac{\mathrm{P}_{\mathrm{H}}}{\mathrm{P}_{\mathrm{B}}}}\right)}
$$

находили площадь мембраны $\Delta \mathrm{F}_{\mathrm{j}}$ в $\mathrm{j}$-й ячейке. Общую площадь мембраны $\mathrm{F}$ в мембранном аппарате находили по формуле

$$
F=\sum_{j=2}^{n} \Delta F_{j}
$$

Отметим, что для первой ячейки $\mathrm{j}=1$ (BTK), в которой мембрана отсутствует, $\Delta \mathrm{Q}_{\mathrm{p}}=0$ и $\Delta \mathrm{F}_{1}=0$.

При достаточно большом общем числе ячеек $\mathrm{n}=100-200$, систему уравнений (3)-(9) в комплексе с одним из возможных алгоритмов ее решения можно рассматривать как математическую модель режима идеального вытеснения при мембранном извлечении водорода из продуктов паровой конверсии углеводородов в присутствии катализатора конверсии метана в надмембранном пространстве.

\section{3. Анализ параметров ряда МК-устройств получения высокочистого водорода из природного газа}

Несмотря на достаточно большое количество научной и патентной информации по МК-системам (библиографию можно найти соответственно в обзорах[10] и [11]), наибольшие практические результаты достигнуты рядом японских компаний, включая Tokyo Gas Co Ltd и Mitsubishi Heavy Industries Ltd [1, 2, 12, 13, 19]. 
Анализ параметров и технологических режимов проводили на примере трех мембранно-каталитических устройств, представленных японскими исследователями $[1,2,12,13,19]$. Отметим, что все рассматриваемые в данном разделе МК-устройства имели одну элементную базу (мембранные элементы плоского типа) и исходное углеводородное сырье (природный газ из городской газовой сети) одинакового химического состава: $88,5 \% \mathrm{CH}_{4}$; $4,6 \% \mathrm{C}_{2} \mathrm{H}_{6} ; 5,4 \% \mathrm{C}_{3} \mathrm{H}_{8}$ и $1,5 \% \mathrm{C}_{4} \mathrm{H}_{10}[2]$.

\section{1. Сравнение расчетной статической расходной характеристики с опытными данны- ми для МК-реформера производительностью $40 \mathrm{M}^{3} \mathrm{H}_{2} / u$}

В работе [2] представлены результаты испытаний стационарной опытнопромышленной установки получения особо чистого водорода $(99,999$ об. \%) из природного газа (ПГ) с максимальной производительностью 40 м $3 /$ на базе мембранного реформера. Габаритные размеры установки составляли $3560 \times 2560 \times 2300$ мм. Внешний вид установки получения высокочистого водорода из природного газа на базе МК-реформера представлен на рис. 3 из работы [2].

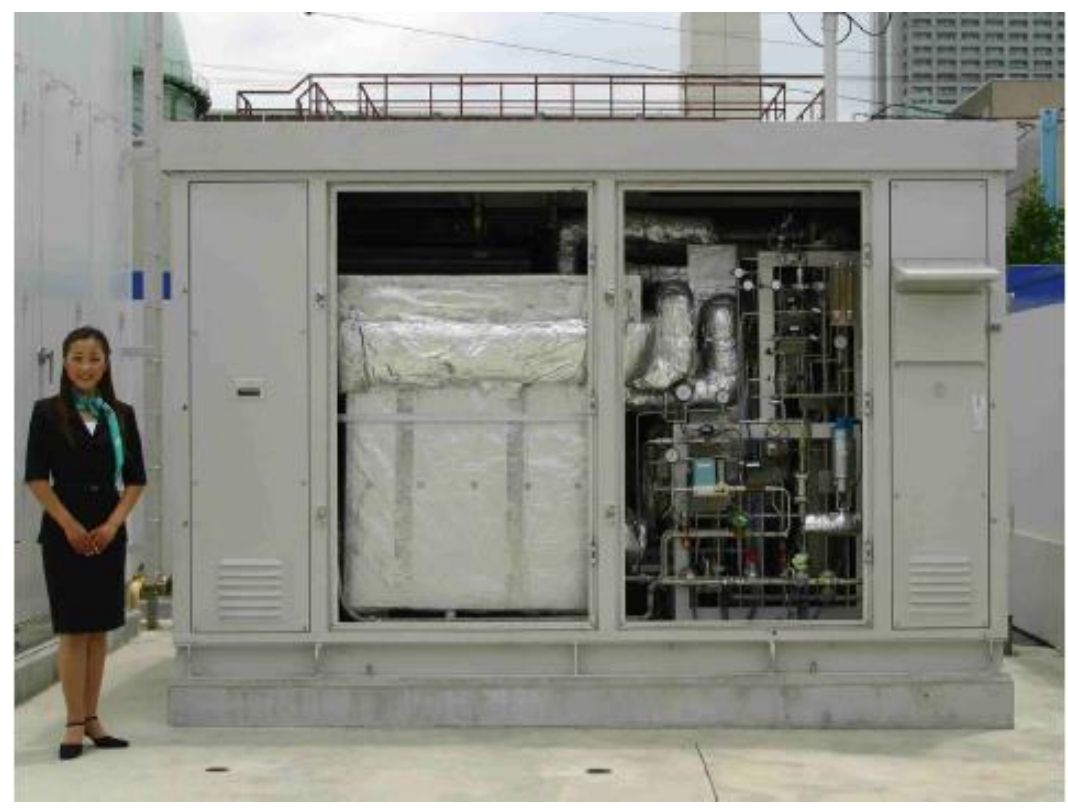

Рис. 3. Внешний вид установки получения водорода из природного газа производительностью $40 \mathrm{~m}^{3} \mathrm{H}_{2} / \mathrm{ч}$ на базе мембранного реформера [2]

Схема собственно МК-реформера производительностью $40 \mathrm{~m}^{3} \mathrm{H}_{2} /$ ч представлена на рис. 4 [16]. Мембранный конвертор [2] состоит из 112 параллельно работающих индивидуальных мембранных реакторов 5 с размерами $86 \times 615 \times 25$ мм, помещенных в печь 11 с габаритными размерами $1200 \times 750 \times 1350$ мм и обогреваемых снаружи двумя газовыми горелками 10.

Внутри каждого единичного МК-реактора помещены два мембранных элемента (6, рис. 4) плоского типа с размерами $40 \times 460 \times 10$ мм (рис. 12 в работе [14]), снабженные мембраной толщиной около 20 мкм из сплава палладия с редкоземельным элементом, который обладал коэффициентом удельной водородопроницаемости, в несколько раз выше традиционного сплава Pd-23Ag. Единичные МК-реакторы объединены в 16 МК-модулей по 7 единичных МК-реакторов в каждом (рис. 4). Общее количество мембранных элементов в МК-реформере производительностью $40 \mathrm{~m}^{3} /$ ч составило 224 единицы. На основании общего количества и размеров мембранных элементов водорода оценили величину общей установленной площади мембраны в мембранном конверторе [2], которая составила $\mathrm{F}_{\text {уст. }}=0,46 \times 0,1 \times 224=10,3 \mathrm{~m}^{2}$ и по величине совпала с данными, представленными в работе [16].

Vandyshev A. B. / Analyzing the parameters of membrane catalytic systems for extraction of highly pure 

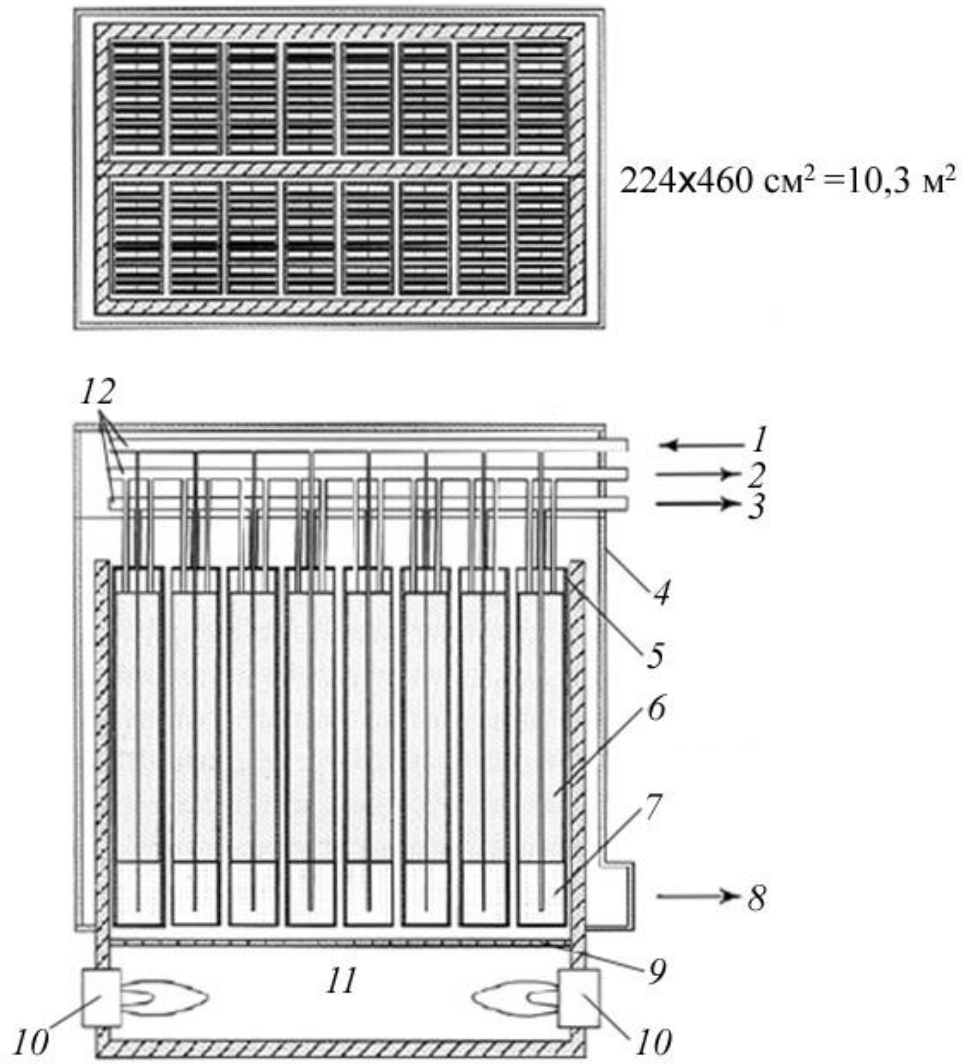

Рис. 4. Схема МК-реформера производительностью $40 \mathrm{~m}^{3} \mathrm{H}_{2} /$ ч [16]:

1 - ввод в общий коллектор смеси природного газа и водяного пара; 2 - выход из общего коллектора высокочистого водорода; 3 - выход из общего коллектора сбросного газа; 4 - рубашка; 5 - единичный мембранный реактор; 6 - мембранный элемент; 7 -полость предварительного конвертора ПГ; 8 - выход топочных газов; 9 - распределительная пластина; 10 - горелки; 11 - печь; 12 - газовые коллекторы

В каждом индивидуальном МК-реакторе по ходу исходного газового потока последовательно размещены: стандартный $\mathrm{Ni} / \mathrm{Al}_{2} \mathrm{O}_{3}$ катализатор в виде гранул с размерами 2-3 мм, который выполнял функцию предварительного конвертора природного газа (7, рис. 4), и монолитный рифленый никелевый катализатор, установленный вдоль поверхности мембраны и образующий канал между катализатором и мембраной для прохождения разделяемой газовой смеси. Для удаления водорода-продукта из подмембранного пространства единичных МКреакторов, объединенных в один общий коллектор (2, рис. 4), использован металлогидридный побудитель расхода водорода.

Установка получения высокочистого водорода из природного газа с максимальной производительностью $40 \mathrm{~m}^{3} /$ ч на базе мембранного конвертора [2] была испытана при номинальной производительности порядка $30 \mathrm{~m}^{3} \mathrm{H}_{2} /$ ч в течение 3010 часов на природном газе (состав ПГ приведен в разд. 3) из городской газовой сети и выдержала 61 теплосмену, что свидетельствовало о достаточной надежности самой установки и мембранного отделителя водорода с тонкой 20 мкм мембраной из палладиевого сплава.

В данном разделе предпринята попытка на основании модельных представлений и методик расчета параметров системы ВТК-ВТМА [5-7, 9] рассчитать статическую расходную характеристику мембранного конвертора и сравнить ее с опытными данными, представленными в работе [2].

Экспериментальные точки для построения расходной характеристики мембранного конвертора, представляющей собой графическую зависимость производительности по высокочистому водороду $\left(\mathrm{Q}_{\mathrm{p}}\right)$ от расхода природного газа $\left(\mathrm{Q}_{\Pi \Gamma}\right)$, перенесли из работы [2] (табл. 1). 
Таблица 1 - Экспериментальные точки расходной характеристики мембранного конвертора

\begin{tabular}{|c|c|c|c|c|c|c|}
\hline Обозначение & \multicolumn{7}{|c|}{ Расход, м ${ }^{3} /$ } \\
\hline $\mathrm{Q}_{П Г}$ & 3,14 & 5,1 & 8,12 & 10,61 & 10,98 & 11,6 \\
\hline $\mathrm{Q}_{\mathrm{p}}$ & 6,2 & 18,2 & 26,5 & 35,3 & 37,4 & 40,5 \\
\hline
\end{tabular}

Практически все необходимые исходные данные (кроме отсутствующего коэффициента удельной водородопроницаемости $\gamma$ ) для проведения расчетов расходной характеристики и других параметров мембранного конвертора были взяты из работы [2]. Рабочую температуру мембранного конвертора из указанного температурного диапазона $\left(495-540{ }^{\circ} \mathrm{C}\right)$ приняли равной нижнему пределу т.е. $495^{\circ} \mathrm{C}$.

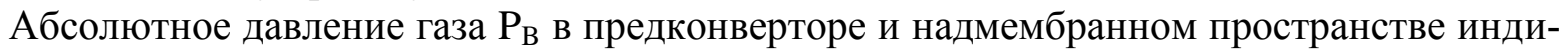
видуального МК-конвертора принято равным 0,9 МПа [2], а абсолютное давление водородапродукта $\mathrm{P}_{\mathrm{H}}$ в подмембранном пространстве принято равным 0,048 МПа, что достаточно близко к верхнему пределу диапазона входных давлений металлогидридного побудителя расхода водорода 0,02-0,04 МПа, приведенного в работе [2].

В качестве исходного сырья для получения высокочистого водорода в мембранном конверторе принята смесь водяного пара с природным газом с величиной отношения $\mathrm{H}_{2} \mathrm{O} / \mathrm{C}=3,2$, соответствующей верхнему пределу указанного в работе [2] диапазона отношений $\mathrm{H}_{2} \mathrm{O} / \mathrm{C}$ от 3,0 до 3,2. Природный газ из городской газовой сети имел следующий химический состав: $88,5 \% \mathrm{CH}_{4} ; 4,6 \% \mathrm{C}_{2} \mathrm{H}_{6} ; 5,4 \% \mathrm{C}_{3} \mathrm{H}_{8}$ и $1,5 \% \mathrm{C}_{4} \mathrm{H}_{10}$ [2]. Поскольку детальные сведения о мембранном материале и его коэффициенте удельной водородопроницаемости в работе [2] отсутствовали, для расчетов при температуре $495{ }^{\circ} \mathrm{C}$ принят коэффициент $\gamma=0,0039 \mathrm{M}^{3} \mathrm{H}_{2} \cdot \mathrm{M} /\left(\mathrm{M}^{2} \cdot \mathrm{ч} \cdot \mathrm{MПа}^{0,5}\right)$ для сплава $\mathrm{Pd}-8 \mathrm{Y}$ из работ $[15,17]$.

Принимая во внимание, что максимальный расход природного газа в исходной смеси природный газ - водяной пар, по данным работы [2], составлял 11,6 м³/ч, для расчета расходной характеристики мембранного конвертора из интервала расходов природного газа от 0 до 11,6 м $3 /$ ч выбрали пять фиксированных значений $\mathrm{Q}_{П г}$, равных 4, 6, 8, 10 и 11,6 м³/ч (1-5, табл. 2).

Таблица 2 - Параметры мембранного конвертора при температуре $495{ }^{\circ} \mathrm{C}$

\begin{tabular}{|c|c|c|c|c|c|}
\hline \multirow{2}{*}{$\begin{array}{c}\text { № } \\
\text { точки }\end{array}$} & \multicolumn{5}{|c|}{ Параметры } \\
\cline { 2 - 6 } & $\mathrm{Q}_{\Pi \Gamma}, \mathrm{m}^{3} / \mathbf{ч}$ & $\mathrm{Q}_{0}, \mathrm{~m}^{3} / \mathbf{ч}$ & $\mathrm{Q}_{1}, \mathrm{~m}^{3} / \mathrm{ч}$ & $\mathrm{F}_{\text {расч., }} \mathrm{M}^{2}$ & $\mathrm{Q}_{\mathrm{p}}, \mathrm{M}^{3} / \mathbf{ч}$ \\
\hline 1 & 4 & 16,8 & 17,9 & 1,6 & 13,6 \\
\hline 2 & 6 & 25,2 & 26,85 & 2,1 & 20,4 \\
\hline 3 & 8 & 33,6 & 35,8 & 3,4 & 27,4 \\
\hline 4 & 10 & 42 & 44,7 & 3,7 & 34,2 \\
\hline 5 & 11,6 & 48,7 & 51,9 & 4,0 & 39,6 \\
\hline
\end{tabular}

Учитывая мольные доли ПГ и $\mathrm{H}_{2} \mathrm{O}$ в исходной смеси природный газ - водяной пар, равные соответственно $\mathrm{X}_{\Pi г}=0,238$ и $\mathrm{X}_{\mathrm{H}_{2} \mathrm{O}}=0,762$ для точек 1-5 (табл. 2), рассчитали расходы исходной смеси водяного пара с природным газом $\mathrm{Q}_{0}$. Затем с учетом постоянства атомного состава исходной смеси ПГ-3,2 $\mathrm{H}_{2} \mathrm{O}$ и продуктов конверсии $\left(\mathrm{H}_{2}, \mathrm{H}_{2} \mathrm{O}, \mathrm{CO}_{2}, \mathrm{CO}\right.$ и $\left.\mathrm{CH}_{4}\right)$ рассчитали равновесный состав газовой фазы на выходе предконвертора при температуре $495^{\circ} \mathrm{C}$ и абсолютном давлении $\mathrm{P}_{\mathrm{B}}=0,9$ МПа (табл. 3), а также объемный расход смеси про- 
дуктов паровой конверсии $\mathrm{Q}_{1}$ на выходе из предварительного конвертора природного газа для всех 5 точек, представленных в табл. 2. Далее, используя модельные представления, развитые нами для мембранного извлечения водорода из продуктов паровой конверсии углеводородов [9], рассчитали зависимости производительности мембранного конвертора Qp от площади мембраны $\mathrm{F}$ для каждого объемного расхода смеси продуктов паровой конверсии природного газа $\mathrm{Q}_{1}=17,9 ; \mathrm{Q}_{1}=26,85 ; \mathrm{Q}_{1}=35,8 ; \mathrm{Q}_{1}=44,7 ; \mathrm{Q}_{1}=51,9$ м $3 /$ ч (табл. 2 ).

Таблица 3 - Равновесные и атомные составы синтез-газа

\begin{tabular}{|c|c|c|c|c|c|c|c|}
\hline \multicolumn{5}{|c|}{$\begin{array}{c}\text { Мольные доли продуктов конверсии в синтез-газе } \\
\text { на выходе ПК или ВTК }\end{array}$} & \multicolumn{3}{|c|}{$\begin{array}{c}\text { Атомные доли на входе } \\
\text { и выходе ПК или } B T K\end{array}$} \\
\hline $\mathrm{X}_{\mathrm{H}_{2}}$ & $\mathrm{X}_{\mathrm{H}_{2} \mathrm{O}}$ & $\mathrm{X}_{\mathrm{CO}_{2}}$ & $\mathrm{X}_{\mathrm{CO}}$ & $\mathrm{X}_{\mathrm{CH}_{4}}$ & $\mathrm{H}$ & $\mathrm{O}$ & $\mathrm{C}$ \\
\hline \multicolumn{8}{|c|}{ Мембранный конвертор при рабочей температуре $495^{\circ} \mathrm{C}$} \\
\hline 0,1575 & 0,6189 & 0,047 & 0,0022 & 0,1743 & 0,7056 & 0,2243 & 0,0701 \\
\hline
\end{tabular}

Результаты расчетов представлены графически кривыми 1-5 на рис. 5 и в виде рас-

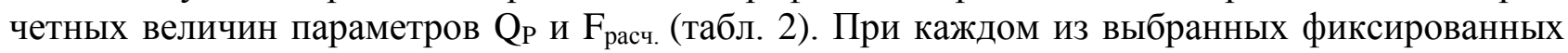
расходов природного газа максимальная расчетная производительность мембранного конвертора по водороду $\mathrm{Q}_{\mathrm{P}}$ с увеличением площади мембраны $\mathrm{F}$ (1-5, рис. 5) возрастает и достигает величин: $Q_{P}=13,6 \mathrm{~m}^{3} /$ ч при $Q_{\Pi г}=4 \mathrm{~m}^{3} / \mathrm{ч} ; Q_{P}=20,4 \mathrm{~m}^{3} / \mathrm{ч}$ при $Q_{\Pi \Gamma}=6 \mathrm{~m}^{3} / \mathrm{q} ; Q_{\mathrm{P}}=27,4 \mathrm{~m}^{3} / \mathrm{\varphi}$ при $Q_{\Pi г}=8 \mathrm{~m}^{3} / \mathrm{ч} ; \mathrm{Q}_{P}=34,2 \mathrm{~m}^{3} /$ ч при $\mathrm{Q}_{\Pi \Gamma}=10 \mathrm{~m}^{3} /$ ч и $\mathrm{Q}_{P}=39,6 \mathrm{~m}^{3} / \mathrm{ч}$ при $\mathrm{Q}_{\Pi г}=11,6 \mathrm{~m}^{3} /$ ч. Выход кривых $\mathrm{Q}_{\mathrm{P}}-\mathrm{F}$ на насыщение происходит при концентрации водорода $\mathrm{X}_{\mathrm{H}_{2}}$ над поверхностью мембраны, приближающейся к концентрационному пределу $\mathrm{X}_{\text {пред. }}=\mathrm{P}_{\mathrm{H}} / \mathrm{P}_{\mathrm{B}}=0,053$ моль долей ( $1^{\prime}-5^{\prime}$, рис. 5).

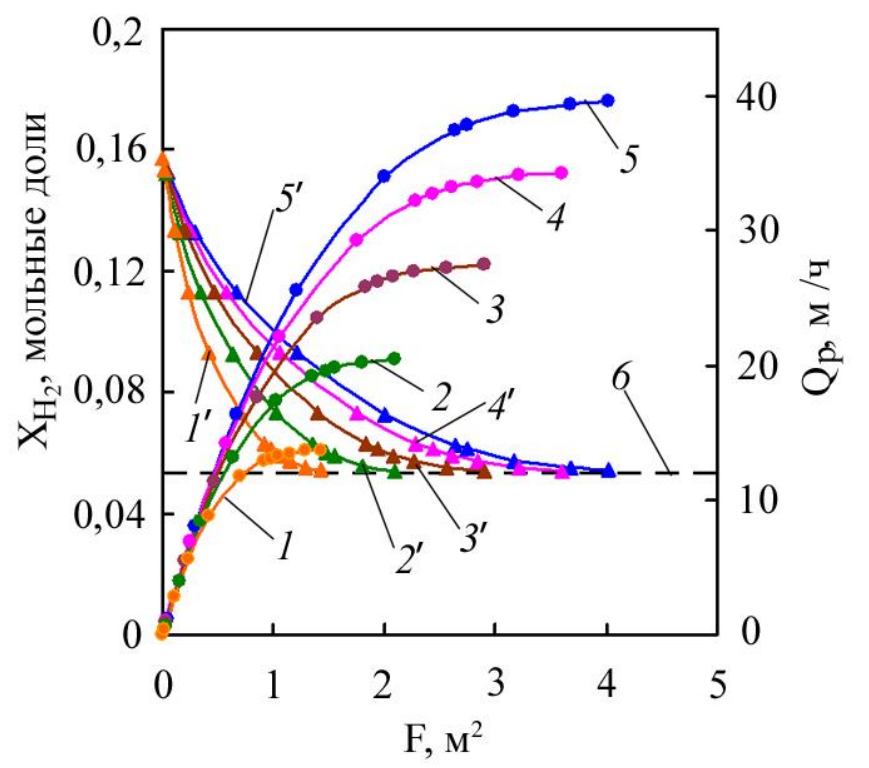

Рис. 5. Зависимость производительности по водороду $\mathrm{Q}_{\mathrm{P}}(1-5)$ и концентрации водорода $\mathrm{X}_{\mathrm{H}_{2}}\left(1^{\prime}-5\right.$ ') от площади мембраны (F) мембранного конвертора [2] при температуре

$495{ }^{\circ} \mathrm{C}, \mathrm{Q}_{\Pi г}: 1-4 \mathrm{~m}^{3} / \mathrm{ч} ; 2-6 \mathrm{~m}^{3} / \mathrm{ч} ; 3-8 \mathrm{~m}^{3} / \mathrm{ч} ; 4-10 \mathrm{~m}^{3} / \mathrm{ч} ; 5-11,6 \mathrm{~m}^{3} / \mathrm{ч}$;

6 - концентрационный предел $\mathrm{X}_{\text {пред. }}=0,053$ мольных долей

Сопоставляя величину расчетной площади мембраны $\mathrm{F}_{\text {расч. }} \approx 4,0 \quad \mathrm{~m}^{2}$ при $\mathrm{Q}_{\Pi \Gamma}=11,6 \mathrm{~m}^{3} /$ (табл. 2) с величиной установленной площади мембраны $\mathrm{F}_{\text {уст. }}=10,3 \mathrm{~m}^{2}$, 
можно сделать вывод о том, что последней с избытком достаточно для обеспечения экспериментально достигнутой максимальной производительности $Q_{P}=40,1 \mathrm{~m}^{3} /$ ч [2] опытнопромышленного мембранного конвертора при указанных условиях. Расхождение рассчитанной нами максимальной производительности и экспериментально измеренной $\mathrm{Q}_{\mathrm{p}}$ [2] при выбранных условиях составило $1,2 \%$.

При дискретном уменьшении потока исходного сырья $\mathrm{Q}_{0}$ с 48,7 до 16,8 м³/ч при фиксированном отношении $\mathrm{H}_{2} \mathrm{O} / \mathrm{C}=3,2$ максимальная производительность мембранного конвертора $\mathrm{Q}_{\mathrm{p}}$ из-за уменьшения в исходном потоке сырья общего содержания молекулярного и связанного $\left(\mathrm{CH}_{4}\right)$ водорода снижается, что отражается на ходе зависимостей $\mathrm{Q}_{\mathrm{p}}-\mathrm{F}(1-5$, рис. 5),

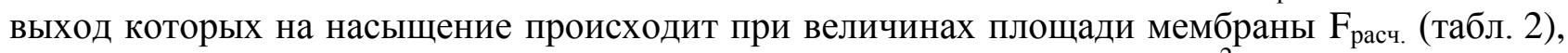
существенно меньших, чем общая установленная площадь $F_{\text {уст. }}=10,3 \mathrm{~m}^{2}$. Метан участвует в процессе мембранного извлечения не прямо, как молекулярный водород, а опосредованно через смещение равновесия (1) вправо по мере отвода водорода из надмембранного пространства через мембрану.

Рассчитанные максимальные величины $\mathrm{Q}_{\mathrm{p}}$ для 5 разных $\mathrm{Q}_{П г}$ (табл. 2) нанесли в виде точек 1 на график (рис. 6). Расчетные точки хорошо укладываются на прямую линию 3, проходящую через начало координат и представляющую расчетную расходную характеристику исследуемого мембранного конвертора. Далее на этот же график в виде треугольных точек 2 нанесли экспериментальные данные работы [2] (табл.1), которые хорошо укладываются на расчетную расходную характеристику 3.

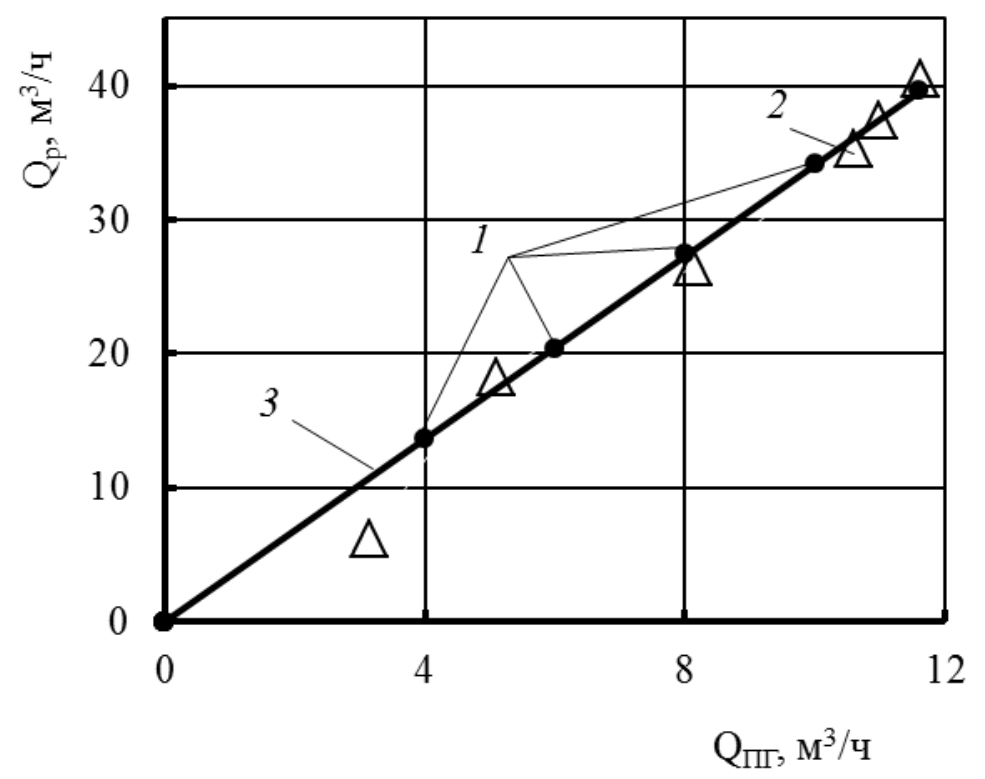

Рис. 6. Расходная характеристика мембранного конвертора:

1 - расчетные точки (табл. 2); 2 - экспериментальные данные [2] (табл. 1); 3 - график расчетной расходной характеристики МК-конвертора [2]

В явном виде прямо пропорциональный характер расходной характеристики $\mathrm{Q}_{\mathrm{p}}-\mathrm{Q}_{0}$ вытекает из уравнения материального баланса водорода (31) в мембранном аппарате для получения высокочистого водорода из химически невзаимодействующих водородсодержащих газовых смесей [18]:

$$
\mathrm{Q}_{\mathrm{P}}=\mathrm{Q}_{0} \frac{\mathrm{X}_{\mathrm{H}_{2}, 0}-\mathrm{X}_{\mathrm{H}_{2}, \mathrm{C}}}{1-\mathrm{X}_{\mathrm{H}_{2}, \mathrm{C}}}
$$


где $\mathrm{X}_{\mathrm{H}_{2}, 0}$ и $\mathrm{X}_{\mathrm{H}_{2}, \mathrm{C}}$ - концентрации водорода на входе и выходе ПВД мембранного аппарата. Применительно к мембранному аппарату для разделения продуктов паровой конверсии углеводородов уравнение (31) приближенно можно представить в следующем виде:

$$
\mathrm{Q}_{\mathrm{P}}=\mathrm{Q}_{0} \frac{\left.\left(\mathrm{X}_{\mathrm{H}_{2}, 0}+4 \mathrm{X}_{\mathrm{CH}_{4}, 0}\right)-\mathrm{X}_{\mathrm{H}_{2}, \mathrm{C}}\right)}{1-\mathrm{X}_{\mathrm{H}_{2}, \mathrm{C}}},
$$

где коэффициент 4 перед концентрацией метана на входе ПВД мембранного аппарата $\mathrm{X}_{\mathrm{CH}_{4}, 0}$ представляет собой стехиометрический коэффициент в химическом равновесии (1). Используя величины $\mathrm{X}_{\mathrm{H}_{2}, 0}=0,1575$ мольных долей $\mathrm{X}_{\mathrm{CH}_{4}, 0}=0,1743$ мольной доли (табл. 3), $\mathrm{Q}_{0}=\mathrm{Q}_{1}=51,9 \mathrm{~m}^{3} /$ ч (табл. 2) и $\mathrm{X}_{\mathrm{H}_{2}, \mathrm{C}}=\mathrm{X}_{\text {пред. }}=0,0533$ мольной доли по формуле (32) приближенно оценили величину максимально возможной производительности МК-реформера, которая составила $Q_{p}=43,9 \mathrm{~m}^{3} /$ ч и лишь на $8,4 \%$ выше $Q_{p}=40,5 \mathrm{~m}^{3} /$ ч (табл. 1 ). Отметим, что в работе [2] не уделялось никакого внимания ни характеру, ни физическому смыслу расходной характеристики исследуемого мембранного реформера.

Расчетная степень конверсии природного газа на выходе предварительного конвертоpa $\left(7\right.$, рис. 4) при температуре $495{ }^{\circ} \mathrm{C}$ составила $22 \%$, что согласуется с интервалом степени конверсии (21-29\%), представленным в работе [2]. Расчетная степень конверсии метана в выходе МК-реформера (3, рис. 4) при той же температуре $495{ }^{\circ} \mathrm{C}$, составила $92 \%$, что также согласуется с данными работы [2] (80-95 \%). Как отмечалось ранее, величина расчетной площади мембраны $\mathrm{F}_{\text {расч. }} \approx 4 \mathrm{~m}^{2}$ (табл. 2) при максимальном расходе природного газа $\mathrm{Q}_{\Pi \Gamma}=11,6 \mathrm{~m}^{3} /$ ч существенно меньше общей установленной площади мембран $\mathrm{F}_{\text {уст. }}=10,3 \mathrm{~m}^{2}$ в мембранном конверторе [2]. Эти обстоятельства свидетельствуют о том, что математическая модель для системы ВТК-ВТМА [9] не только адекватно, но и достаточно точно описывает экспериментальные данные для мембранного конвертора получения высокочистого водорода из природного газа [2]. Основные технологические показатели получения водорода из смеси ПГ-3,2 $\mathrm{H}_{2} \mathrm{O}$ в МК-реформере производительностью $40 \mathrm{~m}^{3} \mathrm{H}_{2} /$ ч [2] представлены в табл. 4.

Таблица 4 - Технологические показатели получения ОЧВ из смеси ПГ-3,2 $\mathrm{H}_{2} \mathrm{O}$

\begin{tabular}{|c|c|c|c|c|}
\hline$F_{\text {pacч. }}, M^{2}$ & $\begin{array}{c}\mathrm{j}_{\text {cp. }}, \\
\mathrm{M}^{3} \mathrm{H}_{2} /\left(\mathrm{M}^{2} \cdot \mathrm{\varphi}\right)\end{array}$ & $\mathrm{m}_{\text {сплава, }} \Gamma$ & $\begin{array}{c}\mathrm{q}_{\mathrm{v}}, \\
\mathrm{m}^{3} \mathrm{H}_{2} / \mathrm{M}^{3} \text { сырья }\end{array}$ & $\mathrm{q}_{\mathrm{m}}$, моль $\mathrm{H}_{2} /$ моль ПГ \\
\hline \multicolumn{5}{|c|}{ MК-реформер $\left(495^{\circ} \mathrm{C}\right)$} \\
\hline 4,0 & 9,9 & 24,2 & 0,81 & 3,4 \\
\hline \multicolumn{5}{|c|}{$\begin{array}{l}\text { Примечание. } \mathrm{F}_{\text {расч. }} \text { - расчетная площадь мембраны; } \mathrm{j}_{\mathrm{cp} .}-\text { средняя плотность диффузион- } \\
\text { ного потока водорода через мембрану; } \mathrm{m}_{\text {сплава }}-\text { масса палладиевого сплава, необходи- } \\
\text { мая для обеспечения удельной производительности } 1 \text { м }^{3} \mathrm{H}_{2} /\left({ }^{2} \cdot \mathrm{M}^{2}\right) ; \mathrm{q}_{\mathrm{v}} \text { и } \mathrm{q}_{\mathrm{m}} \text { - объемный и } \\
\text { мольный удельные выходы водорода. }\end{array}$} \\
\hline
\end{tabular}

При выборе технологических условий эксплуатации МК-устройства важно не допустить углеродоотложения. В данном и последующих разделах оценку вероятности углеродоотложения осуществляли по критерию $\omega=\mathrm{P}_{\mathrm{C}} / \mathrm{P}_{\mathrm{B}}$, предложенному в работе [9], где $\mathrm{P}_{\mathrm{C}}$ - давление углеродоотложения, а $\mathrm{P}_{\mathrm{B}}$ - абсолютное давление газа в надмембранном пространстве. Величину давления углеродоотложения рассчитывали по формуле

$$
\mathrm{P}_{\mathrm{C}}=\mathrm{X}_{\mathrm{CO}_{2}} \cdot \mathrm{K}_{3} \cdot \mathrm{P}_{0}^{0} / \mathrm{X}_{\mathrm{CO}}^{2}
$$


где $\mathrm{X}_{\mathrm{CO}_{2}}$ и $\mathrm{X}_{\mathrm{CO}}$ - равновесные мольные доли диоксида и оксида углерода в газовой фазе; $\mathrm{P}_{0}^{0}$ - абсолютное стандартное давление (в нашем случае $\mathrm{P}_{0}^{0}=0,1 \mathrm{MПа);} \mathrm{K}_{3}$ - константа химического равновесия

$$
\mathrm{C}+\mathrm{CO}_{2} \leftrightarrows 2 \mathrm{CO}
$$

рассчитываемая на основании термодинамических данных.

При величинах критерия $\omega>1$ выпадения углерода из газовой фазы не происходит, а при $\omega \leq 1$ выпадение углерода возможно. На рис. 7 представлены результаты количественной оценки вероятности углеродоотложения в виде графических зависимостей критерия углеродоотложения $\omega$ от площади мембраны для мембранного конвертора при температуре $495^{\circ} \mathrm{C}$ (кривая 1$)$.

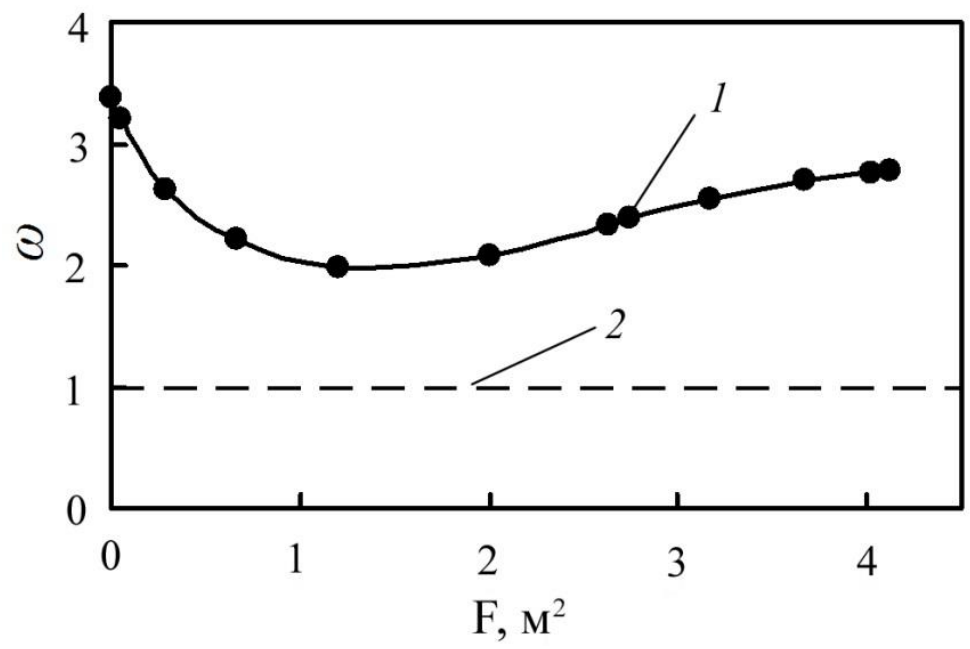

Рис. 7. Зависимости термодинамической вероятности углеродоотложения $\omega$ от площади мембраны F: 1 - расчетные точки; 2 - граница углеродоотложения $(\omega=1)$

На всем рабочем участке площади мембраны от 0 до 4 м$^{2} \omega>1$ и вероятность углеродоотложения отсутствует (рис. 7).

Таким образом, методом математического моделирования подтверждена проектная производительность МК-реформера по высокочистому водороду $\sim 40 \mathrm{~m}^{3} /$ даже при не самом благоприятном сочетании исходных технологических условий.

Однако расчетная производительность МК-реформера, близкая к проектной в рамках используемых модельных представлений достигается при величине расчетной площади мембраны $\sim$ в 2,5 раза меньше, чем установленная площадь мембраны, что свидетельствует о ее нерациональном использовании.

Кроме того, удалось с достаточной точностью описать экспериментальную расходную характеристику и дать физическое обоснование ее прямо пропорциональному характеру, а также оценить ряд важных технологических показателей опытно-промышленного мембранного конвертора получения особо чистого водорода из природного газа.

\section{2. Анализ параметров и режимов МК-реформера производительностью $40 \boldsymbol{м}^{3} \mathrm{H}_{2} / 4$ с учетом состава сбросного газа}

Ниже представлен более сложный вариант использования указанной выше математической модели [9] для анализа параметров и технологических режимов МК-устройств не только с точки зрения их производительности по водороду-продукту, но и с учетом состава сбросного газа, использование которого для поддержания рабочей температуры позволяет 
уменьшить расход природного газа на обогрев и тем самым повысить общую энергоэффективность установки получения высокочистого водорода из природного газа.

Первоначально проанализировали результаты испытаний стационарной опытнопромышленной установки получения высокочистого водорода $(99,999$ об. \%) из природного газа (ПГ) с проектной производительностью $40 \mathrm{~m}^{3} \mathrm{H}_{2} /$ ч на базе мембранного конвертора [2], устройство которого представлено в разд. 3.1. Величина установленной площади мембраны составила $\mathrm{F}_{\text {уст. }}=10,3 \mathrm{~m}^{2}$.

Схема единичного МК-модуля представлена на рис. 8. Исходный газовый поток смеси природного газа с водяным паром $(A$, рис. 8$)$ поступает в полость предварительного конвертора ППК $(2$, рис. 8$)$ со стандартным $\mathrm{Ni} / \mathrm{Al}_{2} \mathrm{O}_{3}$ катализатором в виде гранул с размерами 2-3 мм, на котором осуществлялась паровая конверсия природного газа без извлечения водорода согласно обратимым химическим реакциям $\mathrm{CH}_{4}+2 \mathrm{H}_{2} \mathrm{O}=4 \mathrm{H}_{2}+\mathrm{CO}_{2}, \mathrm{CO}+\mathrm{H}_{2} \mathrm{O}=\mathrm{H}_{2}+\mathrm{CO}_{2}$.

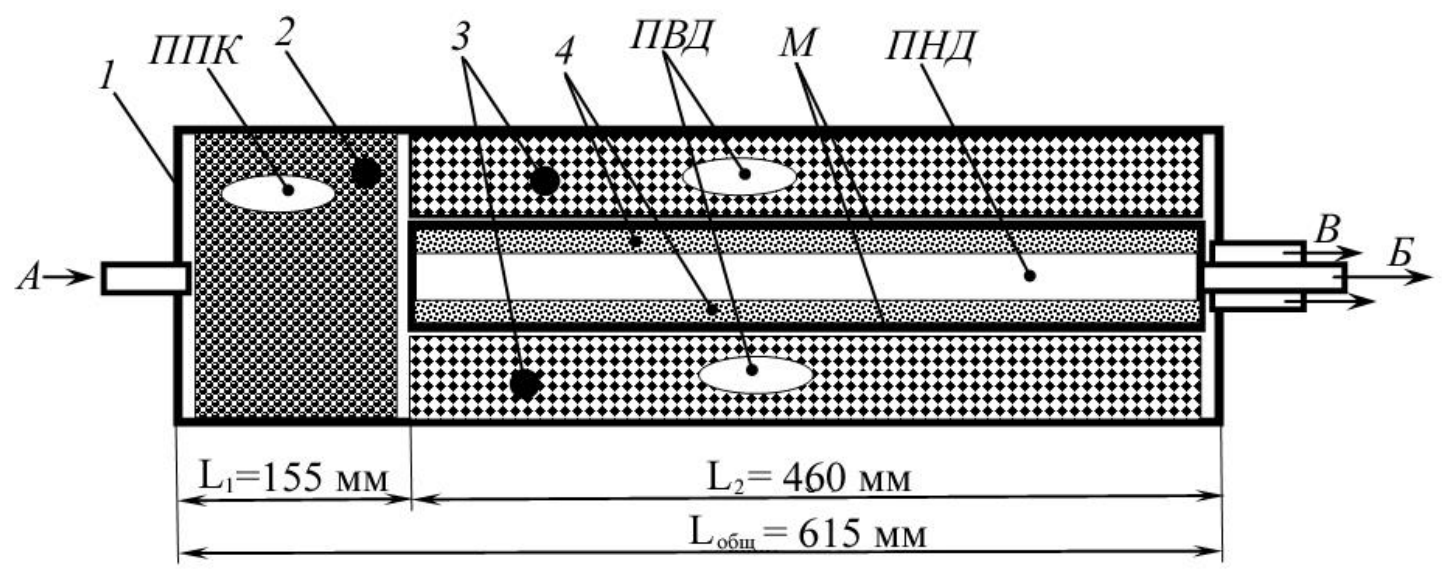

Рис. 8. Схема индивидуального МК-реактора плоского типа:

$A$ - смесь природного газа с парами воды; $D$ - водород-продукт; $B$ - сбросной газ;

$L_{1}$-участок предварительного конвертора; $L_{2}$ - участок конвертора, совмещенного с мем-

бранным извлечением водорода; $L_{\text {общ. }}$ - участок мембранно-каталитического модуля;

$M$ - мембрана из Pd-8Y сплава; ППК - полость предварительного конвертора;

ПВД - полость высокого давления; ПНД - полость низкого давления;

1 - корпус мембранно-каталитического модуля; 2 - традиционный катализатор;

3 - дополнительный катализатор; 4 - пористая подложка из нержавеющей стали

Далее продукты паровой конверсии ПГ в виде газовой смеси, содержащей $\mathrm{H}_{2}, \mathrm{H}_{2} \mathrm{O}$, $\mathrm{CO}_{2}, \mathrm{CO}$ и $\mathrm{CH}_{4}$, поступали в полость высокого давления (ПВД, рис. 8), где вдоль поверхности мембраны установлен дополнительный никелевый катализатор рифленого типа (3, рис. 8), образующий каналы между катализатором и мембраной для прохождения разделяемой газовой смеси. Для удаления водорода-продукта $(5$, рис. 8$)$ из полости низкого давления (ПНД, рис. 8) в мембранном конверторе использован металлогидридный побудитель расхода водорода [2].

Отметим, что конструкция единичного МК-конвертора практически полностью совпадает с расчетной схемой, заложенной нами в основу математической модели [9] (рис. 8). Исходные эксплуатационные данные и результаты расчетов МК-устройства производительностью $40 \mathrm{M}^{3} \mathrm{H}_{2} /$ и и экспериментальный состав сбросного газа представлены в табл. 5 [2].

Расчетами показано, что для рабочей температуры $500{ }^{\circ} \mathrm{C}$ проектная производительность МК-конвертора $\mathrm{Q}_{\mathrm{p}}=40 \mathrm{~m}^{3} \mathrm{H}_{2} /$ ч подтверждается при использовании в качестве исходных данных эксплуатационных технологических параметров при абсолютном давлении водорода-продукта в подмембранном пространстве $\mathrm{P}_{\mathrm{H}}=0,048$ МПа (табл. 5). 
Однако расчетный состав сбросного газа (в пересчете на сухой газ) существенно отличается от экспериментального. Расчетная площадь мембраны $\mathrm{F}_{\text {расч }}=4,025 \mathrm{~m}^{2}$ при этих исходных данных составляет $39 \%$ от $\mathrm{F}_{\text {уст. }}=10,3 \mathrm{~m}^{2}$. Средняя расчетная плотность диффузионного потока водорода через мембрану в этом случае составляет $\mathrm{J}_{\mathrm{H}_{2}}=\mathrm{Q}_{\mathrm{p}} / \mathrm{F}_{\text {расч. }}=40 / 4,025=9,94 \mathrm{м}^{3} \mathrm{H}_{2} /\left(\mathrm{M}^{2} \mathrm{u}\right)$ и в 2,56 раза превышает проектную $-\mathrm{J}_{\mathrm{H}_{2}}=\mathrm{Q}_{\mathrm{p}} / \mathrm{F}_{\text {расч. }}=40 / 10,3=3,88 \mathrm{~m}^{3} \mathrm{H}_{2} /\left(\mathrm{M}^{2} ч\right)$ (табл. 5).

Таблица 5 - Эксплуатационные и расчетные параметры мембранного конвертора производительностью $40 \mathrm{~m}^{3} \mathrm{H}_{2} / \mathrm{ч}$

\begin{tabular}{|c|c|c|c|c|c|c|c|}
\hline \multicolumn{8}{|c|}{ Параметры мембранного конвертора производительностью 40 м $^{3} \mathrm{H}_{2} / \mathrm{ч}$} \\
\hline \multicolumn{3}{|c|}{ Эксплуатационные } & \multicolumn{5}{|c|}{ Расчетные } \\
\hline \multirow{2}{*}{\multicolumn{2}{|c|}{$\begin{array}{c}\text { Температура, }{ }^{\circ} \mathrm{C} \\
\text { Отношение } \\
\text { пар/углерод }\end{array}$}} & $500-550$ & \multicolumn{3}{|c|}{500} & \multicolumn{2}{|c|}{550} \\
\hline & & $3-3,2$ & & & 3 & & \\
\hline \multicolumn{2}{|c|}{$\mathrm{Q}_{\Pi \Gamma}, \mathrm{m}^{3} / \mathrm{u}$} & 11,6 & \multicolumn{2}{|c|}{11,6} & 14,796 & 11,6 & 11,874 \\
\hline \multicolumn{2}{|c|}{$\mathrm{P}_{\mathrm{B}}, \mathrm{MПа}$} & 0,9 & \multicolumn{5}{|c|}{0,9} \\
\hline \multicolumn{2}{|c|}{$\mathrm{P}_{\mathrm{H}}, \mathrm{MПа}$} & $0,02-0,04$ & 0,048 & \multicolumn{2}{|c|}{0,073} & 0,048 & 0,073 \\
\hline \multicolumn{2}{|c|}{$\mathrm{F}, \mathrm{M}^{2}$} & 10,3 & 4,025 & 5,773 & 7,335 & 2,233 & 3,626 \\
\hline \multicolumn{2}{|c|}{$\mathrm{Q}_{\mathrm{P}}, \mathrm{M}^{3} \mathrm{H}_{2} / \mathrm{u}$} & 40 & 40 & 31,36 & 40 & 42,16 & 40 \\
\hline \multicolumn{2}{|c|}{$\mathrm{J}_{\mathrm{H}_{2}}, \mathrm{M}^{3} \mathrm{H}_{2} /\left(\mathrm{M}^{2} \mathrm{u}\right)$} & 3,88 & 9,94 & 5,43 & 5,45 & 18,9 & 11,03 \\
\hline \multirow{4}{*}{$\begin{array}{c}\text { Состав } \\
\text { сбросного } \\
\text { газа, об \% }\end{array}$} & $\mathrm{H}_{2}$ & 15,5 & 10,93 & 18,06 & 18,06 & 10,55 & 16,15 \\
\hline & $\mathrm{CO}$ & 1,9 & 1,72 & 1,82 & 1,82 & 2,65 & 3,48 \\
\hline & $\mathrm{CO}_{2}$ & 64,73 & 82,0 & 62,0 & 61,98 & 85,73 & 75,62 \\
\hline & $\mathrm{CH}_{4}$ & 17,83 & 5,35 & 18,12 & 18,13 & 1,06 & 4,75 \\
\hline
\end{tabular}

Поскольку, согласно модельным представлениям [9], ответственным параметром за отток водорода через мембрану является концентрационный предел $\mathrm{X}_{\text {пред. }}=\mathrm{P}_{\mathrm{H}} / \mathrm{P}_{\mathrm{B}}$, при проведении дальнейших расчетов мы увеличили $\mathrm{P}_{\mathrm{H}}$ с 0,048 МПа до 0,073 МПа, а остальные исходные параметры сохранили неизменными. При указанных исходных данных расчетный состав сбросного газа удовлетворительно коррелирует с экспериментальными данными, но расчетная производительность МК-устройства $Q_{p}$ уменьшилась с 40 до $31,36 \mathrm{~m}^{3} \mathrm{H}_{2} /$ ч (табл. 5), т.е. ниже проектной производительности $40 \mathrm{~m}^{3} \mathrm{H}_{2} /$ ч, но практически совпала с номинальной эксплуатационной производительностью по водороду-продукту МК-устройства $\mathrm{Q}_{\mathrm{p}}=30 \mathrm{~m}^{3} \mathrm{H}_{2} /$ ч [2] при условиях его длительной эксплуатации ( 3000 ч). Расчетная площадь

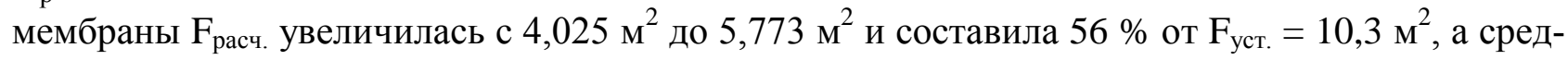
няя расчетная плотность диффузионного потока водорода через мембрану $\mathrm{J}_{\mathrm{H}_{2}}$ в этом случае уменьшилась с 9,94 до 5,43 м $\mathrm{m}_{2}^{3} /\left(\mathrm{M}^{2} ч\right)$ и приблизилась к проектной $\mathrm{J}_{\mathrm{H}_{2}}=3,88 \mathrm{~m}^{3} \mathrm{H}_{2} /\left(\mathrm{M}^{2} \mathrm{q}\right)$ (табл. 5). Дополнительными расчетами установлено, что при снижении рабочей температуры до $475^{\circ} \mathrm{C}\left(\mathrm{P}_{\mathrm{B}}=0,9 \mathrm{MПа} ; \mathrm{P}_{\mathrm{H}}=0,057 \mathrm{MПа} ; \mathrm{Q}_{\Pi \Gamma}=11,6 \mathrm{~m}^{3} /\right.$ ч) расчетный состав сбросного газа еще ближе к экспериментальному. При указанных выше условиях расчетные концентрации водорода, диоксида углерода, оксида углерода и метана составили соответственно: 15,23; 66,61; 1,19 и 16,97 об. \%. Производительность МК-реформера составила $Q_{p}=32,9$ м/ч (незначительно отличается от $\left.\mathrm{Q}_{\mathrm{p}}=31,36 \mathrm{~m}^{3} \mathrm{H}_{2} / \mathrm{ч}\right)$, а $\mathrm{F}_{\text {расч. }}=5,96 \mathrm{~m}^{2}$, что достаточно близко к $\mathrm{F}_{\text {расч. }}=5,773 \mathrm{M}^{2}$ (табл. 5). 
Для сохранения проектной производительности на уровне $\mathrm{Q}_{\mathrm{p}}=40 \mathrm{~m}^{3} \mathrm{H}_{2} /$ ч при неизменных условиях предыдущего расчета расход природного газа $\mathrm{Q}_{\Pi \Gamma}$ в исходной сырьевой смеси увеличили с 11,6 до $14,796 \mathrm{~m}^{3} /$ ч. В этом случае $\mathrm{J}_{\mathrm{H}_{2}}$ и расчетный состав сбросного газа практически не изменились, а расчетная площадь мембраны составила 7,335 м² и приблизилась к установленной площади мембраны и составила $71 \%$ от $\mathrm{F}_{\text {уст. }}=10,3$ м 2 (табл. 5). К косвенному

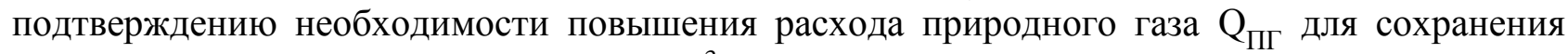
производительности на уровне $\mathrm{Q}_{\mathrm{p}}=40 \mathrm{~m}^{3} \mathrm{H}_{2} /$ ч следует отнести увеличение числа индивидуальных МК-реакторов в мембранном конверторе со 112 до 128 единиц, отмеченное в более поздней работе японских исследователей [19].

В графическом виде результаты расчетов при температуре $500{ }^{\circ} \mathrm{C}, \mathrm{Q}_{\Pi \Gamma}=14,796 \mathrm{~m}^{3} /$ ч и $\mathrm{P}_{\mathrm{H}}=0,073$ МПа представлены на рис. 9. По мере прохождения многокомпонентной газовой смеси вдоль поверхности мембраны за счет оттока водорода через мембрану и смещения химического равновесия (1) вправо равновесная концентрация водорода $\mathrm{X}_{\mathrm{H}_{2}}$ над участком поверхности мембраны (кривая 2) уменьшается и приближается к концентрационному пределу $\mathrm{X}_{\text {пред }}=\mathrm{P}_{\mathrm{H}} / \mathrm{P}_{\mathrm{B}}=0,0811$ мольной доли, отмеченному горизонтальной пунктирной линией 3 (рис. 9).

При этих условиях движущая сила процесса диффузии водорода через мембрану стремится к нулю, а производительность МК-устройства (кривая 1) приближается к проектной величине $\mathrm{Q}_{\mathrm{p}}=40 \mathrm{~m}^{3} \mathrm{H}_{2} /$ ч, отмеченной горизонтальной пунктирной линией 4 . Установленная площадь мембраны $\mathrm{F}_{\text {уст. }}=10,3$ м² представлена вертикальной пунктирной линией 5 (рис. 9).

Результаты аналогичного анализа для рабочей температуры $550{ }^{\circ} \mathrm{C}$ приведены также в табл. 5. При исходном расходе природного газа $\mathrm{Q}_{\Pi \Gamma}=11,6 \mathrm{~m}^{3} /$ и и $\mathrm{P}_{\mathrm{H}}=0,048$ МПа расчетная производительность МК-устройства несколько выше проектной и составляет $\mathrm{Q}_{\mathrm{p}}=42,16 \mathrm{~m}^{3} \mathrm{H}_{2} /$ ч, а расчетная площадь мембраны $\mathrm{F}_{\text {расч. }}=2,233 \mathrm{~m}^{2}\left(21,7 \%\right.$ от $\left.\mathrm{F}_{\text {уст. }}=10,3 \mathrm{~m}^{2}\right)$.

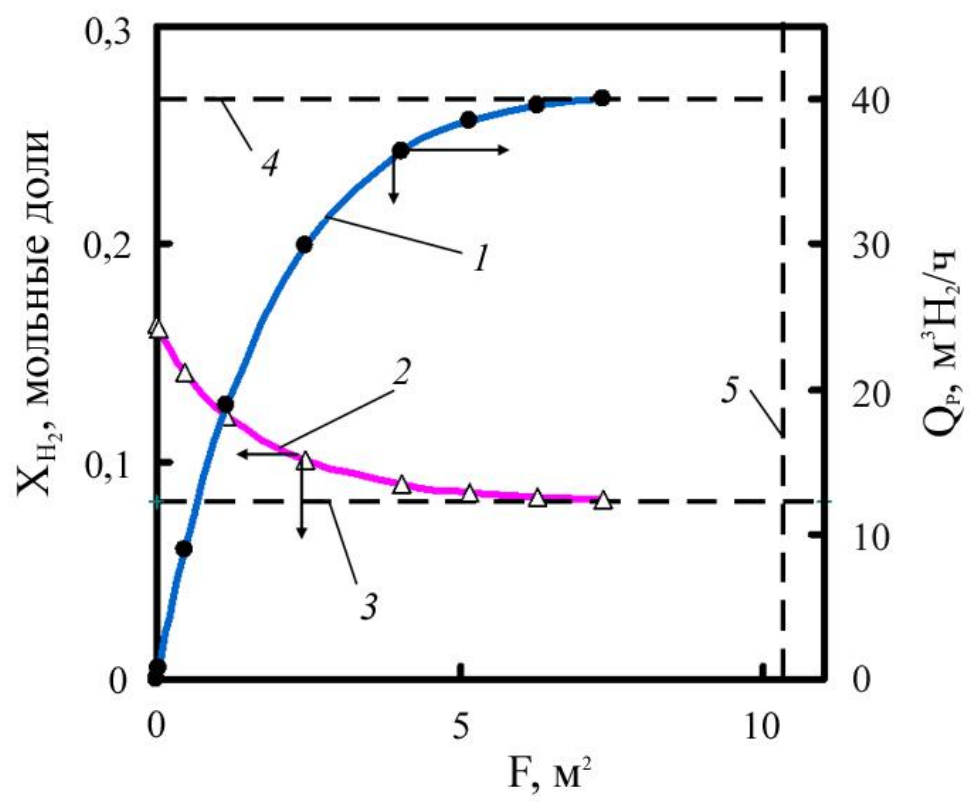

Рис. 9. Зависимости производительности $\mathrm{Q}_{\mathrm{p}}(1)$ и концентрации водорода $\mathrm{X}_{\mathrm{H}_{2}}(2)$ от площади мембраны F для мембранного конвертора производительностью $40 \mathrm{~m}^{3} \mathrm{H}_{2} / \mathrm{ч} ; 3$ - уровень концентрационного предела $\mathrm{X}_{\text {пред . }}=0,0811$ мольных долей; 4 - уровень проектной производительности $\mathrm{Q}_{\mathrm{p}}=40 \mathrm{~m}^{3} \mathrm{H}_{2} / \mathrm{q} ; 5$ - уровень установленной площади мембраны $\mathrm{F}_{\text {уст. }}=10,3 \mathrm{~m}^{2}$ 
При увеличении $\mathrm{P}_{\mathrm{H}}$ с 0,048 МПа до 0,073 МПа для увеличения расчетной производительности МК-конвертора до уровня проектной $\mathrm{Q}_{\mathrm{p}}=40 \mathrm{~m}^{3} \mathrm{H}_{2} /$ ч поток природного газа $\mathrm{Q}_{\Pi Г}$ в исходной смеси незначительно изменили с 11,6 до $11,874 \mathrm{~m}^{3} /$ ч. При этих условиях расчетная площадь мембраны $\mathrm{F}_{\text {расч. }}=3,626 \mathrm{~m}^{2}$ и составляет $35,2 \%$ от $\mathrm{F}_{\text {уст }}=10,3 \mathrm{~m}^{2}$. Однако расчетный состав сбросного газа при рабочей температуре $550{ }^{\circ} \mathrm{C}$ и абсолютных давлениях в ПНД $\mathrm{P}_{\mathrm{H}}$ 0,048 и 0,073 МПа заметно отличается от экспериментального (табл. 5).

Проведенный анализ исследуемого МК-конвертора показал, что для $\mathrm{F}_{\text {уст. }}=10,3 \mathrm{~m}^{2}$ проектная производительность $\mathrm{Q}_{\mathrm{p}}=40 \mathrm{~m}^{3} \mathrm{H}_{2} /$ ч подтверждается как при 500, так и при $550{ }^{\circ} \mathrm{C}$. Показано, что при температуре $500{ }^{\circ} \mathrm{C}$ для согласования расчетных данных с экспериментальными по составу сбросного газа необходимо уменьшить среднюю плотность диффузионного потока водорода через мембрану $\mathrm{J}_{\mathrm{H}_{2}}$, например, путем увеличения давления в полости низкого давления $\mathrm{P}_{\mathrm{H}}$ до 0,073 МПа, а для сохранения проектной производительности необходимо увеличить $\mathrm{Q}_{П г}$ в исходной смеси до $14,796 \mathrm{~m}^{3} /$ ч.

Таким образом, на основании проведенного анализа методом математического моделирования установлено влияние исходных факторов, влияющих на выходные параметры МК-реформера производительностью $40 \mathrm{~m}^{3} \mathrm{H}_{2} /$ ч, на основании которых можно выделить два возможных эксплуатационных режима исследуемого МК-устройства.

В случае 1-го режима при достаточно большом отборе водорода через мембрану, характеризуемого высокой средней плотностью диффузионного потока водорода через мембрану и реализуемого за счет относительно высокого перепада давлений по обе стороны от мембраны, достигается проектная производительность МК-устройства по высокочистому водороду для обеих исследованных температур. Но в этом случае установленная площадь мембраны используется не рационально. Для более рационального использования площади мембраны при штатных параметрах $\left(\mathrm{t}_{\text {раб. }}=500^{\circ} \mathrm{C} ; \mathrm{P}_{\mathrm{B}}=0,9 \mathrm{MПа} ; \mathrm{P}_{\mathrm{H}}=0,048 \mathrm{MПа}\right)$ исходный расход природного газа $\mathrm{Q}_{П г}$ необходимо увеличить до $27,92 \mathrm{~m}^{3}$ /ч. При этих условиях расчетная производительность мембранного реформера по высокочистому водороду при условии сохранения высокой активности катализатора возрастет в 2,38 раза до $\mathrm{Q}_{\mathrm{p}}=95,2$ м³/ч при расчетной площади мембраны $\mathrm{F}_{\text {расч. }}=$ $9,95 \mathrm{~m}^{2}$, не превышающей установленной площади мембраны $\mathrm{F}_{\text {уст. }}=10,3 \mathrm{~m}^{2}$. Очевидно, что при реализации этого режима необходимо иметь в составе установки более производительный металлогидридный компрессор. Расчетный состав сбросного газа остается таким же, как и при исходном расходе природного газа $\mathrm{Q}_{\Pi \Gamma}=11,6 \mathrm{~m}^{3} /$ ч. Однако в этом случае сбросной газ менее пригоден для обогрева МК-реформера.

В случае 2-го режима при условии снижения отбора водорода через мембрану за счет уменьшения перепада давлений (в нашем случае только за счет увеличения абсолютного давления в полости низкого давления) расчетный состав сбросного газа удовлетворительно коррелирует с экспериментальными данными, но только при температуре $500{ }^{\circ} \mathrm{C}$. Еще более лучшая корреляция по составу сбросного газа наблюдается при рабочей температуре $475{ }^{\circ} \mathrm{C}$, что может качественно свидетельствовать о неравномерном нагреве индивидуальных МК-реакторов по высоте. Площадь мембраны при этих условиях используется более рационально, а состав сбросного газа более пригоден для обогрева мембранного реформера с целью повышения общей энергетической эффективности всей установки получения высокочистого водорода из природного газа.

\section{3. Анализ параметров МК-реформера производительностью $20 \mathrm{M}^{3} \mathrm{H}_{2} /$ с состава сбросного газа}

В разделе представлен анализ результатов испытаний стационарной опытнопромышленной установки получения высокочистого водорода из природного газа с проектной производительностью $20 \mathrm{~m}^{3} \mathrm{H}_{2} /$ ч на базе мембранного конвертора, разработанного и испытанного той же японской компанией $[1,12]$.

Vandyshev A. B. / Analyzing the parameters of membrane catalytic systems for extraction of highly pure 


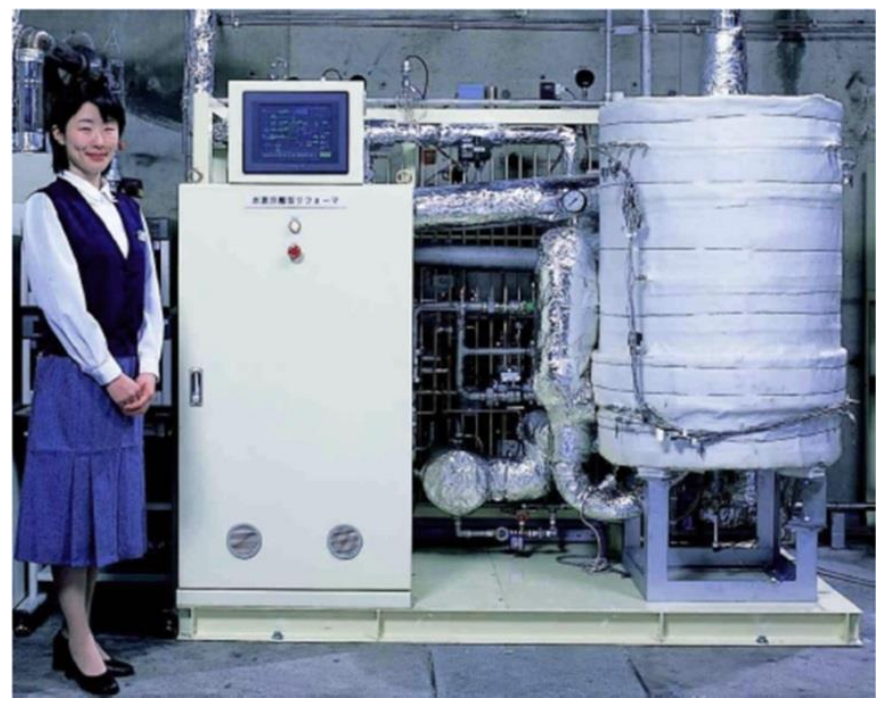

Рис. 10. Внешний вид установки на базе мембранного реформера производительностью $20 \mathrm{M}^{3} \mathrm{H}_{2} /$ ч [12]

Внешний вид установки получения высокочистого водорода из природного газа на базе МК-реформера производительностью $20 \mathrm{~m}^{3} \mathrm{H}_{2} /$ п представлен на рис. 10 , а упрощенная схема собственно МК-реформера - на рис. 11.

Конструктивно мембранный конвертор $\left(20 \mathrm{~m}^{3} \mathrm{H}_{2} /\right.$ ч) отличался от предыдущего $\left(40 \mathrm{~m}^{3} \mathrm{H}_{2} /\right.$ ч) и представлял собой цилиндрический корпус с внешним диаметром 640 мм и высотой 1000 мм [1]. Явно выраженный конструктивно предварительный конвертор природного газа в данном МК-реформере отсутствовал.

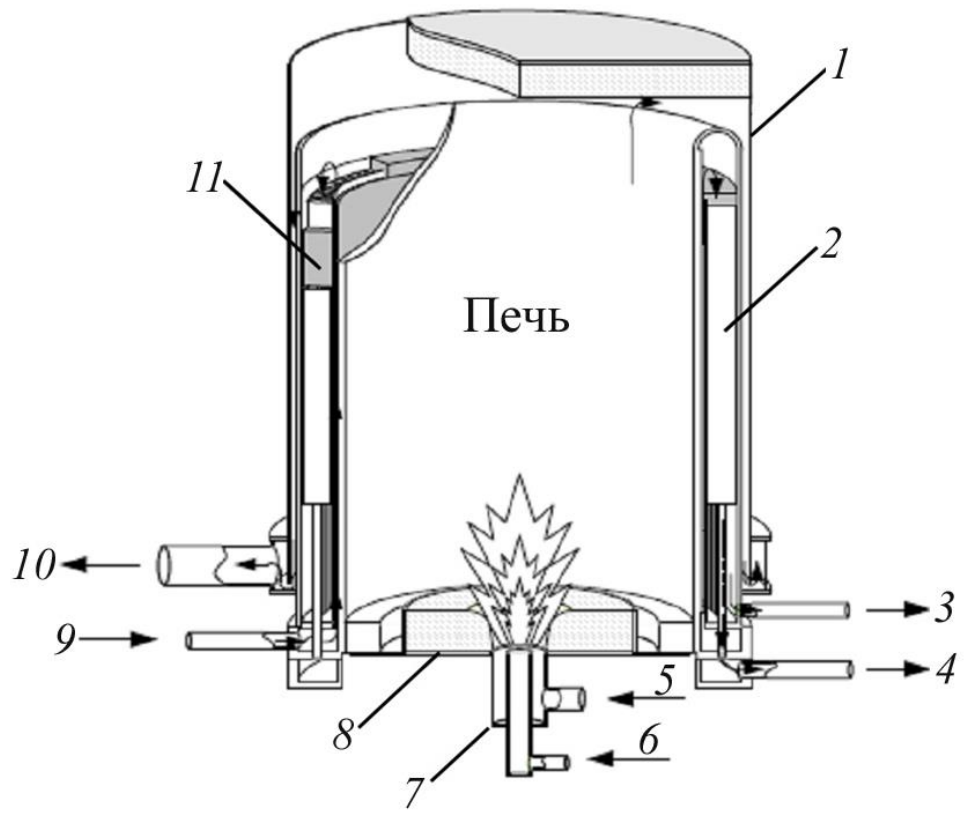

Рис. 11. Схема мембранного реформера производительностью $20 \mathrm{~m}^{3} \mathrm{H}_{2} /$ ч [1]:

1 - корпус; 2 - мембранный элемент плоского типа; 3 - выход сбросного газа;

4 - выход водорода-продукта; 5 - подача воздуха в горелку; 6 - подача топлива в горелку;

7 - горелка; 8 - распределительная плита горелки; 9 - смесь природного газа и водяного пара; 10 - выход топочных газов; 11 - катализатор

В центре цилиндрического корпуса (рис. 11) находилась нагревательная печь. В кольцевом зазоре между корпусами конвертора и нагревательной печи размещены традиционный 
гранулированный катализатор конверсии метана (11) и 96 мембранных элементов (2, рис. 11) плоского типа с размерами $460 \times 40 \times 10$ мм, состоящих из палладиевой мембраны толщиной 20 мкм на пористой металлической подложке.

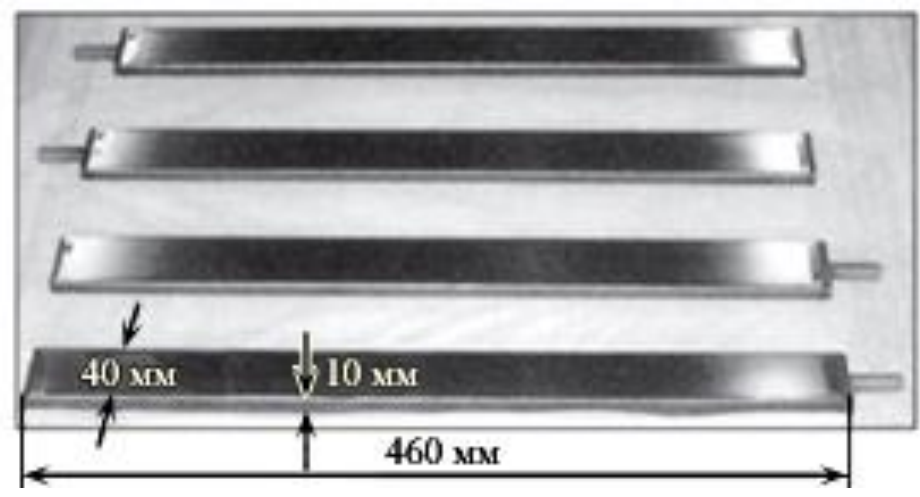

Рис. 12. Внешний вид мембранных элементов плоского типа [14]

Величину общей установленной площади мембраны в МК-устройстве $[1,12]$ оценили на основании размеров одного мембранного элемента и общего количества элементов, которая составила $\mathrm{F}_{\text {уст. }}=0,46 \times 0,1 \times 96=4,42 \mathrm{~m}^{2}$ (рис. 12 ).

Исходные эксплуатационные данные и результаты расчета параметров МК-устройства производительностью $20 \mathrm{~m}^{3} \mathrm{H}_{2} /$ ч представлены в табл. 6. Экспериментальный состав сбросного газа взят из работы [12].

Расчетами показано, что для рабочей температуры 500 и $550{ }^{\circ} \mathrm{C}$ проектная производительность МК-конвертора $\mathrm{Q}_{\mathrm{p}}=20 \mathrm{~m}^{3} \mathrm{H}_{2} /$ ч с запасом подтверждается при использовании в качестве исходных данных эксплуатационных технологических параметров (табл. 6) при абсолютном давлении водорода-продукта в подмембранном пространстве $\mathrm{P}_{\mathrm{H}}=0,048 \mathrm{MПа}$.

Однако расчетный состав сбросного газа (в пересчете на сухой газ) существенно отличается от экспериментального. При температуре $500{ }^{\circ} \mathrm{C}$ расчетная площадь мембраны $\mathrm{F}_{\text {расч. }}=2,318 \mathrm{~m}^{2}$ для исходных данных составляет $53,8 \%$ от $\mathrm{F}_{\text {уст. }}=4,42 \mathrm{~m}^{2}$.

Таблица 6 - Эксплуатационные и расчетные параметры мембранного конвертора производительностью $20 \mathrm{~m}^{3} \mathrm{H}_{2} / \mathrm{\varphi}$

\begin{tabular}{|c|c|c|c|c|c|c|c|}
\hline \multicolumn{8}{|c|}{ Параметры мембранного реактора производительностью 20 м $^{3} \mathrm{H}_{2} / \mathrm{ч}$} \\
\hline \multicolumn{3}{|c|}{ Эксплуатационные } & \multicolumn{5}{|c|}{ Расчетные } \\
\hline \multicolumn{2}{|c|}{ Температура, ${ }^{\circ} \mathrm{C}$} & 550 & \multicolumn{3}{|c|}{500} & \multicolumn{2}{|c|}{550} \\
\hline \multicolumn{2}{|c|}{ Отношение пар/углерод } & 3 & \multicolumn{5}{|c|}{3} \\
\hline \multicolumn{2}{|c|}{$\mathrm{Q}_{\Pi \Gamma}, \mathrm{M}^{3} / \mathrm{u}$} & 6,68 & \multicolumn{2}{|c|}{6,68} & 7,266 & \multicolumn{2}{|c|}{6,68} \\
\hline \multicolumn{2}{|c|}{$\mathrm{P}_{\mathrm{B}}, \mathrm{M \Pi а}$} & 0,93 & \multicolumn{5}{|c|}{0,93} \\
\hline \multicolumn{2}{|c|}{$\mathrm{P}_{\mathrm{H}}, \mathrm{M \Pi а}$} & 0,04 & 0,048 & 0,073 & 0,073 & 0,048 & 0,073 \\
\hline \multicolumn{2}{|c|}{$\mathrm{F}, \mathrm{M}^{2}$} & 4,42 & 2,318 & 3,358 & 3,537 & 1,425 & 1,98 \\
\hline \multicolumn{2}{|c|}{$\mathrm{Q}_{\mathrm{P}}, \mathrm{M}^{3} / \mathrm{\varphi}$} & 21,5 & 23,16 & 18,4 & 20 & 24,36 & 22,64 \\
\hline \multicolumn{2}{|c|}{$\mathrm{J}_{\mathrm{H}_{2}}, \mathrm{M}^{3} \mathrm{H}_{2} /\left(\mathrm{M}^{2} \mathrm{u}\right)$} & 4,86 & 9,73 & 5,48 & 5,65 & 17,1 & 11,43 \\
\hline \multirow{4}{*}{$\begin{array}{c}\text { Состав } \\
\text { сбросного } \\
\text { газа, об. } \\
\% \\
\end{array}$} & $\mathrm{H}_{2}$ & 18,8 & 10,53 & 17,39 & 17,43 & 10,04 & 15,62 \\
\hline & $\mathrm{CO}$ & 2,3 & 1,68 & 1,8 & 1,8 & 2,54 & 3,41 \\
\hline & $\mathrm{CO}_{2}$ & 59,5 & 82,79 & 63,34 & 63,32 & 86,48 & 76,47 \\
\hline & $\mathrm{CH}_{4}$ & 19,3 & 5,01 & 17,37 & 17,45 & 0,94 & 4,5 \\
\hline
\end{tabular}

Примечание. Объемные расходы приведены к нормальным условиям. 
Средняя расчетная плотность диффузионного потока водорода через мембрану в этом случае составляет $\mathrm{J}_{\mathrm{H}_{2}}=\mathrm{Q}_{\mathrm{p}} / \mathrm{F}_{\text {расч. }}=23,16 / 2,318=9,73 \mathrm{~m}^{3} \mathrm{H}_{2} /\left(\mathrm{M}^{2} \mathrm{q}\right)$ и примерно в 2 раза превышает проектную $-\mathrm{J}_{\mathrm{H}_{2}}=\mathrm{Q}_{\mathrm{p}} / \mathrm{F}_{\text {расч. }}=21,5 / 4,42=4,86 \mathrm{~m}^{3} \mathrm{H}_{2} /\left(\mathrm{M}^{2}\right.$ ч) (табл. 6). Как и ранее (разд. 3.2), при проведении дальнейших расчетов мы увеличили $\mathrm{P}_{\mathrm{H}}$ с 0,048 МПа до 0,073 МПа, а остальные исходные параметры сохранили неизменными.

В этом случае расчетный состав сбросного газа хорошо коррелирует с экспериментальными данными, но расчетная производительность МК-устройства $Q_{p}$ уменьшилась с 23,16 до 18,4 м ${ }^{3} \mathrm{H}_{2} /$ ч, что лишь на $8 \%$ ниже проектной производительности $20 \mathrm{~m}^{3} \mathrm{H}_{2} /$ ч. Средняя расчетная плотность диффузионного потока водорода через мембрану в этом случае составила $\mathrm{J}_{\mathrm{H}_{2}}=\mathrm{Q}_{\mathrm{p}} / \mathrm{F}_{\text {расч. }}=18,4 / 3,358=5,47 \mathrm{M}^{3} \mathrm{H}_{2} /\left(\mathrm{M}^{2} \mathrm{q}\right)$ и приблизилась $к$ проектной $\mathrm{J}_{\mathrm{H}_{2}}=4,86 \mathrm{~m}^{3} \mathrm{H}_{2} /\left(\mathrm{M}^{2} \mathrm{u}\right)$ (табл. 6).

Для сохранения проектной производительности на уровне $\mathrm{Q}_{\mathrm{p}}=20 \mathrm{~m}^{3} \mathrm{H}_{2} /$ ч при неизменных условиях предыдущего расчета расход природного газа $\mathrm{Q}_{\Pi г}$ в исходной сырьевой смеси увеличили с 6,68 до $7,266 \mathrm{~m}^{3} /$. В этом случае $\mathrm{J}_{\mathrm{H}_{2}}$ и расчетный состав сбросного газа практически не изменились, а расчетная площадь мембраны $\mathrm{F}_{\text {расч. }}=3,537 \mathrm{м}^{2}$ и составила порядка $80 \%$ от $\mathrm{F}_{\text {уст. }}=4,42 \mathrm{~m}^{2}$, что свидетельствует о более рациональном использовании мембраны.

В графическом виде результаты расчетов при температуре $500{ }^{\circ} \mathrm{C}, \mathrm{Q}_{\Pi \Gamma}=7,266 \mathrm{~m}^{3} / 4$ и $\mathrm{P}_{\mathrm{H}}=0,073$ МПа в виде зависимостей $\mathrm{Q}_{\mathrm{p}}-\mathrm{F}$ (кривая 2) и $\mathrm{X}_{\mathrm{H}_{2}}-\mathrm{F}$ (кривая 4) представлены на рис. 13.

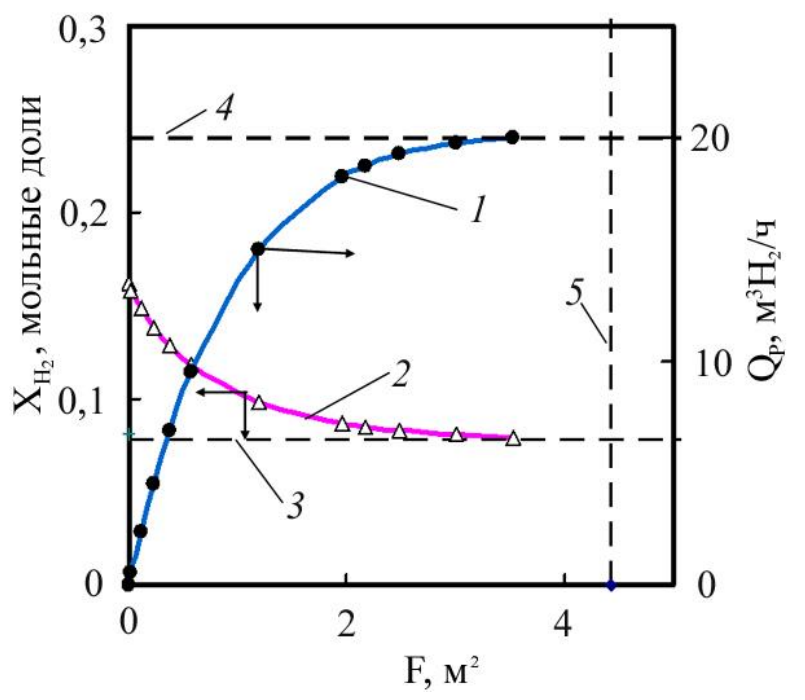

Рис. 13. Зависимости производительности $\mathrm{Q}_{\mathrm{p}}(1)$ и концентрации водорода $\mathrm{X}_{\mathrm{H}_{2}}$ (2) от площади мембраны F для мембранного конвертора производительностью 20 м $^{3} \mathrm{H}_{2} / \mathrm{q} ; 3$ - уровень концентрационного предела $\mathrm{X}_{\text {пред. }}=0,0811$ мольных долей; 4 - уровень проектной производительности $\mathrm{Q}_{\mathrm{p}}=20 \mathrm{~m}^{3} \mathrm{H}_{2} /$ ч; 5 - уровень установленной площади мембраны $\mathrm{F}_{\text {уст. }}=4,42 \mathrm{~m}^{2}$

Результаты аналогичного анализа для рабочей температуры $550{ }^{\circ} \mathrm{C}$ приведены также в табл. 6. При исходном расходе природного газа $\mathrm{Q}_{\Pi \Gamma}=6,68 \mathrm{~m}^{3} /$ и и $\mathrm{P}_{\mathrm{H}}=0,048$ МПа расчетная производительность МК-устройства несколько выше проектной и составляет $\mathrm{Q}_{\mathrm{p}}=24,36 \mathrm{~m}^{3} \mathrm{H}_{2} /$ ч, а расчетная площадь мембраны $-\mathrm{F}_{\text {расч. }}=1,425 \mathrm{~m}^{2}\left(32,2 \%\right.$ от $\left.\mathrm{F}_{\text {уст. }}=4,42 \mathrm{~m}^{2}\right)$. При увеличении $\mathrm{P}_{\mathrm{H}}$ с 0,048 МПа до 0,073 МПа без изменения потока природного газа $\mathrm{Q}_{\Pi \Gamma}=6,68 \mathrm{~m}^{3} /$ ч в исходной смеси $\mathrm{Q}_{\mathrm{p}}=22,64 \mathrm{~m}^{3} \mathrm{H}_{2} /$ ч. При этих условиях расчетная площадь мембраны $\mathrm{F}_{\text {расч. }}=1,98 \mathrm{~m}^{2}$ и составила $44,8 \%$ от $\mathrm{F}_{\text {уст. }}=4,42 \mathrm{~m}^{2}$. Однако расчетный состав 
сбросного газа при рабочей температуре $550{ }^{\circ} \mathrm{C}$ при обоих абсолютных давлениях в ПНД $\mathrm{P}_{\mathrm{H}}$ 0,048 и 0,073 МПа заметно отличался от экспериментального.

Таким образом, проведенный методом математического моделирования анализ параметров МК-конвертора с производительностью $20 \mathrm{~m}^{3} \mathrm{H}_{2} /$ ч показал, что в отличие от МК-реформера с производительностью $40 \mathrm{~m}^{3} \mathrm{H}_{2} /$ его проектная производительность подтверждается расчетами практически во всех случаях без корректировки исходных технологических параметров.

В отличие от МК-реформера с производительностью $40 \mathrm{~m}^{3} \mathrm{H}_{2} /$ ч расхождение расчетного и экспериментального химического состава сбросного газа для МК-конвертора производительностью $20 \mathrm{~m}^{3} \mathrm{H}_{2} /$ п при температуре $500{ }^{\circ} \mathrm{C}, \mathrm{Q}_{\Pi \Gamma}=7,266 \mathrm{~m}^{3} /$ ч и $\mathrm{P}_{\mathrm{H}}=0,073$ МПа существенно меньше. Можно предположить, что причиной лучшей сходимости расчетных и экспериментальных данных для МК-конвертора производительностью $20 \mathrm{~m}^{3} \mathrm{H}_{2} /$ ч является более равномерный нагрев катализатора и мембранных элементов по высоте.

\section{4. Анализ параметров единичного МК-модуля с мембранными элементами плоского типа производительностью $0,39 \mathrm{M}^{3} \mathrm{H}_{2} /$ с с учетом состава сбросного газа}

Методом математического моделирования проанализировали результаты испытаний единичного МК-модуля получения высокочистого водорода из природного газа с максимальной производительностью 0,39 м $^{3} \mathrm{H}_{2} /$ ч компании Tokyo Gas Co Ltd $[12,13]$. Упрощенная схема единичного МК-реактора представлена на рис. 14, а внешний вид - на рис. 15. Опытные эксплуатационные и расчетные параметры единичного МК-реактора производительностью $0,39 \mathrm{M}^{3} \mathrm{H}_{2} /$ ч представлены в табл. 7 .

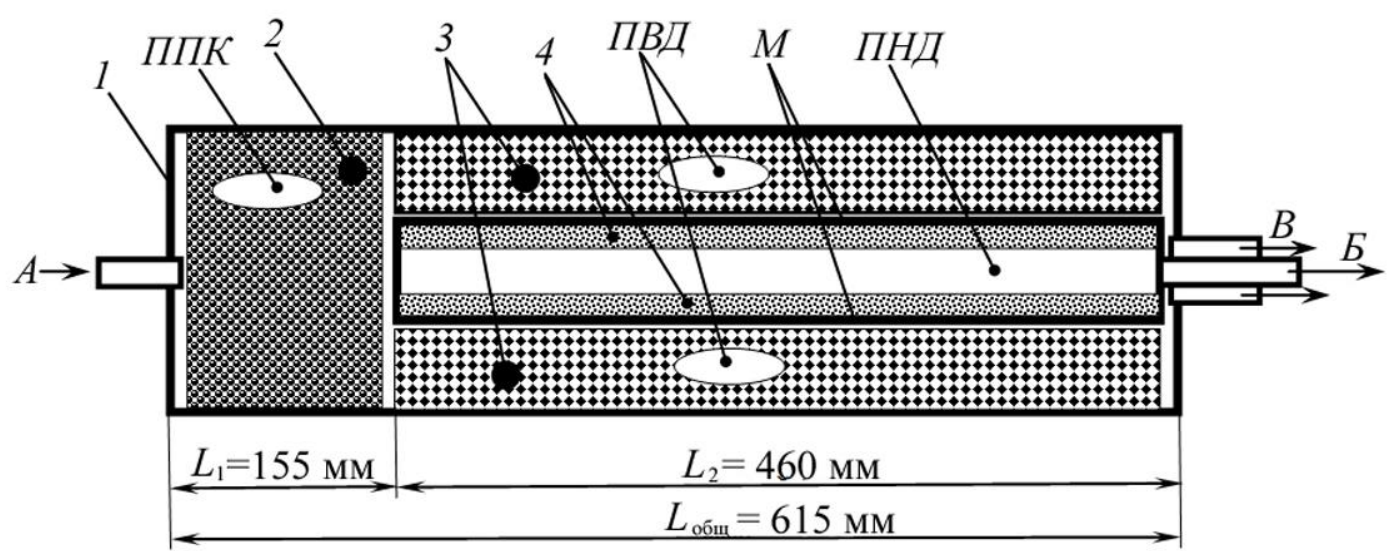

Рис.14. Схема индивидуального мембранно-каталитического модуля плоского типа:

$A$ - смесь природного газа с парами воды; $D$ - водород-продукт; $B$ - сбросной газ;

$L_{1}$ - участок предварительного конвертора; $L_{2}$ - участок конвертора, совмещенного

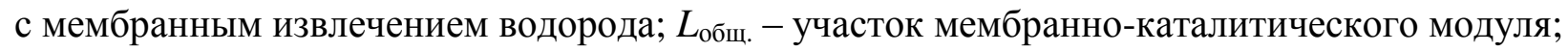

$M$ - мембрана из Pd-8Y сплава; ППК - полость предварительного конвертора;

ПВД - полость высокого давления; ПНД - полость низкого давления; 1 - корпус мембранно-каталитического модуля; 2 - традиционный катализатор; 3 - дополнительный катализатор; 4 - пористая подложка из нержавеющей стали

Поскольку состав сбросного газа в литературе для единичного МК-реактора отсутствовал, расчетные данные в этом случае сравнивали с экспериментальными данными из табл. 5 и 6. 


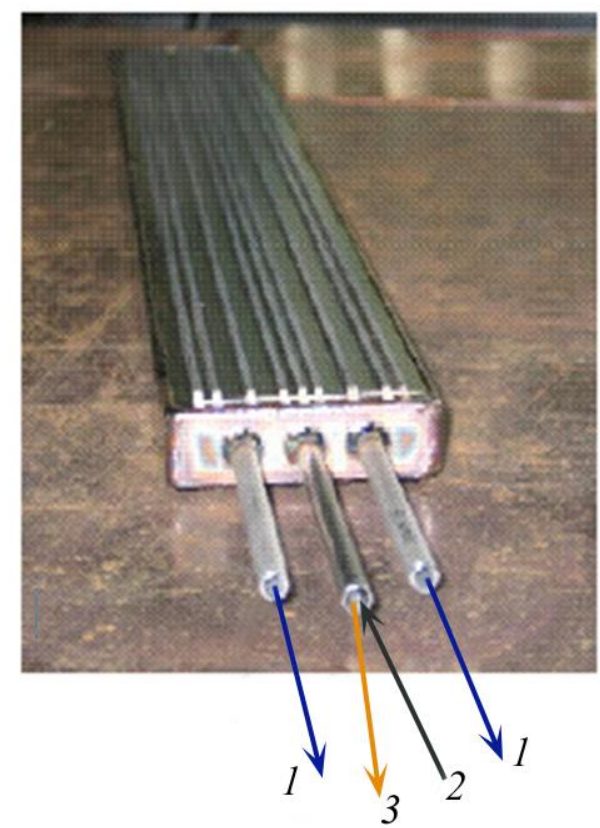

Рис.15. Внешний вид единичного мембранно-каталитического реактора [13]:

1 - выход водорода-продукта; 2 - подача смеси природного газа и водяного пара; 3 - выход сбросного газа

Величину установленной площади мембраны в единичном МК-реакторе $[12,13]$ оценили на основании размеров одного мембранного элемента и общего количества мембранных элементов, которая составила $\mathrm{F}_{\text {уст. }}=0,46 \times 0,1 \times 2=0,092 \mathrm{~m}^{2}$ (рис. 12).

Для рабочей температуры $500{ }^{\circ} \mathrm{C}$ производительность единичного МК-реактора при использовании в качестве исходных данных эксплуатационных технологических параметров (табл. 7) при абсолютном давлении водорода-продукта в подмембранном пространстве $\mathrm{P}_{\mathrm{H}}=0,048$ МПа равна $0,326 \mathrm{~m}^{3} \mathrm{H}_{2} /$ ч, что составляет $83,6 \%$ от проектной производительности $\mathrm{Q}_{\mathrm{p}}=0,39 \mathrm{M}^{3} \mathrm{H}_{2} / \mathrm{\varphi}$.

Таблица 7 - Эксплуатационные и расчетные параметры единичного МК-модуля производительностью $0,39 \mathrm{M}^{3} \mathrm{H}_{2} / \mathrm{ч}$

\begin{tabular}{|c|c|c|c|c|c|c|c|}
\hline \multicolumn{8}{|c|}{ Параметры мембранно-каталитического модуля производительностью 0,39 м ${ }^{3} \mathrm{H}_{2} /$ ч } \\
\hline \multicolumn{3}{|c|}{ Эксплуатационные } & \multicolumn{5}{|c|}{ Расчетные } \\
\hline \multicolumn{2}{|c|}{ Температура, ${ }^{\circ} \mathrm{C}$} & 550 & \multicolumn{3}{|c|}{500} & \multicolumn{2}{|c|}{550} \\
\hline \multicolumn{2}{|c|}{ Отношение пар/углерод } & 3 & \multicolumn{5}{|c|}{3} \\
\hline \multicolumn{2}{|c|}{$\mathrm{Q}_{\Pi \Gamma}, \mathrm{M}^{3} / \mathrm{u}$} & 0,0946 & 0,0946 & 0,1131 & 0,1445 & 0,0946 & 0,1158 \\
\hline \multicolumn{2}{|c|}{$\mathrm{P}_{\mathrm{B}}, \mathrm{M \Pi а}$} & 0,9 & \multicolumn{5}{|c|}{0,9} \\
\hline & & 0,04 & \multicolumn{2}{|c|}{0,048} & 0,073 & 0,048 & 0,073 \\
\hline \multicolumn{2}{|c|}{$\mathrm{F}, \mathrm{M}^{2}$} & 0,092 & 0,032 & 0,04 & 0,073 & 0,019 & 0,035 \\
\hline \multicolumn{2}{|c|}{$Q_{p}, M^{3} / 4$} & 0,39 & 0,326 & 0,39 & 0,39 & 0,344 & 0,39 \\
\hline \multicolumn{2}{|c|}{$\mathrm{J}_{\mathrm{H}_{2}}, \mathrm{M}^{3} \mathrm{H}_{2} /\left(\mathrm{M}^{2} \mathbf{\varphi}\right)$} & 4,23 & 10,2 & 9,75 & 5,34 & 18,1 & 11,1 \\
\hline \multirow{4}{*}{$\begin{array}{c}\text { Состав } \\
\text { сбросного } \\
\text { газа, об \% }\end{array}$} & $\mathrm{H}_{2}$ & - & 10,95 & 10,92 & 18,05 & 10,46 & 16,16 \\
\hline & $\mathrm{CO}$ & - & 1,72 & 1,72 & 1,82 & 2,63 & 3,48 \\
\hline & $\mathrm{CO}_{2}$ & - & 81,95 & 82,03 & 62,03 & 85,88 & 75,6 \\
\hline & $\mathrm{CH}_{4}$ & - & 5,38 & 5,33 & 18,1 & 1,03 & 4,76 \\
\hline
\end{tabular}

Vandyshev A. B. / Analyzing the parameters of membrane catalytic systems for extraction of highly pure hydrogen from hydrocarbon feedstock with the application of mathematical modeling. 
Не смотря на это обстоятельство, оценка общей производительности МК-реформера производительностью $40 \mathrm{~m}^{3} \mathrm{H}_{2} /$, состоящего, по данным работ [2, 12], из 112 единичных МК-реакторов дает величину $\mathrm{Q}_{\mathrm{p}}=0,326 \times 112=36,5 \mathrm{~m}^{3} \mathrm{H}_{2} /$, а при скорректированном числе единичных МК-реакторов, равном 128 единицам, по данным более поздней работы этих же авторов [19], составила $\mathrm{Q}_{\mathrm{p}}=0,326 \times 128=41,7 \mathrm{~m}^{3} \mathrm{H}_{2} /$ ч.

Для одновременного согласования расчетной производительности с проектной и состава сбросного газа с экспериментальными данными (табл. 5 и 6) изменили исходные величины $\mathrm{Q}_{П Г}$ с 0,1131 до $0,1445 \mathrm{~m}^{3} /$ ч и $\mathrm{P}_{\mathrm{H}}$ с 0,048 до 0,073 МПа. Расчетная площадь мембраны при этих условиях увеличилась с 0,04 до $0,073 \mathrm{~m}^{2}$, но не превысила $\mathrm{F}_{\text {уст. }}=0,092 \mathrm{~m}^{2}$. В графическом виде результаты расчетов при температуре $500{ }^{\circ} \mathrm{C} \mathrm{Q}_{\Pi \Gamma}=0,1445 \mathrm{~m}^{3} /$ и и $\mathrm{P}_{\mathrm{H}}=0,073 \mathrm{MПа}$ в виде расчетных зависимостей $\mathrm{Q}_{\mathrm{p}}-\mathrm{F}$ (кривая 1) и $\mathrm{X}_{\mathrm{H}_{2}}-\mathrm{F}$ (кривая 2) представлены на рис. 16. Отметим, что при температуре $500{ }^{\circ} \mathrm{C} \mathrm{Q}_{\Pi \Gamma}=0,1445 \mathrm{~m}^{3} /$ и и $\mathrm{P}_{\mathrm{H}}=0,073$ МПа расчетные (табл. 7) и экспериментальные составы сбросного газа (табл. 6) хорошо коррелируют между собой.

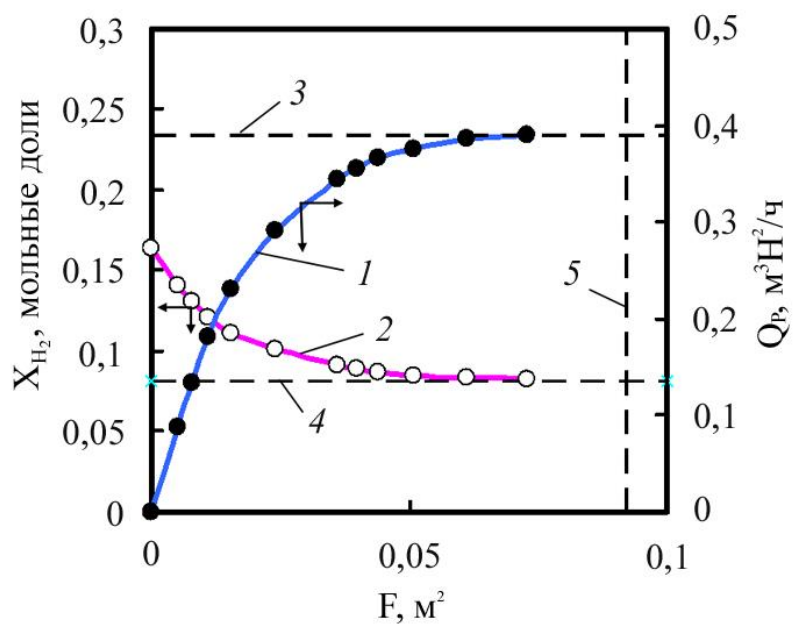

Рис.16. Зависимости производительности $\mathrm{Q}_{\mathrm{p}}(1)$ и концентрации водорода $\mathrm{X}_{\mathrm{H}_{2}}$ (2) от площади мембраны F для единичного МК-модуля производительностью $0,39 \mathrm{~m}^{3} \mathrm{H}_{2} /$ ч; 3 - уровень проектной производительности $\mathrm{Q}_{\mathrm{p}}=0,39 \mathrm{~m}^{3} \mathrm{H}_{2} / \mathrm{ч} ; 4$ - уровень концентрационного предела $\mathrm{X}_{\text {пред. }}=0,0811$ мольных долей; 5 - уровень установленной площади мембраны $\mathrm{F}_{\text {уст. }}=0,092 \mathrm{~m}^{2}$

Результаты аналогичного анализа для рабочей температуры $550{ }^{\circ} \mathrm{C}$ также приведены в табл. 7. При $\mathrm{Q}_{П Г}=0,0946 \mathrm{~m}^{3} /$ и и $\mathrm{P}_{\mathrm{H}}=0,048$ МПа производительность единичного МК-модуля составила $\mathrm{Q}_{\mathrm{p}}=0,344 \mathrm{~m}^{3} \mathrm{H}_{2} /$ ч $\left(88 \%\right.$ от проектной). При увеличении $\mathrm{Q}_{\Pi \Gamma} \mathrm{c} 0,0946$ до $0,1158 \mathrm{~m}^{3} /$ и и $\mathrm{P}_{\mathrm{H}}$ c 0,048 до 0,073 МПа удается поднять производительность единичного МК-реактора до проектного значения $\mathrm{P}_{\mathrm{H}}=0,39 \mathrm{~m}^{3} \mathrm{H}_{2} /$, однако при этих условиях состав сбросного газа, как и в предыдущих примерах, заметно расходится с экспериментальными данными (табл. 5 и 6).

Проведенный анализ единичного МК-модуля (рис. 16) с производительностью 0,39 м $^{3} \mathrm{H}_{2} /$ ч, как и в предыдущих примерах, показал, что при задании определенных технологических условий (температура $500{ }^{\circ} \mathrm{C}, \mathrm{Q}_{\Pi \Gamma}=0,1445 \mathrm{~m}^{3} /$ ч и $\mathrm{P}_{\mathrm{H}}=0,073 \mathrm{MПа)} \mathrm{можно} \mathrm{одновре-}$ менно максимально приблизить расчетную производительность единичного МК-модуля к проектной, а расчетный состав сбросного газа - к экспериментальным данным.

Таким образом, на примере трех различных по конструкции МК-устройств с плоскими мембранными элементами производительностью 40, 20 и 0,39 м ${ }^{3} \mathrm{H}_{2} /$ ч подтверждена адекватность используемой математической модели [9]. 
Установлена хорошая сходимость расчетных и экспериментальных данных не только с точки зрения производительности МК-устройств по водороду-продукту, но и с учетом состава сбросного газа, предназначенного для обогрева мембранного реформера в целях повышения общей энергетической эффективности МК-установки получения высокочистого водорода из природного газа.

\section{4. Анализ параметров получения высокочистого водорода из метана в лабораторном мембранном конверторе трубчатого типа с палладиевой мембраной толщиной 4 мкм}

В данном разделе с помощью той же математической модели [9] на ряде примеров проанализированы экспериментальные данные, полученные на лабораторном мембранном конверторе трубчатого типа $[20,21]$ с мембраной из чистого палладия толщиной порядка 4 мкм.

Подробная схема лабораторной установки с МК-конвертором приведена в работе [21]. Упрощенная схема собственно самого лабораторного МК-конветора с общей рабочей длиной 60 мм изображена на рис. 17. Лабораторный мембранный конвертор $[20,21]$ представлял собой две коаксиально расположенные трубы, в кольцевой зазор между которыми помещен катализатор конверсии метана К (рис. 17). Снаружи лабораторный МК-конветор обогревался электронагревателем.

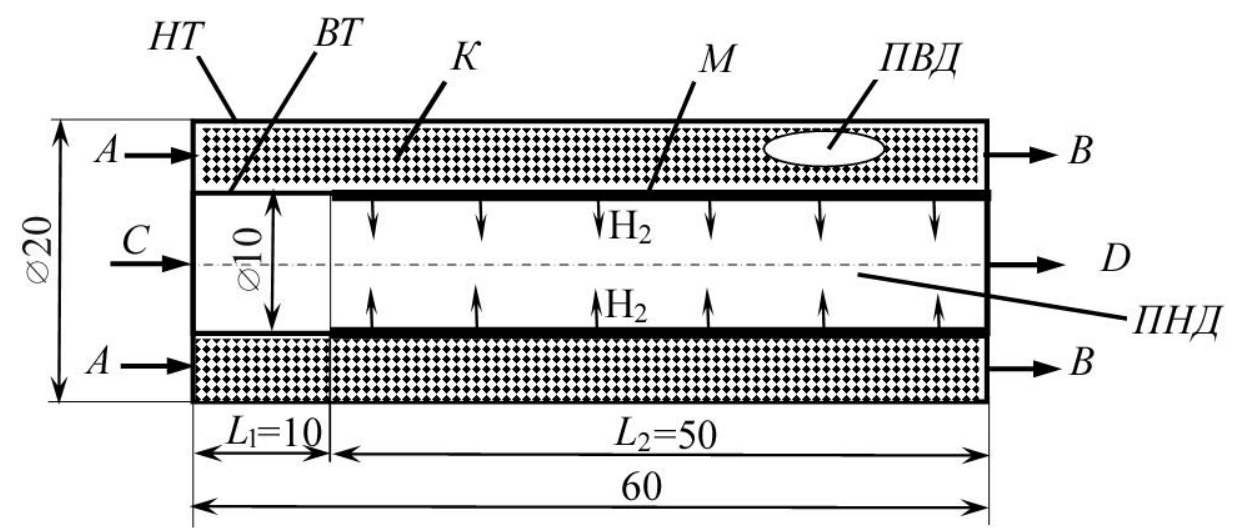

Рис.17. Схема лабораторного мембранного конвертора [20]:

$A$ - вход исходной смеси $\mathrm{CH}_{4}-3 \mathrm{H}_{2} \mathrm{O} ; B$ - выход сбросного газа; $C$ - вход продувочного газа (Ar); $D$ - выход смеси водорода и продувочного газа; $K$ - катализатор конверсии метана; $M$ - Pd-мембрана; $L_{1}$ - зона традиционной конверсии метана; $L_{2}-$ зона мембранного извлечения водорода, совмещенного с конверсией метана; ПВД - полость высокого давления; ПНД полость низкого давления; $H T$ - наружная труба; $B T$ - внутренняя труба

Наружная труба лабораторного МК-конвертора $(H T)$ с внутренним диаметром 20 мм изготовлена из нержавеющей стали. Внутренняя труба (BT) лабораторного МК-конвертора с наружным диаметром 10 мм изготовлена из керамики $\left(\mathrm{Al}_{2} \mathrm{O}_{3}\right)$, на пористом участке которой $L_{2}=50$ мм нанесена тонкопленочная мембрана из чистого палладия толщиной порядка 4 мкм. Средний размер пор керамической подложки составлял 500 нм. В качестве исходного сырья для получения ОЧВ использована смесь $\mathrm{CH}_{4}-3 \mathrm{H}_{2} \mathrm{O}$, которую подавали на вход $A$ лабораторного МК-конвертора. В кольцевом зазоре МК-конвертора или в полости высокого давления (ПВД) на начальном участке $L_{1}=10$ мм осуществлялась традиционная паровая конверсия метана с образованием пятикомпонентной газовой смеси $\left(\mathrm{H}_{2}, \mathrm{H}_{2} \mathrm{O}, \mathrm{CO}_{2}, \mathrm{CO}\right.$ и $\left.\mathrm{CH}_{4}\right)$, согласно обратимым химическим реакциям и $\mathrm{CH}_{4}+2 \mathrm{H}_{2} \mathrm{O}=4 \mathrm{H}_{2}+\mathrm{CO}_{2}, \mathrm{CO}+\mathrm{H}_{2} \mathrm{O}=\mathrm{H}_{2}+\mathrm{CO}_{2}$. Далее продукты паровой конверсии метана по кольцевому зазору поступали в зону $L_{2}$, в которой под действием перепада давлений на мембране происходило извлечение водорода, совмещенное с каталитической конверсией метана. Обедненная по водороду многокомпонентная газовая

Vandyshev A. B. / Analyzing the parameters of membrane catalytic systems for extraction of highly pure 
смесь удалялась из кольцевого зазора лабораторного МК в виде сбросного газа через выход $B$. Водород диффундировал через палладиевую мембрану во внутреннюю полость керамической трубы или в полость низкого давления (ПНД) и вместе с продувочным газом (Ar) удалялся из МК через выход $D$. Подача продувочного газа (Ar) в MК осуществлялась через вход $C$. Продувочный газ использовался в лабораторном мембранном конверторе [20] для снижения парциального давления водорода в ПНД с целью интенсификации процесса его мембранного извлечения (рис. 17).

Первоначально методом математического моделирования проанализировали представленные в графическом виде экспериментальные температурные зависимости плотности диффузионного потока водорода через мембрану $\mathrm{J}_{\mathrm{H}_{2}}$ в диапазоне температур $450-550{ }^{\circ} \mathrm{C}$ [20]. Опыты проводили при фиксированном абсолютном давлении в ПВД лабораторного мембранного конвертора $\mathrm{P}_{\mathrm{B}}=0,9$ МПа и постоянном отношении потока продувочного газа к потоку метана I $=\mathrm{Q}_{\mathrm{Ar}} / \mathrm{Q}_{\mathrm{CH}_{4}}=2,6[20]$.

При отсутствии полного набора исходных данных [20], необходимых для проведения расчетов, объемный расход исходной смеси $\mathrm{CH}_{4}-3 \mathrm{H}_{2} \mathrm{O}$ задали постоянным и равным $\mathrm{Q}_{0}=0,019 \mathrm{~m}^{3} /$, а парциальное давление водорода в ПНД лабораторного МК-конвертора приближенно приняли также фиксированным и равным $\mathrm{p}_{\mathrm{B}}=0,055$ МПа. Отметим, что в данном разделе все объемные расходы приведены к нормальным условиям. Необходимый для проведения вычислений коэффициент удельной водородопроницаемости $\gamma\left(\mathrm{cm}^{3} \mathrm{H}_{2} \mathrm{Mm} \mathrm{cm}^{-2} \mathrm{aTM}^{-0.5}\right)$ для чистого палладия оценивали по уравнению

$$
\gamma=0,20711 \cdot \exp (-17372,9 / 8,314 \cdot \mathrm{T})
$$

полученному на основании регрессионного анализа экспериментальных данных [17, 22] по изучению водородопроницаемости чистого палладия.

В качестве иллюстраций результаты расчетов с использованием математической модели [9] для трех температур 450, 500 и $550{ }^{\circ} \mathrm{C}$ представлены на рис. 18. При фиксированном потоке исходной газовой смеси $\mathrm{CH}_{4}-3 \mathrm{H}_{2} \mathrm{O} \mathrm{Q}_{0}=0,019 \mathrm{~m}^{3} / 4$ производительность исследуемого лабораторного МК-конвертора по водороду $\mathrm{Q}_{\mathrm{p}}(1-3)$ с увеличением температуры растет. Однако выход кривых $\mathrm{Q}_{\mathrm{p}}-\mathrm{F}$ на насыщение происходит при разных величинах площади мембраны, причем, чем выше температура, тем меньшая площадь мембраны требуется для выхода на насыщение.

Результаты расчетов, представленные кривыми l'-3' на рис. 18 показывают, что при увеличении температуры, с одной стороны, возрастает концентрация водорода на входе в зону $L_{2}$ лабораторного МК-конвертора (рис. 17), а с другой стороны, с ростом температуры согласно уравнению (34) увеличивается коэффициент удельной водородопроницаемости палладиевой мембраны. Оба эти фактора влияют на скорость оттока водорода через мембрану, что отражается на ходе кривых 1'-3' при их выходе на концентрационный предел $\mathrm{X}_{\text {пред. }}=\mathrm{p}_{\mathrm{H}} / \mathrm{P}_{\mathrm{B}}=0,055 / 0,9=0,061$ моль. доли при расчетных площадях $\mathrm{F}$, меньших установленной площади мембраны $\mathrm{F}_{\text {уст. }}=15,7 \mathrm{~cm}^{2}$.

При достижении концентрации водорода $\mathrm{X}_{\mathrm{H}_{2}}$ в разделяемой газовой смеси в объеме ПВД над участком поверхности мембраны $\Delta \mathrm{F}$ концентрационного предела 3 движущая сила процесса диффузии водорода через мембрану становится близкой к нулю и дальнейшее увеличение производительности лабораторного мембранного конвертора по ОЧВ не происходит (1-3, рис. 18). 


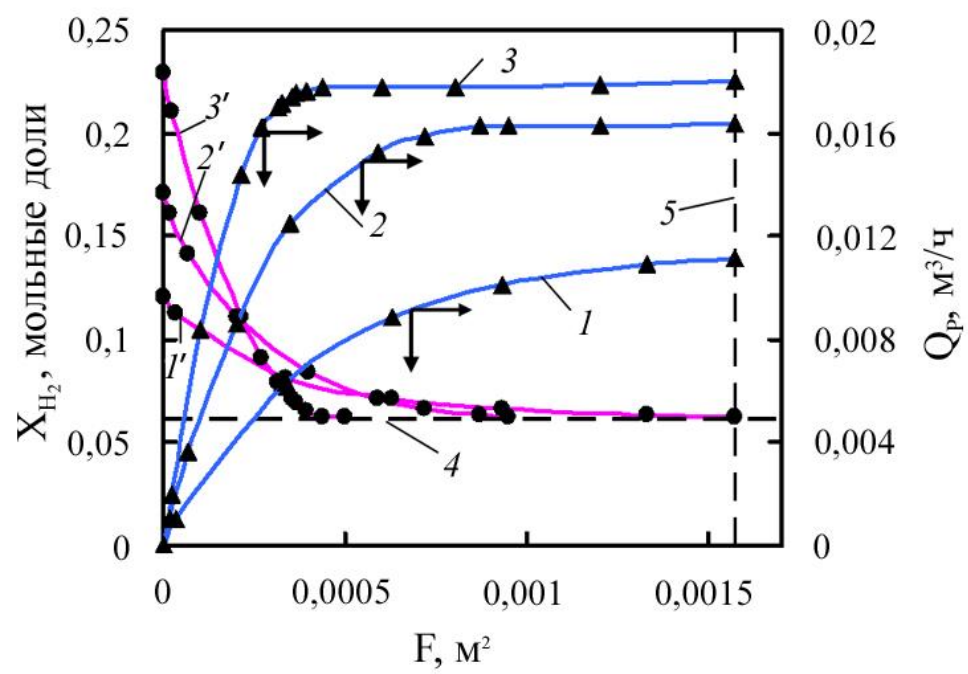

Рис. 18. Зависимости производительности лабораторного $\mathrm{MK}_{\mathrm{P}}(1-3)$ и концентрации водорода $\mathrm{X}_{\mathrm{H}_{2}}\left(1^{\prime}-3^{\prime}\right)$ от площади мембраны $\mathrm{F}$ при $\mathrm{P}_{\mathrm{B}}=0,9 \mathrm{MПа}, \mathrm{P}_{\mathrm{H}}=0,055 \mathrm{MПа}$, $\mathrm{Q}_{0}=0,019 \mathrm{м}^{3} /$ ч и $\mathrm{I}=\mathrm{Q}_{\mathrm{Ar}} / \mathrm{Q}_{\mathrm{CH}_{4}}=2,6 ; 1$ и $1^{\prime}-450 ; 2$ и $2^{\prime}-500 ; 3$ и $3{ }^{\prime}-550{ }^{\circ} \mathrm{C}$;

4 - уровень концентрационного предела $\mathrm{X}_{\text {пред. }}=0,061$ мольной доли; 5 - уровень установленной площади мембраны $\mathrm{F}_{\text {уст. }}=0,00157 \mathrm{~m}^{2}$

Вертикальной пунктирной линией 5 на рис. 18 отмечен уровень установленной площади мембраны $F_{\text {уст. }}=15,7 \mathrm{~cm}^{2}$. Аналогичные расчеты были проведены и при других температурах в исследуемом температурном интервале $450-550{ }^{\circ} \mathrm{C}$, результаты которых представлены в табл. 8.

Таблица 8 - Влияние температуры на параметры лабораторного мембранного конвертора [20]

\begin{tabular}{|c|c|c|c|c|c|c|c|c|}
\hline$t,{ }^{\circ} \mathrm{C}$ & $\begin{array}{c}p_{\mathrm{H}}, \\
\mathrm{M \Pi а}\end{array}$ & $Q_{p}, M^{3 / u}$ & $\mathrm{~F}, \mathrm{M}^{2}$ & $\begin{array}{c}J_{\mathrm{H}_{2}}, \\
\mathrm{M}^{3} /\left(\mathrm{\Psi} \cdot \mathrm{M}^{2}\right)\end{array}$ & $\begin{array}{c}\mathrm{J}_{\mathrm{H}_{2}}^{1} \\
\mathrm{M}^{3} /(\mathrm{Y} \\
\left.\mathrm{M}^{2}\right)\end{array}$ & $\begin{array}{c}\mathrm{q}_{\mathrm{v}}, \\
\mathrm{M}^{3} \mathrm{H}_{2} / \\
\mathrm{m}^{3} \\
\text { сырья }\end{array}$ & $\begin{array}{c}\mathrm{q}_{\mathrm{M}}, \\
\text { моль.Н } \mathrm{H}_{2} / \text { моль.С } \\
\mathrm{H}_{4}\end{array}$ & $\mathrm{CK}, \%$ \\
\hline 450 & 0,047 & 0,01094 & 0,001333 & $6,94 / 7,32 *$ & 8,2 & 0,576 & 2,3 & 68,5 \\
\hline 475 & 0,054 & 0,0143 & 0,001123 & $9,1 / 8,8^{*}$ & 12,7 & 0,752 & 3,01 & 79,6 \\
\hline 500 & 0,057 & 0,0163 & 0,000872 & $10,4 / 10,2^{*}$ & 18,7 & 0,858 & 3,43 & 89,98 \\
\hline 525 & 0,058 & 0,0173 & 0,000598 & $11,1 / 11,0^{*}$ & 28,9 & 0,91 & 3,64 & 95,4 \\
\hline 560 & 0,06 & 0,0187 & 0,000453 & $11,91 / 11,9 *$ & 41,3 & 0,98 & 3,82 & 97,8 \\
\hline
\end{tabular}

Используя рассчитанные величины $\mathrm{Q}_{\mathrm{p}}$ (табл. 8) для каждой из исследованных температур, вычислили средние плотности диффузионного потока водорода через мембрану $\mathrm{J}_{\mathrm{H}_{2}}$ по формуле $\mathrm{J}_{\mathrm{H}_{2}}=\mathrm{Q}_{\mathrm{p}} / \mathrm{F}_{\text {уст. }}\left(\right.$ где $\left.\mathrm{F}_{\text {уст. }}=15,7 \mathrm{~cm}^{2}[20]\right)$ и $\mathrm{J}_{\mathrm{H}_{2}}^{1}$ по формуле $\mathrm{J}_{\mathrm{H}_{2}}^{1}=\mathrm{Q}_{\mathrm{p}} / \mathrm{F}_{\text {расч., }}$ где $\mathrm{F}_{\text {расч. }}-$ расчетная площадь мембраны, необходимая для достижения максимальной производительности лабораторного МК.

На основании расчетных данных в координатах $\mathrm{J}_{\mathrm{H}_{2}}-\mathrm{t}$ построили температурные зависимости средней плотности потока диффузии водорода через мембрану $\mathrm{J}_{\mathrm{H}_{2}}$ и $\mathrm{J}_{\mathrm{H}_{2}}^{1}$, представленные на рис. 19, соответственно, кривыми 1 и 2.

Треугольными точками на рис. 19 нанесены экспериментальные величины $\mathrm{J}_{\mathrm{H}_{2}}$ из работы [20], отмеченные звездочкой в табл. 8, которые хорошо укладываются на расчетную кривую 1, что свидетельствует об адекватности применяемой математической модели [9] 
в том случае, когда расчет $\mathrm{J}_{\mathrm{H}_{2}}$ осуществляется на всю установленную площадь мембраны $0,00157 \mathrm{~m}^{2}$.

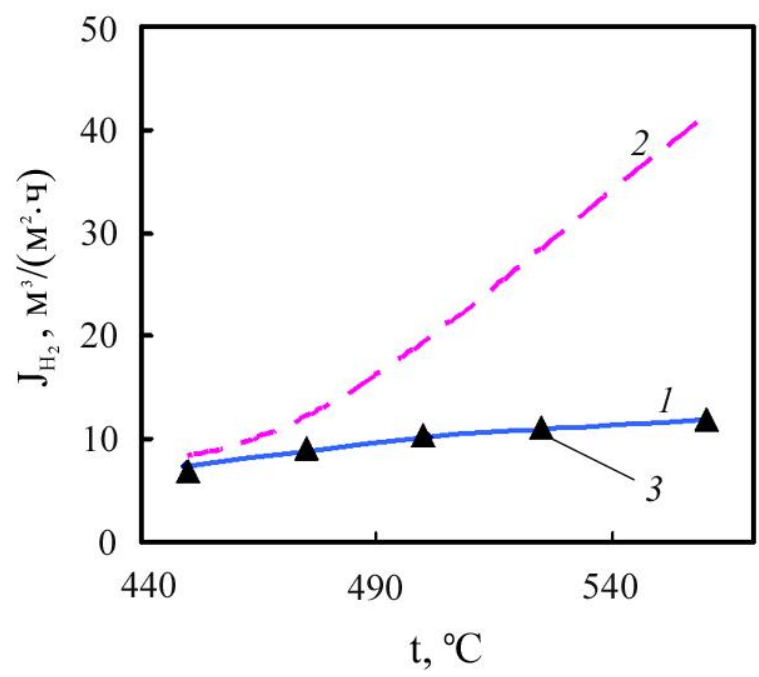

Рис. 19. Температурные зависимости плотности диффузионного потока водорода через мембрану при $\mathrm{P}_{\mathrm{B}}=0,9 \mathrm{MПа,} \mathrm{P}_{\mathrm{H}}=0,055 \mathrm{MПа}, \mathrm{Q}_{0}=0,019 \mathrm{~m}^{3} /$ ч и $\mathrm{I}=\mathrm{Q}_{\mathrm{Ar}} / \mathrm{Q}_{\mathrm{CH}_{4}}=2,6$ : 1 - расчет на установленную площадь мембраны $\left(\mathrm{F}=0,00157 \mathrm{~m}^{2}\right) ; 2$ - расчет на рабочую площадь мембраны (табл. 8); 3 - экспериментальные данные для лабораторного мембранного конвертора [20]

Расчетная кривая 2 на рис. 19 располагается выше кривой 1 поскольку в этом случае учитывалось изменение расчетной рабочей площади мембраны, необходимой для достижения максимальной производительности по ОЧВ $\mathrm{Q}_{\mathrm{p}}$, которая при увеличении рабочей температуры уменьшается и в соответствии с рис. 18 и табл. 8 принимает значения, меньше установленной площади мембраны $\mathrm{F}_{\text {уст. }}=15,7 \mathrm{~cm}^{2}[20]$. В этом случае величины средних плотностей диффузионных потоков водорода через мембрану $\mathrm{J}_{\mathrm{H}_{2}}^{1}$ существенно выше величин $\mathrm{J}_{\mathrm{H}_{2}}$ (табл. 8). Кроме того, форма кривой 2 на рис. 19 более адекватно отражает физический смысл экспоненциальной температурной зависимости средней плотности диффузионного потока водорода через палладиевую мембрану.

Из проведенного анализа следует, что для экспериментального достижения высоких средних плотностей диффузии водорода через мембрану $\mathrm{J}_{\mathrm{H}_{2}}$ необходимо с увеличением температуры повышать поток исходной газовой смеси $\mathrm{CH}_{4}-3 \mathrm{H}_{2} \mathrm{O} \mathrm{Q}_{0}$ таким образом, чтобы в процессе извлечения водорода в лабораторном мембранном конверторе была задействована вся установленная площадь мембраны. Далее по формуле

$$
\mathrm{p}_{\mathrm{H}}=\mathrm{P}_{\mathrm{H}} /\left(1+\mathrm{I} \cdot \frac{\mathrm{Q}_{0} \cdot 0,25}{\mathrm{Q}_{\mathrm{P}}}\right)
$$

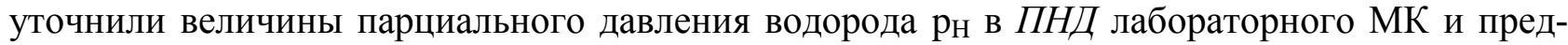
ставили в табл. 8. При вычислениях абсолютное давление в ПНД лабораторного мембранного конвертора принято равным атмосферному $\left(\mathrm{P}_{\mathrm{H}}=0,1 \mathrm{MПа}\right)$, поскольку согласно схеме лабораторной установки [21] полость низкого давления мембранного конвертора сообщена с атмосферой через измеритель расхода газа. Для проведения вычислений по приведенной выше формуле (4) величина отношения потоков продувочного газа и метана $\mathrm{I}=\mathrm{Q}_{\mathrm{Ar}} / \mathrm{Q}_{\mathrm{CH}_{4}}=2,6$ известна по условиям проведения эксперимента [20]. Величина потока 
исходного сырья, принятая нами $\mathrm{Q}_{0}=0,019 \mathrm{~m}^{3} /$ ч, также известна, а значения $\mathrm{Q}_{\mathrm{p}}$ для каждой исследуемой температуры для проведения расчетов брали из табл. 8.

Результаты вычислений парциального давления водорода $\mathrm{p}_{\mathrm{H}}$ в ПВД лабораторного мембранного конвертора по формуле (4) представлены в табл. 8. Средняя величина рн при температурах $450,475,550,525$ и $550{ }^{\circ} \mathrm{C}$ составила 0,0552 МПа и практически не отличалась от заданной нами величины $\mathrm{p}_{\mathrm{H}}=0,055 \mathrm{MПа.} \mathrm{Отметим,} \mathrm{что} \mathrm{несмотря} \mathrm{на} \mathrm{принятые} \mathrm{допущения}$ сходимость расчетных и экспериментальных данных [20] в координатах $\mathrm{J}_{\mathrm{H}_{2}}-\mathrm{t}$ (1, рис. 19) вполне удовлетворительная. Дополнительно был рассчитан ряд техноэкономических показателей: удельные объемный $\mathrm{q}_{\mathrm{v}}$ и мольный qм выходы водорода, а также степень конверсии метана $(C K)$ табл. 8. Эти показатели дают наглядное представление об эффективности получения водорода в лабораторном мембранном конверторе.

В качестве 2-го примера с помощью математического моделирования проанализировали экспериментальные графические зависимости [20] плотности диффузионного потока водорода через мембрану $\mathrm{J}_{\mathrm{H}_{2}}$ от отношения потока продувочного газа к потоку метана $\mathrm{I}=\mathrm{Q}_{\mathrm{Ar}} / \mathrm{Q}_{\mathrm{CH}_{4}}$.

Таблица 9 - Влияние отношения продувки I $=\mathrm{Q}_{\mathrm{Ar}} / \mathrm{Q}_{\mathrm{CH}_{4}}$ на параметры лабораторного мембранного конвертора [20]

\begin{tabular}{|c|c|c|c|c|c|c|c|}
\hline $\begin{array}{l}\mathrm{p}_{\mathrm{H}} \\
\mathrm{M \Pi а}\end{array}$ & $\mathrm{I}=\mathrm{Q}_{\mathrm{Ar}} / \mathrm{Q}_{\mathrm{CH}_{4}}$ & $\mathrm{Q}_{0}, \mathrm{M}^{3} / \mathrm{u}$ & $Q_{p} M^{3} / \mathrm{u}$ & $\mathrm{F} \mathrm{M}^{2}$ & $\mathrm{~J}_{\mathrm{H}_{2}} \mathrm{M}^{3} /\left(\mathrm{\Psi} \cdot \mathrm{M}^{2}\right)$ & $\mathrm{J}_{\mathrm{H}_{2}}^{\prime} \quad \mathrm{M}^{3} /\left(\mathrm{u} \cdot \mathrm{M}^{2}\right)$ & $\mathrm{CK}, \%$ \\
\hline 0,1 & 0 & \multirow{6}{*}{0,0257} & 0,0112 & 0,00157 & 7,1 & 7,12 & 62,9 \\
\hline 0,09 & 0,252 & & 0,0142 & 0,00155 & 9,02 & 9,09 & 71,42 \\
\hline 0,08 & 0,656 & & 0,0169 & 0,00145 & 10,74 & 11,61 & 79,26 \\
\hline 0,06 & 2,196 & & 0,0212 & 0,00112 & 13,48 & 18,98 & 91,6 \\
\hline 0,05 & 3,517 & & 0,0227 & 0,00093 & 14,43 & 24,5 & 95,6 \\
\hline 0,04 & 5,537 & & 0,0237 & 0,00073 & 15,1 & 32,4 & 98,08 \\
\hline
\end{tabular}

В этом случае фиксированными технологическими параметрами являлись рабочая температура $\mathrm{t}=550{ }^{\circ} \mathrm{C}$ и абсолютное давление в ПВД лабораторного мембранного конвертоpa (рис. 17) $\mathrm{P}_{\mathrm{B}}=0,5 \mathrm{MПа} \mathrm{[20].} \mathrm{При} \mathrm{недостатке} \mathrm{исходных} \mathrm{данных,} \mathrm{необходимых} \mathrm{для} \mathrm{проведе-}$ ния расчетов, расход исходной смеси $\mathrm{CH}_{4}-3 \mathrm{H}_{2} \mathrm{O}$ был принят нами равным $\mathrm{Q}_{0}=0,0257 \mathrm{~m}^{3} /$ ч. Для проведения дальнейших расчетов задали ряд фиксированных значений парциального давления водорода $\mathrm{p}_{\mathrm{H}}$ в ПВД лабораторного мембранного конвертора, равных соответственно: 0,$1 ; 0,09 ; 0,08 ; 0,06$ и 0,04 МПа (табл. 9).

Для каждой величины парциального давления водорода $\mathrm{p}_{\mathrm{H}}$ в ПВД лабораторного мембранного конвертора в диапазоне от 0,1 до 0,04 МПа (табл. 9) с помощью математической модели [9] рассчитали зависимости $\mathrm{Q}_{\mathrm{p}}-\mathrm{F}$ и $\mathrm{X}_{\mathrm{H}_{2}}-\mathrm{F}$. В качестве иллюстраций результаты расчетов для трех фиксированных величин парциального давления водорода $\mathrm{p}_{\mathrm{H}}$ в подмембранном пространстве лабораторного мембранного конвертора, равных 0,09; 0,06 и 0,04 МПа, в виде графиков приведены на рис. 20. 


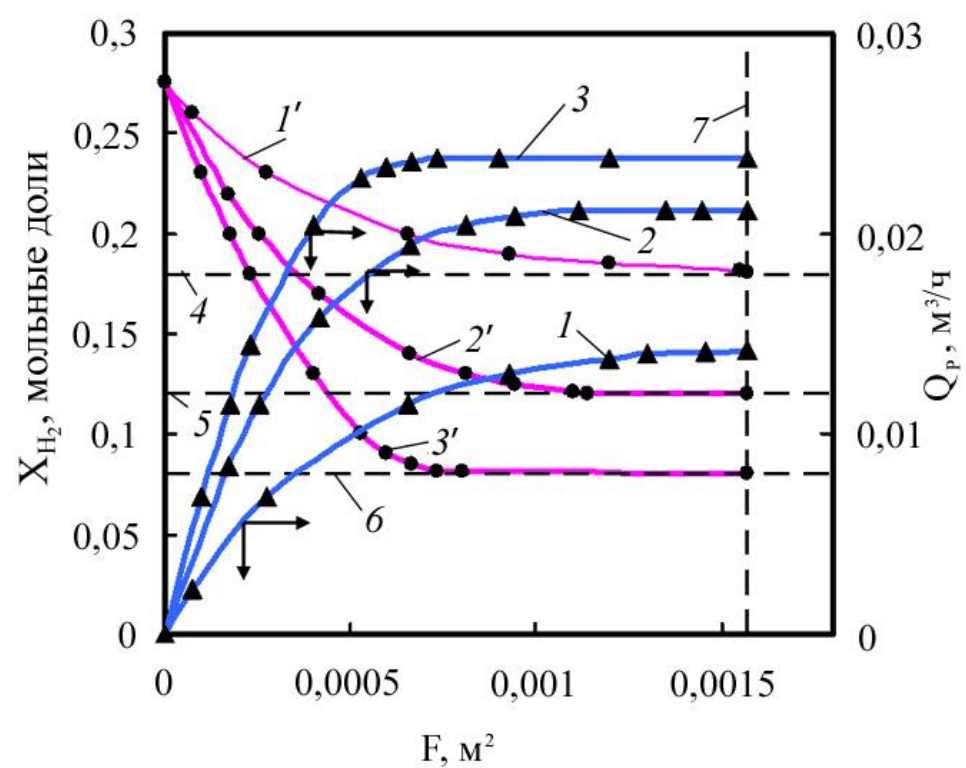

Рис. 20. Зависимости производительности лабораторного мембранного конвертора $\mathrm{Q}_{\mathrm{p}}(1-3)$

и концентрации водорода $\mathrm{X}_{\mathrm{H}_{2}}\left(1^{\prime}-3^{\prime}\right)$ от площади мембраны $\mathrm{F}$ при $\mathrm{P}_{\mathrm{B}}=0,5 \mathrm{MПа}$,

$\mathrm{Q}_{0}=0,0257 \mathrm{~m}^{3} /$ и и температуре $550{ }^{\circ} \mathrm{C}: 1$ и $1^{\prime}-\mathrm{p}_{\mathrm{H}}=0,09 ; 2$ и $2^{\prime}-\mathrm{p}_{\mathrm{H}}=0,06$;

3 и $3^{\prime}-\mathrm{p}_{\mathrm{H}}=0,04 \mathrm{MПа;} 4,5$ и $6-$ уровни концентрационного предела $\mathrm{X}_{\text {пред. }}$ соответственно равные 0,$18 ; 0,12$ и 0,08 моль. долей; 7 - уровень установленной площади мембраны

$$
\mathrm{F}=0,00157 \mathrm{~m}^{2}
$$

С уменьшением парциального давления водорода $\mathrm{p}_{\mathrm{H}}$ от 0,1 до 0,04 МПа производительность лабораторного мембранного конвертора $Q_{p}(1-3)$ увеличивается с 0,0112 до 0,0237 $\mathrm{m}^{3} /$ ч. При этом площадь мембраны, необходимая для достижения максимальной производительности по водороду, сокращается с 0,00157 до 0,00073 м² (табл. 9). Из $\mathrm{Q}_{\mathrm{p}}-\mathrm{F}$ зависимости величина расчетной площади мембраны $\mathrm{F}_{\text {расч. }}=0,00073 \mathrm{~m}^{2}$ при $\mathrm{p}_{\mathrm{H}}=0,04$ МПа составляет $47 \%$ от общей установленной площади мембраны $\mathrm{F}_{\text {уст. }}=15,7 \mathrm{~cm}^{2}$ в лабораторном мембранном конверторе.

Результаты расчетов, представленные кривыми 1'-3' на рис. 20, поясняют влияние парциального давления водорода $\mathrm{p}_{\mathrm{H}}$ в ПНД лабораторного мембранного конвертора, связанного с отношением продувки $\mathrm{I}=\mathrm{Q}_{\mathrm{Ar}} / \mathrm{Q}_{\mathrm{CH}_{4}}[20]$, на производительность по ОЧВ $\mathrm{Q}_{\mathrm{p}}$.

Уменьшение парциального давления водорода $\mathrm{p}_{\mathrm{H}}$ с 0,09 до 0,04 МПа приводит к снижению концентрационного предела $\mathrm{X}_{\text {пред. }}$ от 0,18 до 0,08 мольных долей $(4,5,6$ рис. 20) и как следствие к увеличению движущей силы процесса диффузии водорода через мембрану, что отражается на увеличении производительности МК по водороду (1-3 рис. 20).

Повышение интенсивности оттока водорода через мембрану при фиксированном потоке исходной газовой смеси $\mathrm{CH}_{4}-3 \mathrm{H}_{2} \mathrm{O} \mathrm{Q}_{0}=0,0257 \mathrm{~m}^{3} /$ ч сокращает площадь мембраны с 0,00155 до $0,00073 \mathrm{~m}^{2}$, необходимую для максимально полного извлечения водорода при данных условиях эксплуатации. Из $\mathrm{X}_{\mathrm{H}_{2}}-\mathrm{F}$ зависимости при $\mathrm{p}_{\mathrm{H}}=0,04$ МПа величина площади мембраны, необходимой для полного извлечения водорода $\left(\mathrm{F}_{\text {расч. }}=0,00073 \mathrm{~m}^{2}\right)$, составляет $46,5 \%$ от установленной площади мембраны $\mathrm{F}_{\text {уст. }}=15,7 \mathrm{~cm}^{2}[20]$.

По формуле

$$
\left.\mathrm{I}=\left[\left(\mathrm{P}_{\mathrm{H}} / \mathrm{p}_{\mathrm{H}}\right)-1\right)\right] / 0,25 \cdot \mathrm{Q}_{0},
$$


зная величину абсолютного давления в ПНД лабораторного МК-конвертора $\mathrm{P}_{\mathrm{H}}=0,1 \mathrm{MПа}$, расход исходной газовой смеси $\mathrm{Q}_{0}=0,0257 \mathrm{~m}^{3} /$ ч для каждого принятого значения $\mathrm{p}_{\mathrm{H}}$ (табл. 9) рассчитали отношения продувки I, которые также поместили в табл. 9 (колонка 2). Далее, используя величины $\mathrm{Q}_{\mathrm{P}}$ и $\mathrm{F}$, приведенные соответственно в колонках 4 и 5 табл. 9, по формулам $\mathrm{J}_{\mathrm{H}_{2}}=\mathrm{Q}_{\mathrm{P}} / \mathrm{F}_{\text {уст. }}$ и $\mathrm{J}_{\mathrm{H}_{2}}^{\prime}=\mathrm{Q}_{\mathrm{P}} / \mathrm{F}_{\text {расч. }}$ рассчитали средние плотности потока диффузии водорода $\mathrm{J}_{\mathrm{H}_{2}}$ и $\mathrm{J}_{\mathrm{H}_{2}}^{\prime}$ (табл. 9). На основании расчетных данных на рис. 21 в координатах $\mathrm{J}_{\mathrm{H}_{2}}-\mathrm{I}(\mathrm{I}=$ $\mathrm{Q}_{\mathrm{Ar}} / \mathrm{Q}_{\mathrm{CH}_{4}}$ ) построили зависимости средних плотностей потоков диффузии водорода через палладиевую мембрану⿰ $\mathrm{H}_{2}-\mathrm{I}(1)$ и $\mathrm{J}_{\mathrm{H}_{2}}^{\prime}-\mathrm{I}(2)$ от отношения продувки I.

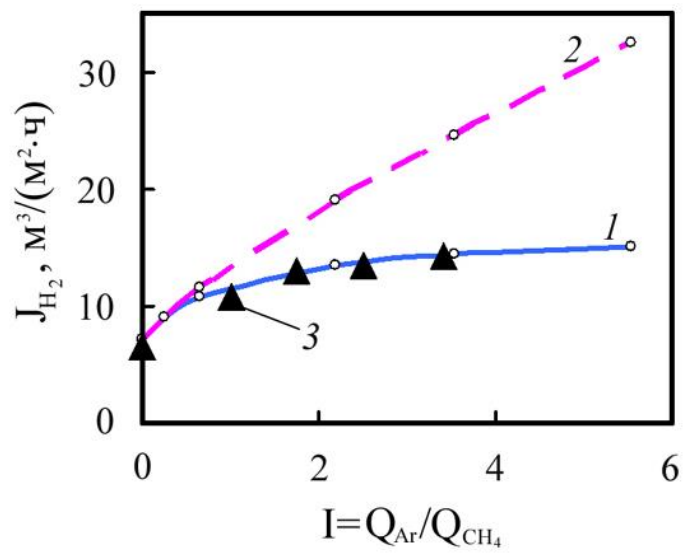

Рис. 21. Зависимость плотности потока диффузии водорода через мембрану от коэффициента продувки $\mathrm{I}=\mathrm{Q}_{\mathrm{Ar}} / \mathrm{Q}_{\mathrm{CH}_{4}}$ при $\mathrm{P}_{\mathrm{B}}=0,5 \mathrm{MПа}, \mathrm{Q}_{0}=0,0257 \mathrm{~m}^{3} /$ ч и температуре $550{ }^{\circ} \mathrm{C}$ :

1 - расчет на всю площадь мембраны $\left(F=0,00157 \mathrm{~m}^{2}\right) ; 2$ - расчет на рабочую площадь мембраны; 3 - экспериментальные точки для лабораторного мембранного конвертора [20]

На график (рис. 21) нанесли координаты экспериментальных точек $\mathrm{J}_{\mathrm{H}_{2}}$ из работы [20] равных: 6,$5 ; 10,8 ; 13 ; 13,5 ; 14,2 \mathrm{~m}^{3} / \mathrm{M}^{2} ч$ соответственно при отношениях продувки $\mathrm{I}=\mathrm{Q}_{\mathrm{Ar}} / \mathrm{Q}_{\mathrm{CH}_{4}}: 0 ; 1,0 ; 1,75 ; 2,5 ; 3,4$, которые хорошо укладываются на расчетную кривую 1 , что свидетельствует об адекватности используемой математической модели [9], в том случае, когда расчет $\mathrm{J}_{\mathrm{H}_{2}}$ осуществляется на всю установленную площадь мембраны.

Расчетная кривая 2 на рис. 21 располагается выше кривой 1 , поскольку в этом случае учитывалось изменение расчетной рабочей площади мембраны, необходимой для достижения максимальной производительности по высокочистому водороду $\mathrm{Q}_{\mathrm{p}}$, которая при увеличении отношения продувки $\mathrm{I}=\mathrm{Q}_{\mathrm{Ar}} / \mathrm{Q}_{\mathrm{CH}_{4}}$ уменьшается и в соответствии с рис. 20 и табл. 9 принимает значения меньше установленной площади мембраны $\mathrm{F}_{\text {уст. }}=15,7 \mathrm{~cm}^{2}$ [20].

Из проведенного анализа следует, что для экспериментального достижения высоких средних плотностей диффузии водорода через мембрану $\mathrm{J}_{\mathrm{H}_{2}}$ необходимо при увеличении отношения продувки $\mathrm{I}=\mathrm{Q}_{\mathrm{Ar}} / \mathrm{Q}_{\mathrm{CH}_{4}}$ поток $\mathrm{Q}_{0}$ исходной газовой смеси $\mathrm{CH}_{4}-3 \mathrm{H}_{2} \mathrm{O}$ повышать таким образом, чтобы в процессе извлечения водорода в лабораторном мембранном конверторе участвовала вся установленная площадь мембраны.

Отметим, что в рассмотренных выше двух случаях хорошая корреляция результатов моделирования и экспериментальных данных [20] достигнута при использовании в расчетах наиболее достоверных величин коэффициентов удельной водородопроницаемости $\gamma$ для чистого палладия [22].

На основании указанного выше обстоятельства можно полагать, что в случае лабораторного мембранного конвертора [20] с мембраной толщиной 4 мкм процесс оттока водорода из полости высокого в полость низкого давления на каждом участке площади мембраны $\Delta \mathrm{F}$ 
лимитируется диффузионной стадией. В этом случае наличие пористой керамической подложки практически не оказывает влияния на механизм проникновения водорода через мембрану из чистого палладия толщиной 4 мкм.

Таким образом, проведенный в разделе анализ показал, что с помощью математической модели идеального вытеснения [9], учитывающей сток массы водорода через мембрану и химическое взаимодействие в газовой фазе, удалось количественно описать основные экспериментальные зависимости лабораторного мембранного конвертора трубчатого типа с мембраной из чистого палладия толщиной 4 мкм и площадью 15,7 см².

\section{5. Анализ расчетных параметров модельного мембранно-каталитического конвертора трубчатого типа для получения высокочистого водорода из метана}

В предыдущих разделах показано, что математическая модель мембранного извлечения высокочистого водорода в режиме идеального вытеснения [9] из продуктов паровой конверсии углеводородов, учитывающая отток водорода под действием перепада давлений через сплошную мембрану из палладиевого сплава и химическое взаимодействие между компонентами газовой фазы, адекватно описывает экспериментальные данные МК-устройств разной производительности.

В данном разделе с помощью указанной выше модели [9] проанализированы основные расчетные параметры модельного мембранного реформера трубчатого типа [23], для расчетов использована "кинетическая" математическая модель реактора идеального вытеснения с одновременным отводом водорода через палладиевую мембрану. Особое внимание в этой модели уделялось учету тепло- и массопереноса в направлении, поперечном основным газовым потокам в реакционном пространстве мембранного реформера. Известны подобные кинетические математические модели и других авторов [24, 25].

Конструктивно модельный мембранный реформер, выбранный в качестве объекта исследований, состоял из 25 трубчатых МК-элементов [23] длиной 400 мм, обогреваемых сна-

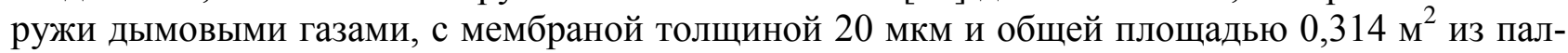
ладиевого сплава В-1 [23] на пористой подложке.

Упрощенная схема единичного МК-элемента представлена на рис. 22. Исходное сырье в виде смеси $\mathrm{CH}_{4}+3 \mathrm{H}_{2} \mathrm{O}$ ( $A$, рис. 22) поступает в полость предварительного конвертора (участок $L_{1}=40$ мм) с гранулированным катализатором $\left(K_{1}\right)$ диаметром 3 мм, на котором осуществляется паровая конверсия метана без извлечения водорода согласно обратимым химическим реакциям:

$$
\mathrm{CH}_{4}+2 \mathrm{H}_{2} \mathrm{O}=4 \mathrm{H}_{2}+\mathrm{CO}_{2}, \quad \mathrm{CO}+\mathrm{H}_{2} \mathrm{O}=\mathrm{H}_{2}+\mathrm{CO}_{2} \text {. }
$$

Далее продукты паровой конверсии метана в виде газовой смеси, содержащей $\mathrm{H}_{2}$, $\mathrm{H}_{2} \mathrm{O}, \mathrm{CO}_{2}, \mathrm{CO}, \mathrm{CH}_{4}$, поступают в полость высокого давления (ПВД) - участок $L_{2}=400$ мм, где вдоль поверхности мембраны $M$ установлен дополнительный структурированный никелевый катализатор $K_{2}$, обладающий высокой каталитической активностью. Удаление сбросного газа осуществляется через выход $B$. 


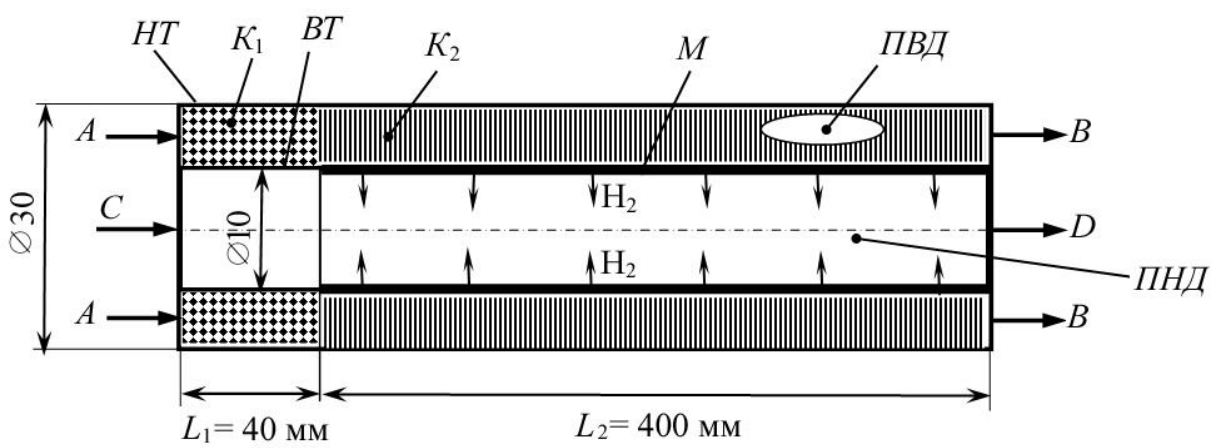

Рис. 22. Схема единичного МК-элемента модельного мембранного конвертора [23]: $A$ - вход исходной смеси $\mathrm{CH}_{4}-3 \mathrm{H}_{2} \mathrm{O} ; B$ - выход сбросного газа; $C$ - вход продувочного газа (пар); $D$ - выход водорода или смеси водорода и продувочного газа; $K_{1}$ и $K_{2}$ - гранулированный и структурированный катализаторы конверсии метана соответственно; $M$ - мембрана; $L_{1}-$ зона традиционной конверсии метана; $L_{2}-$ зона мембранного извлечения водорода, совмещенного с конверсией метана; ПВД - полость высокого давления; ПНД - полость низкого давления;

$H T$ и $B T$ - наружная и внутренняя труба модельного МК-конвертора соответственно

В качестве одного из вариантов удаление водорода-продукта осуществляется из полости низкого давления (ПНД) самотеком через выход $D$. В качестве другого варианта для принудительного удаления высокочистого водорода из ПНД модельного мембранного конвертора через выход $D$ использовался водяной пар (1,5 кг/ч), подаваемый через вход $C$ [23].

Рабочая температура МК-реформера составляет $600{ }^{\circ} \mathrm{C}$ абсолютное давление газа над мембраной $\mathrm{P}_{\mathrm{B}}=1,0 \mathrm{MПа,} \mathrm{а} \mathrm{расход} \mathrm{метана} \mathrm{в} \mathrm{исходной} \mathrm{CH}_{4}+3 \mathrm{H}_{2} \mathrm{O}$ смеси $\mathrm{Q}_{\mathrm{CH}_{4}}=0,624 \mathrm{~m}^{3} / 4$ [23]. Рассмотрены два основных режима работы модельного МК-устройства: режим 1 - без продувки полости низкого давления паром и режим 2 - с продувкой ПНД водяным паром. В первом случае абсолютное давление водорода-продукта принято равным 0,1 МПа, а во втором $-\mathrm{P}_{\mathrm{H}}=0,05 \mathrm{MПа,} \mathrm{эквивалентное} \mathrm{разбавлению} \mathrm{водорода-продукта} \mathrm{водяным} \mathrm{паром.} \mathrm{Необ-}$ ходимые для проведения расчетов величины коэффициентов удельной водородопроницаемости водорода для сплава В-1 взяты из работы [27].

Принципы методики расчетов в рамках модели [9] проиллюстрированы графически на рис. 23. По мере увеличения площади мембраны $\mathrm{F}$ производительность модельного мембранного реформера по водороду-продукту $\mathrm{Q}_{\mathrm{P}}$ (кривая 1, рис. 23) для режима 1 возрастает до тех пор, пока концентрация водорода $\mathrm{X}_{\mathrm{H}_{2}}$ (кривая 3, рис. 23) над участком поверхности мембраны за счет оттока $\mathrm{H}_{2}$ через мембрану с учетом смещения химического равновесия (1) вправо не приблизится к концентрационному пределу $\mathrm{X}_{\text {пред. }}=\mathrm{P}_{\mathrm{H}} / \mathrm{P}_{\mathrm{B}}=0,1$ МПа, изображенному на рис. 23 горизонтальной пунктирной линией 3 '.

В случае режима 2 производительность модельного мембранного реформера по водороду-продукту $\mathrm{Q}_{\mathrm{p}}$ (кривая 2, рис. 23) по мере увеличения площади мембраны увеличивается до тех пор пока концентрация водорода $\mathrm{X}_{\mathrm{H}_{2}}$ (кривая 4, рис. 2) не приблизится к концентрационному пределу $\mathrm{X}_{\text {пред. }}=0,05$ мольных долей, отмеченному на рис.23 пунктирной линией 4'. Изменение расчетных концентраций метана $\mathrm{X}_{\mathrm{CH}_{4}}$ в надмембранном пространстве представлено на рис. 23 кривыми 5 и 6 и иллюстрирует опосредованное участие метана в извлечении высокочистого водорода через смещение химического равновесия (1) вправо по мере отвода водорода через мембрану. Числовые значения основных параметров модельного мембранного реформера для режимов 1 и 2 в рамках модели [9] представлены в табл. 10 (строки 1 и 2). Горизонтальными пунктирными линиями 1', 2' на рис. 23 изображены уровни производительности модельного мембранного реформера для двух рассматриваемых режимов по 
данным работы [23]. В круглых скобках (строки 1 и 2, табл. 10) приведены величины расчетных параметров из работы [23], отмеченные $(*)$.

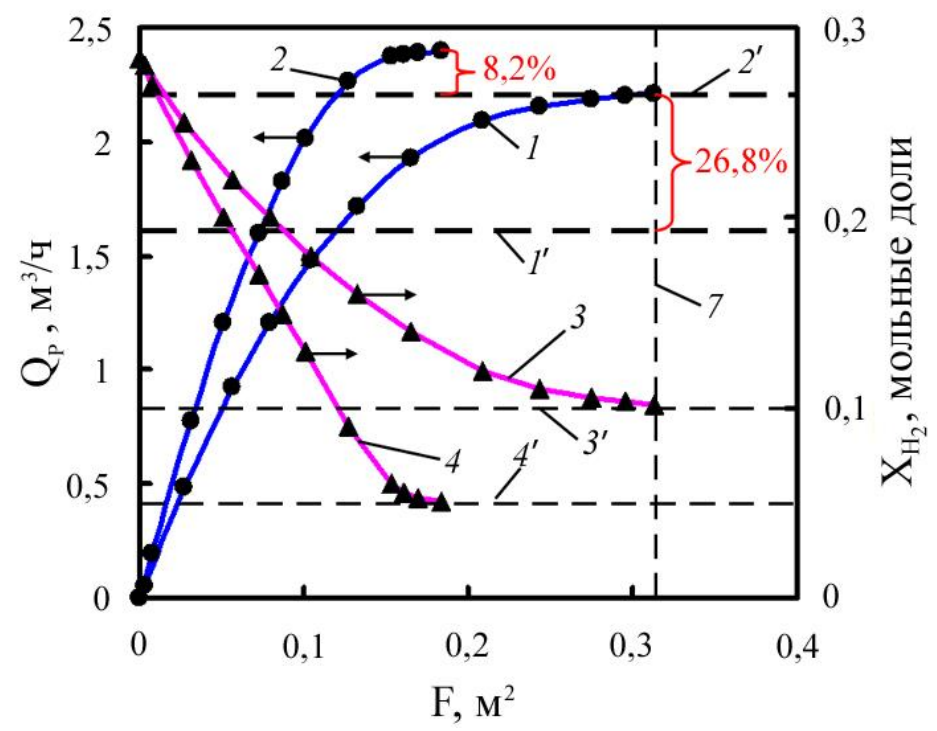

Рис. 23. Зависимости производительности $\mathrm{Q}_{\mathrm{p}}(1,2)$, а также концентраций водорода $\mathrm{X}_{\mathrm{H}_{2}}(3,4)$ от площади мембраны $\mathrm{F}$ модельного мембранного конвертора при температуре $600{ }^{\circ} \mathrm{C}$ : 1, 3- $\mathrm{P}_{\mathrm{H}}=0,1 \mathrm{MПа;} \mathrm{2,} \mathrm{4-} \mathrm{p}_{\mathrm{H}}=0,05 \mathrm{MПа;} 1^{\prime}-$ уровень производительности $\mathrm{Q}_{\mathrm{p}}=1,61 \mathrm{~m}^{3} /$ ч без продувки [23]; 2'- уровень производительности $\mathrm{Q}_{\mathrm{p}}=2,2$ м $3 /$ ч с продувкой [23]; 3'- уровень $\mathrm{X}_{\text {пред. }}=0,1$ мольные доли; 4'- уровень $\mathrm{X}_{\text {пред. }}=0,05$ мольных долей; 7 - уровень установленной площади мембраны $\mathrm{F}_{\text {уст. }}=0,314 \mathrm{~m}^{2}$

Для режима 1 производительность по водороду-продукту $\left(\mathrm{Q}_{\mathrm{p}}\right)$ из работы [23] ниже наших расчетов на 26,8 \% (рис. 23), степень конверсии метана (СК) меньше наших расчетов на $20 \%$, а объемный выход водорода (qv) ниже на 27,3\% (табл. 10). Степень конверсии производили по формуле (37) из работы [20]. $\mathrm{CK}=\left(\mathrm{X}_{\mathrm{CO}}+\mathrm{X}_{\mathrm{CO}_{2}}\right) /\left(\mathrm{X}_{\mathrm{CO}}+\mathrm{X}_{\mathrm{CO}_{2}}+\mathrm{X}_{\mathrm{CH}_{4}}\right)$ (37), где $\mathrm{X}_{\mathrm{CO}}, \mathrm{X}_{\mathrm{CO}_{2}}, \mathrm{X}_{\mathrm{CH}_{4}}$ - мольные доли компонентов газовой фазы.

В случае режима 2 параметры модельного мембранного реформера (величины в круглых скобках в строке 2, табл. 10) из работы [23] ниже наших расчетов: $\mathrm{Q}_{\mathrm{P}}$ на 8,2 \% (рис. 23), степень конверсии метана (СК) на 4,7 \%, объемный выход водорода (qv) на 6,3\%. Расчетная площадь мембраны по нашим расчетам для режима $1 \mathrm{~F}_{\text {расч. }}$ составила 0,314 м $^{2}$ и совпала с $\mathrm{F}_{\text {уст. }}$. По нашим оценкам, расчетная площадь $\mathrm{F}_{\text {расч., }}$ сопряженная с катализатором $\mathrm{K}_{2}$ (рис. 22) для режима 2 составила $0,184 \mathrm{~m}^{2}$ (строка 2, табл. 10 и кривая 2, рис. 23), т. е. всего $58,6 \%$ от $\mathrm{F}_{\text {уст. }}=0,314 \mathrm{~m}^{2}$, что свидетельствует о нерациональном использовании мембраны. Этому факту никакого внимания в работе [23] не уделялось.

Более того, оценка расчетной площади мембраны по формуле $\mathrm{F}_{\text {расч. }}=\mathrm{Q}_{\mathrm{p}} / \mathrm{J}_{\mathrm{H}_{2}}$, с учетом данных работы [23] (строка 2, табл. 10 величины в круглых скобках), показала, что $\mathrm{F}_{\text {расч. }}=2,2 / 7,1=0,31 \mathrm{~m}^{2}$ и практически совпадает с $\mathrm{F}_{\text {уст. }}=0,314 \mathrm{~m}^{2}$, но существенно расходится с нашими данными $\mathrm{F}_{\text {расч. }}=0,184 \mathrm{~m}^{2}$.

В рамках модельных представлений [9] рациональное использование мембраны для режима 2 можно достичь путем увеличения исходного расхода метана $\mathrm{Q}_{\mathrm{CH}_{4}}$ с 0,624 до $1,05 \mathrm{~m}^{3} /$ ч (строка 3 , табл. 10). При этих условиях расчетная рабочая площадь мембраны увеличивается до $\mathrm{F}_{\text {расч. }}=0,308 \mathrm{~m}^{2}$ и приближается к величине $\mathrm{F}_{\text {уст. }}=0,314 \mathrm{~m}^{2}$. В этом случае максимальная производительность модельного МК-устройства $\mathrm{Q}_{\mathrm{P}}$ возрастает в 1,68 раза с 2,39 до 4,03 м ${ }^{3} \mathrm{H}_{2} /$ ч (строка 3 , табл.10), а другие параметры $\mathrm{J}_{\mathrm{H}_{2}}, \mathrm{X}_{\mathrm{H}_{2}}$, степень конверсии метана 
CК, объемный $\mathrm{q}_{\mathrm{v}}$ и мольный $\mathrm{q}_{\mathrm{m}}$ выходы водорода остаются на прежнем уровне, как и в строке 2 , табл. 10.

Таблица 10 - Расчетные параметры модельного мембранного реформера с мембраной из палладиевого сплава В-1 толщиной 20 мкм

\begin{tabular}{|c|c|c|c|c|c|c|c|c|c|c|c|}
\hline \multirow{2}{*}{$\begin{array}{l}\text { № } \\
\text { ПП }\end{array}$} & \multicolumn{11}{|c|}{ Параметры модельного мембранного конвертора } \\
\hline & $\stackrel{\mathrm{t}}{{ }^{\circ} \mathrm{C}}$ & $\begin{array}{l}\mathrm{Q}_{\mathrm{CH}_{4}}, \\
\mathrm{M}^{3} / \mathrm{u}\end{array}$ & $\begin{array}{c}\mathrm{P}_{\mathrm{B}}, \\
\mathrm{MПа}\end{array}$ & $\begin{array}{l}\mathrm{P}_{\mathrm{H}}, \\
\mathrm{MПа}\end{array}$ & $\begin{array}{c}\mathrm{F}_{\text {pacu. }}, \\
\mathrm{M}^{2}\end{array}$ & $\begin{array}{c}\mathrm{Q}_{\mathrm{P}}, \\
\mathrm{M}^{3} \mathrm{H}_{2} / \mathrm{Y}\end{array}$ & $\begin{array}{c}\mathrm{J}_{\mathrm{H}_{2}}, \\
\mathrm{M}^{3} /\left(\mathrm{M}^{2} \mathrm{u}\right)\end{array}$ & $\begin{array}{c}\mathrm{X}_{\mathrm{H}_{2}}, \\
\text { мольая } \\
\text { доля }\end{array}$ & $\mathrm{CK}$ & $\begin{array}{c}\mathrm{q}_{\mathrm{v}}, \\
\frac{\mathrm{M}^{3} \mathrm{H}_{2}}{\mathrm{M}^{3} \mathrm{cырья}}\end{array}$ & $\begin{array}{c}\mathrm{q}_{\mathrm{m}}, \\
\frac{\text { мол. } \mathrm{H}_{2}}{\text { мол. } \mathrm{CH}_{4}}\end{array}$ \\
\hline \multicolumn{12}{|c|}{ Мембрана из палладиевого сплава В-1 } \\
\hline 1 & \multirow{3}{*}{600} & \multirow[t]{3}{*}{0,624} & \multirow{3}{*}{1,0} & 0,1 & 0,314 & $\begin{array}{c}2,2 \\
(1,61 *)\end{array}$ & $\begin{array}{c}7,0 \\
\left(5,1^{*}\right)\end{array}$ & 0,102 & \begin{tabular}{|c|}
0,963 \\
$\left(0,77^{*}\right)$
\end{tabular} & $\begin{array}{c}0,881 \\
(0,64 *)\end{array}$ & 3,52 \\
\hline 2 & & & & \multirow[t]{2}{*}{0,05} & 0,184 & $\begin{array}{c}2,39 \\
(2,2 *)\end{array}$ & $\begin{array}{c}13,0 \\
\left(7,1^{*}\right)\end{array}$ & 0,051 & \begin{tabular}{|c|}
0,997 \\
$\left(0,95^{*}\right)$
\end{tabular} & $\begin{array}{c}0,95 \\
(0,89 *)\end{array}$ & 3,84 \\
\hline 3 & & & & & 0,308 & 4, & 13,1 & 0,051 & 0,997 & 0,96 & 3,84 \\
\hline 4 & \multirow{2}{*}{550} & \multirow{2}{*}{0,624} & 1,0 & 0,1 & 0,316 & 1,69 & 5,35 & 0,12 & 0,775 & 0,678 & 2,71 \\
\hline 5 & & & 1,0 & 0,05 & 0,311 & 2,37 & 7,62 & 0,0528 & 0,987 & 0,951 & 3,8 \\
\hline 6 & \multirow[b]{2}{*}{500} & \multirow{2}{*}{0,624} & \multirow[b]{2}{*}{1,0} & 0,1 & 0,315 & 0,941 & 2,98 & 0,114 & 0,48 & 0,377 & 1,51 \\
\hline 7 & & & & 0,05 & 0,312 & 1,97 & 6,3 & 0,07 & 0,837 & 0,664 & 2,66 \\
\hline 8 & 600 & 0,624 & 1,8 & 0,15 & 0,3 & 2,2 & 7,33 & 0,0843 & 0,947 & 0,883 & 3,53 \\
\hline \multicolumn{12}{|c|}{$\begin{array}{l}\text { Примечание. } \mathrm{Q}_{\mathrm{CH}_{4}}-\text { расход метана в исходной паро-метановой смеси; } \mathrm{P}_{\mathrm{B}} \text { и } \mathrm{P}_{\mathrm{H}}-\text { абсолютные } \\
\text { давления над и под мембраной, соответственно; } \mathrm{F}_{\text {расч. }}-\text { расчетная площадь мембраны; } \\
\mathrm{Q}_{\mathrm{P}}-\text { производительность по водороду-продукту; } \mathrm{J}_{\mathrm{H}_{2}}-\text { средняя диффузионная плотность по- } \\
\text { тока водорода через мембрану; } \mathrm{X}_{\mathrm{H}_{2}}-\text { концентрация водорода над участком поверхности мем- } \\
\text { браны; } \mathrm{q}_{\mathrm{v}} \text { и } \mathrm{q}_{\mathrm{m}}-\text { объемный и мольный выходы водорода; * - данные из работы [8]. }\end{array}$} \\
\hline
\end{tabular}

Подводя предварительные итоги проведенного анализа, можно сделать вывод о том, что несмотря на различие подходов, использованных при разработке математических моделей в работах [9] и [23], количественная корреляция основных параметров модельного МК-устройства при рабочей температуре $600{ }^{\circ} \mathrm{C}$ вполне удовлетворительная, особенно для режима 2 (при $\mathrm{P}_{\mathrm{H}}=0,05 \mathrm{MПа).}$

Учитывая, что зарубежные мембранные конверторы эксплуатируются при температуpax ниже $600{ }^{\circ} \mathrm{C}[1,2]$, проведена дополнительная проверка работоспособности модельного мембранного реформера [23] с мембраной из сплава В-1 при температурах 550 и $500{ }^{\circ} \mathrm{C}$. Расчеты показали, что для штатного исходного расхода $\mathrm{Q}_{\mathrm{CH}_{4}}=0,624 \mathrm{~m} / \mathrm{q}, \mathrm{P}_{\mathrm{H}}=0,1$ МПа и мембраны из палладиевого сплава В-1 снижение рабочей температуры исследуемого мембранного реформера до $550{ }^{\circ} \mathrm{C}$ приводит к максимальной производительности по водородупродукту $\mathrm{Q}_{\mathrm{P}}=1,69 \mathrm{~m}^{3} \mathrm{H}_{2} /$ при расчетной площади мембраны $\mathrm{F}_{\text {расч. }}=0,316 \mathrm{~m}^{2}$, близкой к $\mathrm{F}_{\text {уст. }}=0,314 \mathrm{~m}^{2}$ (строка 4 , табл. 10). Обращает на себя внимание, что при этих условиях расчетная концентрация водорода над поверхностью мембраны $\mathrm{X}_{\mathrm{H}_{2}}=0,12$ мольных долей (строка 4, табл. 10) больше $\mathrm{X}_{\text {пред. }}=0,1$ мольной доли, что свидетельствует о неполном завершении мембранного извлечения водорода из-за ограничения в площади мембраны.

Степень конверсии метана составляет 0,775 (строка 4, табл. 10). Поскольку величины этих двух основных параметров $\left(\mathrm{Q}_{\mathrm{P}}=1,69 \mathrm{~m}^{3} \mathrm{H}_{2} /\right.$ ч, $\left.\mathrm{CK}=0,77\right)$ не сильно отличаются от величин $\mathrm{Q}_{\mathrm{P}}=1,61 \mathrm{~m}^{3} \mathrm{H}_{2} /$ и и $\mathrm{CK}=0,77$, приведенных в круглых скобках строки 1 , табл. 10 для режима 1 при температуре $600{ }^{\circ} \mathrm{C}$, можно предположить, что ограничения, введенные в модель [23], оказывают такое же влияние, как и снижение температуры с 600 до $550{ }^{\circ} \mathrm{C}$ в нашей модели [9]. Отметим, что в этом случае снижаются и другие техноэкономические параметры 
$\mathrm{q}_{\mathrm{v}}=0,678 \mathrm{~m}^{3} \mathrm{H}_{2} / \mathrm{m}^{3}$ сырья, $\mathrm{q}_{\mathrm{m}}=2,71$ мольН $\mathrm{H}_{2}$ мольСН $\mathrm{H}_{4}$ (строка 4, табл. 10), характеризующие более низкую эффективность МК-способа получения высокочистого водорода.

Проведенные в рамках модели [9] расчеты показали, что для исходного расхода метана $\mathrm{Q}_{\mathrm{CH}_{4}}=0,624 \mathrm{~m}^{3} /$ ч, $\mathrm{P}_{\mathrm{H}}=0,05$ МПа и мембраны из палладиевого сплава В-1 (строка 5, табл. 10) снижение рабочей температуры до $550{ }^{\circ} \mathrm{C}$ приводит к максимальной производительности по водороду-продукту $\mathrm{Q}_{\mathrm{P}}=2,37 \mathrm{~m}^{3} \mathrm{H}_{2} /$ ч при расчетной площади мембраны $\mathrm{F}_{\text {расч. }}=0,311 \mathrm{~m}^{2}$, близкой к $\mathrm{F}_{\text {уст. }}=0,314 \mathrm{~m}^{2}$. Средняя плотность потока диффузии водорода через мембрану $\mathrm{J}_{\mathrm{H}_{2}}=7,62 \mathrm{~m}^{3} \mathrm{H}_{2} /\left(\mathrm{M}^{2} \mathrm{Y}\right)$, техноэкономические показатели следующие: $\mathrm{CK}=0,987$; $\mathrm{q}_{\mathrm{v}}=0,951 \mathrm{~m}^{3} \mathrm{H}_{2} / \mathrm{m}^{3}$ сырья; $\mathrm{q}_{\mathrm{m}}=3,8$ мольН $\mathrm{H}_{2} /$ мольСН $\mathrm{H}_{4}$.

Поскольку величины двух основных параметров $Q_{\mathrm{P}}=2,37 \quad \mathrm{~m}^{3} \mathrm{H}_{2} / \mathrm{u} \quad$ и $\mathrm{J}_{\mathrm{H}_{2}}=7,62 \mathrm{~m}^{3} \mathrm{H}_{2} /\left(\mathrm{M}^{2} \mathrm{u}\right)$ незначительно отличаются от величин $\mathrm{Q}_{\mathrm{P}}=2,2 \quad \mathrm{~m}^{3} \mathrm{H}_{2} / \mathrm{u}$ и $\mathrm{J}_{\mathrm{H}_{2}}=7,1 \mathrm{~m}^{3} \mathrm{H}_{2} /\left(\mathrm{M}^{2} \Psi\right)$, указанных в круглых скобках строки 2, табл. 10 при температуре $600{ }^{\circ} \mathrm{C}$ и $\mathrm{P}_{\mathrm{H}}=0,05 \mathrm{MПа}$, можно предположить, что и в случае режима 2 ограничения по тепло- и массопереносу в поперечном направлении основного газового потока, введенные в модель [23], оказывают такое же влияние, как снижение температуры с 600 до $550{ }^{\circ} \mathrm{C}$ при использовании нашей модели [9].

Дальнейшие расчеты показали, что при $\mathrm{P}_{\mathrm{H}}=0,1$ МПа снижение рабочей температуры до $500{ }^{\circ} \mathrm{C}$ приводит к еще более низкой производительности по высокочистому водороду $\mathrm{Q}_{\mathrm{p}}=0,941 \mathrm{~m}^{3} /$ ч при расчетной площади мембраны $\mathrm{F}_{\text {расч. }}=0,315 \mathrm{~m}^{2}$, близкой к установленной площади мембраны $\mathrm{F}_{\text {уст. }}=0,314 \mathrm{~m}^{2}$ (строка 6 , табл. 10). При этих условиях расчетная концентрация водорода над поверхностью мембраны $\mathrm{X}_{\mathrm{H}_{2}}=0,114$ мольных долей (строка 6 , табл. 10) больше $\mathrm{X}_{\text {пред. }}=0,1$ мольной доли, что свидетельствует о неполном завершении мембранного извлечения водорода из-за ограничения в площади мембраны. Кроме того, величины расчетных параметров СК, q $\mathrm{q}_{\mathrm{v}}$ и q $\mathrm{q}_{\mathrm{m}}$ получились достаточно низкими и свидетельствовали о еще более низкой эффективности процесса получения высокочистого водорода при этих условиях. Для рабочей температуры $500{ }^{\circ} \mathrm{C}$ и $\mathrm{P}_{\mathrm{H}}=0,05 \mathrm{MПа} \mathrm{(строка} 7$, табл. 10) расчетная производительность $\mathrm{Q}_{\mathrm{P}}=1,97 \mathrm{~m}^{3} /$ ч при $\mathrm{F}_{\text {расч. }}=0,312 \mathrm{~m}^{2}$, достаточно близкой к $\mathrm{F}_{\text {уст. }}=0,314 \mathrm{~m}^{2}$. При этих условиях расчетная концентрация водорода над поверхностью мембраны $\mathrm{X}_{\mathrm{H}_{2}}=0,07$ мольных долей (строка 7 , табл. 10) больше величины $\mathrm{X}_{\text {пред. }}=0,05$ мольных долей, что свидетельствует о неполном завершении мембранного извлечения водорода из-за ограничения в площади мембраны. Поэтому техноэкономические показатели получились более низкими: СК = 0,837,

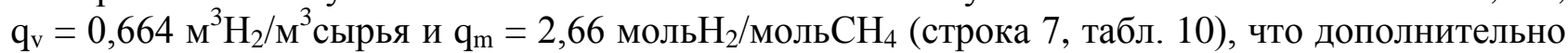
указывает на недостаточную эффективность получения высокочистого водорода из метана в мембранном реформере при этих условиях.

Таким образом, модельный реформер с мембраной из сплава В-1 в базовом конструктивном исполнении [23] сохраняет приемлемую производительность порядка $2,37 \mathrm{~m}^{3} /$ ч и хорошие технологические показатели $\mathrm{CK}, \mathrm{q}_{\mathrm{v}}$ и $\mathrm{q}_{\mathrm{m}}$ при рабочей температуре $550{ }^{\circ} \mathrm{C}$ и абсолютном давлении водорода-продукта, равном 0,05 МПа. При рабочей температуре $500{ }^{\circ} \mathrm{C}$ производительность $\mathrm{Q}_{\mathrm{p}}$ и параметры $\mathrm{CK}, \mathrm{q}_{\mathrm{v}}$ и $\mathrm{q}_{\mathrm{m}}$ заметно ниже при обоих исследованных абсолютных давлениях водорода-продукта 0,05 и 0,1 МПа.

Отметим, что продувка полости низкого давления модельного мембранного реформеpa [23] водяным паром с точки зрения целевого назначения МК-устройства, а именно получения высокочистого водорода, нам представляется в практическом смысле нецелесообразной. Кроме того, выходное давление водорода-продукта 0,1 МПа, равное атмосферному, затрудняет его дальнейшее использование потребителем.

Одним из успешных и экспериментально проверенных вариантов удаления водородапродукта из МК-устройств является применение металлогидридного компрессора с пониженным давлением на входе порядка 0,02-0,04 МПа [2]. Другим вариантом может служить удаление водорода-продукта из ПНД модельного МК-устройства самотеком и под избыточ- 
ным давлением, что достигается изменением соотношения давлений над мембраной ( $\left.\mathrm{P}_{\mathrm{B}}\right)$ и под мембраной $\left(\mathrm{P}_{\mathrm{H}}\right)$.

Для оценки второго варианта удаления водорода-продукта приняты следующие исходные данные: рабочая температура мембранного реформера $600{ }^{\circ} \mathrm{C}$, расход метана $\mathrm{Q}_{\mathrm{CH}_{4}}=0,624 \mathrm{~m}^{3} /$, абсолютные давления $\mathrm{P}_{\mathrm{B}}=1,8 \mathrm{MПа} \mathrm{и} \mathrm{P}_{\mathrm{H}}=0,15 \mathrm{MПа} \mathrm{(строка} \mathrm{8,} \mathrm{табл.} \mathrm{10).}$

В графическом виде результаты расчетов для второго варианта удаления водородапродукта представлены на рис. 24. Концентрационный предел $\left(\mathrm{X}_{\text {пред. }}\right)$ в этом случае составляет 0,0833 мольных долей, отмеченный на рис. 24 горизонтальной пунктирной линией 4.

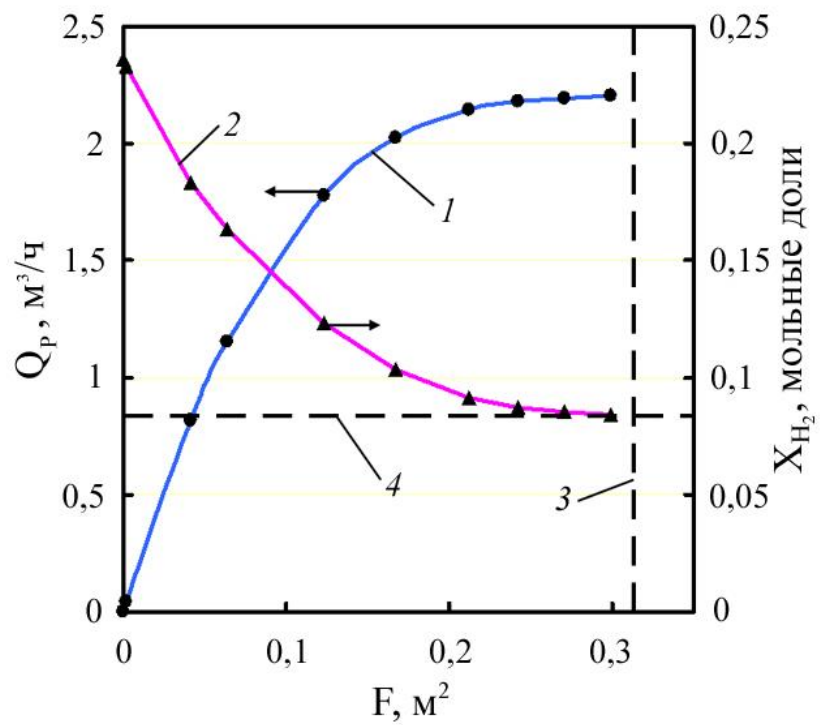

Рис.24. Зависимости производительности $\mathrm{Q}_{\mathrm{P}}(1)$ и концентрации водорода $\mathrm{X}_{\mathrm{H}_{2}}(2)$ от площади мембраны $\mathrm{F}$ модельного мембранного конвертора при температуре $600{ }^{\circ} \mathrm{C}$; 3 - уровень установленной площади мембраны $\mathrm{F}_{\text {уст. }}=0,314 \mathrm{~m}^{2}$; 4 - уровень концентрационного предела $\mathrm{X}_{\text {пред. }}=0,0833$ мольной доли

При этих условиях максимальная производительность мембранного конвертора составляет $\mathrm{Q}_{\mathrm{P}}=2,2 \mathrm{~m}^{3} \mathrm{H}_{2} /$ ч при площади мембраны $\mathrm{F}_{\text {расч. }}=0,3 \mathrm{~m}^{2}$, что практически совпадает с $\mathrm{F}_{\text {уст. }}=0,314 \mathrm{~m}^{2}$ (вертикальная пунктирная линия 3, рис. 24). Достаточно высокую эффективность получения высокочистого водорода подтверждают расчетные величины параметров СК, $\mathrm{q}_{\mathrm{v}}$ и $\mathrm{q}_{\mathrm{m}}$ (строка 8, табл. 10).

Также представляет интерес рассмотреть без изменения конструктивных параметров влияние материала мембраны на выходные характеристики модельного мембранного реформера [30] при температурах 550 и $500{ }^{\circ} \mathrm{C}$ путем замены сплава В-1 на сплав Pd-8Y [2] с более высокими коэффициентами удельной водородопроницаемости, данные для проведении расчетов взяты из работ $[15,17]$.

В рамках модельных представлений [9] расчетным путем установлено, что для мембраны из сплава $\mathrm{Pd}-8 \mathrm{Y}$ толщиной 20 мкм при температуре $550{ }^{\circ} \mathrm{C}$ и $\mathrm{P}_{\mathrm{H}}=0,1 \mathrm{MПа} \mathrm{максималь-}$ ная производительность МК-устройства $\mathrm{Q}_{\mathrm{P}}=1,97 \quad \mathrm{M}^{3} \mathrm{H}_{2} /$ (строка 1 , табл. 11) при $\mathrm{F}_{\text {расч. }}=0,24 \mathrm{~m}^{2}$ меньшей, чем $\mathrm{F}_{\text {уст. }}=0,314 \mathrm{~m}^{2}$. Степень конверсии метана $\mathrm{CK}=0,865$; $\mathrm{q}_{\mathrm{v}}=0,788 \mathrm{~m}^{3} \mathrm{H}_{2} / \mathrm{m}^{3}$ сырья; $\mathrm{q}_{\mathrm{m}}=3,15$ мольН $\mathrm{H}_{2} /$ мольСН $_{4}$ (строка 1 , табл. 11 ). Отметим, что в этом случае площадь мембраны используется не рационально. С целью более рационального использования площади мембраны увеличили $\mathrm{Q}_{\mathrm{CH}_{4}}$ с 0,624 до 0,825 м $3 /$ ч (строка 2, табл. 11), что привело к росту производительности по высокочистому водороду $\mathrm{Q}_{\mathrm{P}}$ до $2,6 \mathrm{~m}^{3} \mathrm{H}_{2} /$ ч при $\mathrm{F}_{\text {расч. }}=0,313 \mathrm{~m}^{2}$, близкой к $\mathrm{F}_{\text {уст. }}=0,314 \mathrm{~m}^{2}$. Величины техноэкономических показателей $\mathrm{CK}, \mathrm{q}_{\mathrm{v}}$ и $\mathrm{q}_{\mathrm{m}}$ не изменились и остались точно такими же, как в строке 1, табл. 11. 
Таблица 11 - Расчетные параметры модельного мембранного реформера с мембраной из палладиевого сплава Pd-8Y толщиной 20 мкм

\begin{tabular}{|c|c|c|c|c|c|c|c|c|c|c|c|}
\hline \multirow[b]{2}{*}{$\begin{array}{l}\text { № } \\
\text { ПП }\end{array}$} & \multicolumn{11}{|c|}{ Параметры модельного мембранного конвертора } \\
\hline & $\mathrm{t},{ }^{\circ} \mathrm{C}$ & $\begin{array}{l}\mathrm{Q}_{\mathrm{CH}_{4}}, \\
\mathrm{M}^{3} / \mathrm{u}\end{array}$ & $\begin{array}{l}\mathrm{P}_{\mathrm{B}} \\
\mathrm{MПа}\end{array}$ & $\begin{array}{l}\mathrm{P}_{\mathrm{H}}, \\
\text { МПа }\end{array}$ & $\begin{array}{c}\mathrm{F}_{\text {pacu. }}, \\
\mathrm{M}^{2}\end{array}$ & $\begin{array}{l}\mathrm{Q}_{\mathrm{P}}, \\
\mathrm{M}^{3 / \mathrm{u}}\end{array}$ & $\begin{array}{c}\mathrm{J}_{\mathrm{H}_{2}} \\
\mathrm{M}^{3} /\left(\mathrm{M}^{2} \mathrm{u}\right)\end{array}$ & $\begin{array}{c}\mathrm{X}_{\mathrm{H}_{2}}, \\
\text { мольной } \\
\text { доли }\end{array}$ & CK & $\begin{array}{c}\mathrm{q}_{\mathrm{v}}, \\
\frac{\mathrm{m}^{3} \mathrm{H}_{2}}{\mathrm{M}^{3} \text { сырья }}\end{array}$ & $\begin{array}{c}\mathrm{q}_{\mathrm{m}}, \\
\frac{\text { мольН }}{2} \\
\text { мольС } \mathrm{CH}_{4}\end{array}$ \\
\hline \multicolumn{12}{|c|}{ Мембрана из сплава Pd-8Y } \\
\hline 1 & 550 & 0,624 & \multirow{5}{*}{1,0} & \multirow[b]{3}{*}{0,1} & 0,24 & 1,97 & 7,88 & 0,101 & 0,865 & 0,788 & 3,15 \\
\hline 2 & 550 & 0,825 & & & 0,313 & 2,6 & 8,31 & 0,101 & 0,865 & 0,788 & 3,15 \\
\hline 3 & \multirow{3}{*}{500} & 0,624 & & & 0,29 & 1,26 & 4,27 & 0,101 & 0,588 & 0,503 & 2,01 \\
\hline 4 & & 0,624 & & \multirow[t]{2}{*}{0,05} & 0,207 & 2,27 & 10,9 & 0,051 & 0,942 & 0,909 & 3,63 \\
\hline 5 & & 0,945 & & & 0,311 & 3,43 & 10,5 & 0,051 & 0,942 & 0,908 & 3,63 \\
\hline
\end{tabular}

Примечание. $\mathrm{Q}_{\mathrm{CH}_{4}}$ - расход метана в исходной паро-метановой смеси; $\mathrm{P}_{\mathrm{B}}$ и $\mathrm{P}_{\mathrm{H}}-$ абсолютные

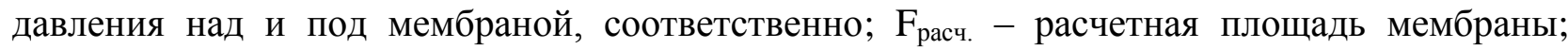
$\mathrm{Q}_{\mathrm{P}}$-производительность по водороду-продукту; $\mathrm{J}_{\mathrm{H}_{2}}$ - средняя диффузионная плотность потока водорода через мембрану; $\mathrm{X}_{\mathrm{H}_{2}}$ - концентрация водорода над участком поверхности мембраны; $\mathrm{q}_{\mathrm{v}}$ и $\mathrm{q}_{\mathrm{m}}$ - объемный и мольный выходы водорода.

Дальнейшая оценка показала, что при температуре $500{ }^{\circ} \mathrm{C}$ и $\mathrm{P}_{\mathrm{H}}=0,1 \mathrm{MПа} \mathrm{(строка} \mathrm{3,}$ табл. 11) расчетная производительность снизилась до $\mathrm{Q}_{\mathrm{P}}=1,26 \mathrm{~m}^{3} \mathrm{H}_{2} /$ п при $\mathrm{F}_{\text {расч. }}=0,29 \mathrm{м}^{2}$, достаточно близкой к $\mathrm{F}_{\text {уст. }}=0,314 \mathrm{~m}^{2}$. Более низкими оказались и расчетные техноэкономические показатели СК, $\mathrm{q}_{\mathrm{v}}$ и $\mathrm{q}_{\mathrm{m}}$ (строка 3, табл. 11).

При рабочей температуре $500{ }^{\circ} \mathrm{C}$ и $\mathrm{P}_{\mathrm{H}}=0,05 \mathrm{MПа} \mathrm{(строка} 4$, табл. 11 ) расчетная производительность $\mathrm{Q}_{\mathrm{P}}$ составила $2,27 \mathrm{~m}^{3} \mathrm{H}_{2} /$ ч при $\mathrm{F}_{\text {расч. }}=0,207 \mathrm{~m}^{2}$, меньшей чем $\mathrm{F}_{\text {уст. }}=0,314 \mathrm{~m}^{2}$, что свидетельствует о нерациональном использовании площади мембраны. Тем не менее величины расчетных техноэкономических показателей оказались достаточно высокими: $\mathrm{CK}=0,942 ; \mathrm{q}_{\mathrm{v}}=0,909 \mathrm{~m}^{3} \mathrm{H}_{2} / \mathrm{m}^{3}$ сырья и $\mathrm{q}_{\mathrm{m}}=3,63$ мольН $\mathrm{H}_{2} /$ мольСН $\mathrm{CH}_{4}$ (строка 4 , табл. 11$)$. С целью более рационального использования площади мембраны увеличили $\mathrm{Q}_{\mathrm{CH}_{4}}$ с 0,624 до $0,945 \mathrm{~m}^{3} /$ ч (строка 5 , табл. 2). В этом случае расчетная производительность по высокочистому водороду выросла с 2,27 $\mathrm{m}^{3} \mathrm{H}_{2} /$ ч до $\mathrm{Q}_{\mathrm{P}}=3,43 \mathrm{~m}^{3} \mathrm{H}_{2} /$ ч при $\mathrm{F}_{\text {расч. }}=0,311 \mathrm{~m}^{2}$, близкой к $\mathrm{F}_{\text {уст. }}=0,314 \mathrm{~m}^{2}$. Величины расчетных техноэкономических показателей $\mathrm{CK}, \mathrm{q}_{\mathrm{v}}$ и $\mathrm{q}_{\mathrm{m}}$ оказались на прежнем высоком уровне, что и в строке 4, табл. 11. Заметим, что мембрана из сплава В-1 при толщине 20 мкм не может обеспечить указанную выше высокую производительность по высокочистому водороду $\left(\mathrm{Q}_{\mathrm{p}}\right)$ и техноэкономические показатели $\left(\mathrm{CK}, \mathrm{q}_{\mathrm{v}}\right.$ и $\left.\mathrm{q}_{\mathrm{m}}\right)$ модельного МК-устройства при температуре $500{ }^{\circ} \mathrm{C}$. Эффективность использования мембраны из сплава $\mathrm{Pd}-8 \mathrm{Y}$ толщиной 20 мкм при рабочих температурах 500, $550{ }^{\circ} \mathrm{C}$ в МК-реформере производительностью $40 \mathrm{~m}^{3} \mathrm{H}_{2} /$ э экспериментально подтверждена в работе [2].

Таким образом, в данном разделе продемонстрирована возможность использования математической модели идеального вытеснения при получении высокочистого водорода из продуктов паровой конверсии углеводородов в системе высокотемпературный конвертор мембранный annapam для анализа результатов расчета основных параметров по другой «кинетической» модели для модельного МК-реформера с мембраной из палладиевого сплава В-1.

Установлена удовлетворительная корреляция расчетных технологических параметров модельного МК-реформера при рабочей температуре $600{ }^{\circ} \mathrm{C}$ по обеим моделям особенно для режима, предусматривающего удаление высокочистого водорода из подмембранного пространства с применением пара в качестве продувочного газа. 
Расчетным путем установлено, что применение мембраны из сплава В-1 в рамках модельного МК-реформера возможно при снижении рабочей температуры до $550{ }^{\circ} \mathrm{C}$, но только для режима с продувкой водяным паром.

Для рабочей температуры $600{ }^{\circ} \mathrm{C}$ предложен другой достаточно эффективный режим удаления высокочистого водорода без применения продувки водяным паром.

C помощью расчетов показано, что путем замены мембраны из сплава В-1 на сплав $\mathrm{Pd}-8 \mathrm{Y}$ при той же толщине можно снизить рабочую температуру рассматриваемого модельного МК-конвертора до $500{ }^{\circ} \mathrm{C}$.

\section{6. Заключение}

Приведены результаты анализа методом математического моделирования основных параметров ряда различных по конструкции и производительности мембраннокаталитических систем получения высокочистого водорода из продуктов паровой конверсии углеводородов.

На основании хорошей корреляции расчетных и экспериментальных данных можно судить об адекватности используемой математической модели идеального вытеснения при мембранном извлечении высокочистого водорода из продуктов паровой конверсии углеводородов с учетом химического взаимодействия между компонентами газовой фазы.

Расчетным путем установлены взаимосвязи между входными и выходными параметрами мембранно-каталитических устройств, позволяющие проводить проектные и проверочные расчеты в целях оптимизации их конструкций и технологических режимов.

Проиллюстрирована возможность проверки работоспособности других моделей путем сравнения расчетных данных при одинаковых эксплуатационных условиях.

\section{Литература}

1. Uemiya S. Brief review of steam reforming using a metal membrane reactor // Topics in Catalysis. - 2004. - Vol. 29, iss. 1. - P. 79-84. - DOI: 10.1023/B:TOCA.0000024930.45680.c7.

2. Development of membrane reformer system for highly efficient hydrogen production from natural gas / Y. Shirasaki, T. Tsuneki, Y. Ota, I. Yasuda, S. Tachibana, H. Nakajima, K. Kobayashi // International Journal of Hydrogen Energy. - 2009. - Vol. 34, iss. 10. - P. 4482-4487. DOI: $10.1016 /$ j.ijhydene.2008.08.056.

3. Терещенко Г. Ф., Орехова Н. В., Ермилова М. М. Металлосодержащие мембранные реакторы // Критические технологии. Мембраны. - 2007. - № 1. - С. 4-20.

4. Vandyshev A. B., Kulikov V. A. Preparation of specially pure hydrogen at $500-700^{\circ} \mathrm{c}$ from methane in high-temperature converter-membrane equipment, combined with a $\mathrm{CH}_{4}$ conversion catalyst // Chemical and Petroleum Engineering. - 2011. - Vol. 47, nos. 5-6. - P. 327-333. DOI: $10.1007 / \mathrm{s} 10556-011-9469-\mathrm{z}$.

5. Vandyshev A. B., Kulikov V. A. Determination of efficiency of special-purity hydrogen production from products of methane conversion with oxygen in membrane apparatus in combination with catalytic methane or carbon monoxide conversion. // Chemical and Petroleum Engineering. - 2011. - Vol. 47, nos. 7-8. - P. 468-474. - DOI: 10.1007/s10556-011-9494-y.

6. Vandyshev A. B., Kulikov V. A. Extraction of extra pure hydrogen from methane steam conversion products in membrane equipment, combined simultaneously with two $\mathrm{CO}$ and $\mathrm{CH}_{4}$ conversion catalysts // Chemical and Petroleum Engineering. - 2012. - Vol. 47, nos. 11-12. P. 831-836. - DOI: 10.1007/s10556-012-9558-7.

7. Vandyshev A. B., Kulikov V. A. Evaluation of efficiency of special-purity hydrogen production from products of steam conversion of methane and its close homologs in high-temperature converter-membrane equipment system using methane or carbon monoxide conversion catalyst // Chemical and Petroleum Engineering. - 2013. - Vol. 48, iss. 9-10. - P. 566-575. DOI: $10.1007 / \mathrm{s} 10556-013-9659-\mathrm{y}$. 
8. Compact membrane reformer for hydrogen production. - URL: http://www.lindeusengineering.com.

9. Murav'ev L. L., Vandyshev A. B., Makarov V. M. Modeling of membrane extraction of hydrogen from the products of steam conversion of hydrocarbons // Theoretical Foundations of Chemical Engineering. - 1999. - Vol. 33, iss. 3. - P. 258-263.

10. Recent advances on membranes and membrane reactors for hydrogen production (Review) / F. Gallucci, E. Fernandez, P. Corengia, M. Annaland // Chemical Engineering Science. - 2013. Vol. 92. - P. 40-66. - DOI: 10.1016/j.ces.2013.01.008.

11. A Review on Patents for Hydrogen Production Using Membrane Reactors / F. Gallucci, A. Basile, A. Iulianelli, H. Kuipers // Recent Patents on Chemical Engineering. - 2009. - Vol. 2, iss. 3. - P. 207-222. - DOI: 10.2174/1874478810902030207.

12. New concept hydrogen production system based on membrane reformer / A. Kataoka, H. Ishikawa, I. Yasuda, K. Nishikawa, T. Mukai, T. Asakura, T. Azuma, T. Tsuneki, T. Takahashi, Y. Shirasaki, K. Inoue, M. Miyaki, H. Shinkai // Fuel Cell Seminar, Palm Springs, California, USA, November 18-November 21, 2002 : abstracts / Palm Springs Convention Center. - Palm Springs, CA, 2002. - P. 733-736.

13. Development of highly efficient membrane reformer system for hydrogen production from natural gas / H. Kurokawa, Y. Shirasaki, T. Tsuneki, I. Yasuda, S. Tachibana, H. Nakajima, K. Kobayashi // The 17th World Hydrogen Energy Conference (WHEC 2008), Queensland, Australia, 15-19 June, 2008 : proceedings. - P. 41-45.

14. Lukyanov B. N. Obtaining Ultra-Pure Hydrogen for Fuel Cells in the Reactors with Membrane // Chemistry for Sustainable Development. - 2012. - No. 20. - P. 251-263. - URL: http://sibran.ru/upload/iblock/fb6/fb61628e4d8dae3d9f6ee28e7e53d223.pdf.

15. Сплавы палладия для водородной энергетики / Г. С. Бурханов, Н. Б. Горина, Н. Б. Кольчугина, Н. Р. Рошан // Российский химический журнал. - 2006. - Т. 50, № 4. C. $36-40$.

16. Lukyanov B. N., Andreev D. V., Parmon V. N. Catalytic reactors with hydrogen membrane separation // Chemical Engineering Journal. - 2009. - Vol. 154, iss. 1-3. - P. 258-266. DOI: 10.1016/j.cej.2009.04.023.

17. Permeability and diffusivity of hydrogen in palladium-rich Pd-Y(Gd)-Ag ternary alloys / Y. Sakamoto, F. L. Chen, M. Furukawa, M. Noguchi // J. Alloys Compounds. - 1992. - Vol. 185, iss. 2. - P. 191-205. - DOI: 10.1016/0925-8388(92)90468-O.

18. Murav'ev L. L., Vandyshev A. B., Makarov V. M. The modeling of membrane extraction of hydrogen from multicomponent gas mixtures // Theoretical Foundations of Chemical Engineering. 1999. - Vol. 33, iss. 2. - P. 190-192.

19. Development of hydrogen production systems with Pd-based alloy membrane / H. Yakabe, T. Iseki, H. Kurokawa, H. Hikosaka, Y. Takagi, M. Ito // 19th World Hydrogen Energy Conference, Toronto, Canada, 3-7 June, 2012.

20. Hydrogen production capacity of membrane reformer for methane steam reforming near practical working conditions / Y. Chen, Y. Wang, H. Xu, G. Xiong // Journal of Membrane Science. 2008. - Vol. 322, iss. 2. - P. 453-459. - DOI: 10.1016/j.memsci.2008.05.051.

21. Efficient production of hydrogen from natural gas steam reforming in palladium membrane reactor / Y. Chen, Y. Wang, H. Xu, G. Xiong // Appl. Catal. B. - 2008. - Vol. 80. - P. 283-294.

22. Гольцов В. А. Водород в металлах // Вопросы атомной науки и техники. Серия: Атомно-водородная энергетика. - Вып. 1 (2). - Москва : ИАЭ, 1977. - С. 65-100.

23. Shigarov A. B., Kirillov V. A. Modeling of membrane reactor for steam methane reforming: From granular to structured catalysts // Theoretical Foundations of Chemical Engineering. - 2012. Vol. 46, no. 2. - P. 97-107. - DOI: 10.1134/S004057951202011X24.

24. Gallucci F., Paturzo L., Basile A. A simulation study of the steam reforming of methane in a dense tubular membrane reactor // Int. J. Hydrogen Energy. - 2004. - Vol. 29, iss. 6. - P. 611-617. DOI: 10.1016/j.ijhydene.2003.08.003. 
25. Fernandes F. A. N., Soares A. B. Modeling of methane reforming in a palladium membrane reactor // Latin American Applied Research. - 2006. - Vol. 36, no. 3. - P. 155-161.

26. Analysis of a power system based on low-temperature fuel cells and a fuel processor with a membrane hydrogen separator / V. A. Kirillov, V. D. Meshcheryakov, O. F. Brizitskii, V. Ya. Terent'ev // Theoretical Foundations of Chemical Engineering. - 2010. - Vol. 44, no. 3. P. 227-235. - DOI: 10.1134/S0040579510030012.

27. Vandyshev A. B., Kulikov V. A. Hydrogen permeability of palladium membranes made of alloy V-1 in laboratory investigations and membrane devices // Chemical and Petroleum Engineering. - 2015. - Vol. 51, iss. 5-6. - P. 396-401. DOI: 10.1007/s10556-015-0058-4. 